\title{
METALS AND CERAMICS DIVISION PROGRESS REPORT FOR PERIOD ENDING JUNE 39,1984
}

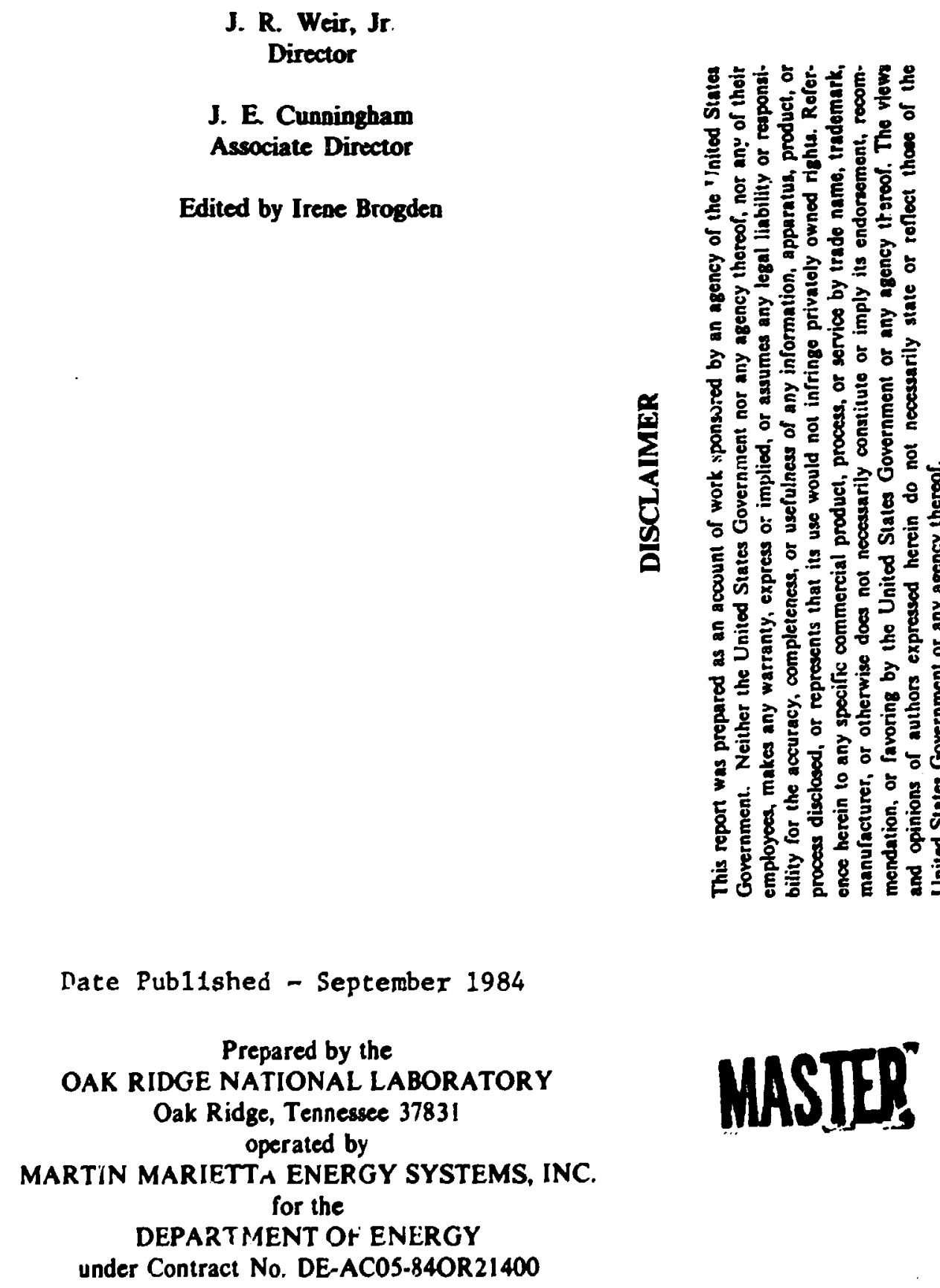




\section{Creports}

D. L. LeComte

Componition and Makeup 


\section{CONTENTS}

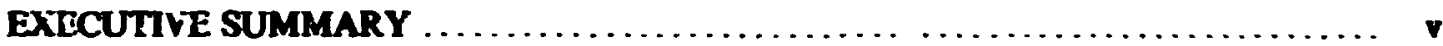

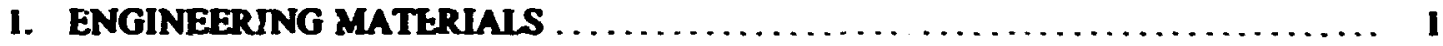

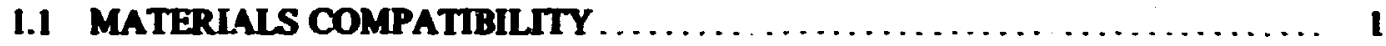

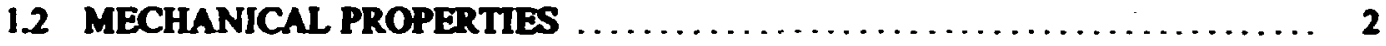

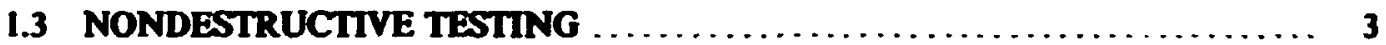

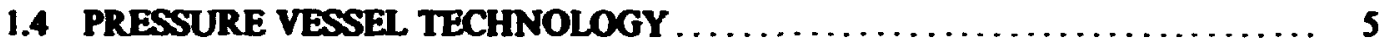

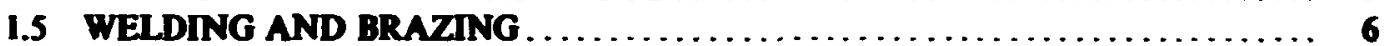

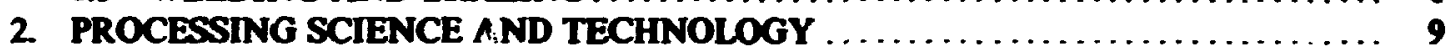

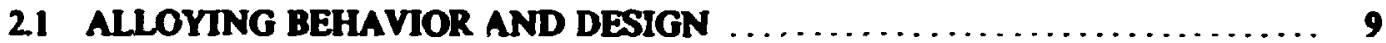

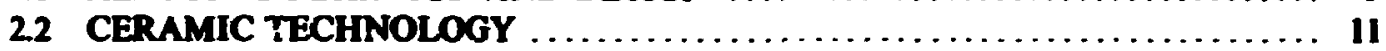

23 COATINGS AND TRIBULOGY $\ldots \ldots \ldots \ldots \ldots \ldots \ldots \ldots \ldots \ldots \ldots \ldots \ldots \ldots \ldots, 13$

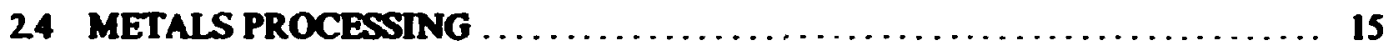

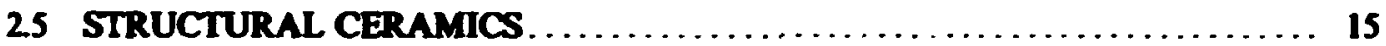

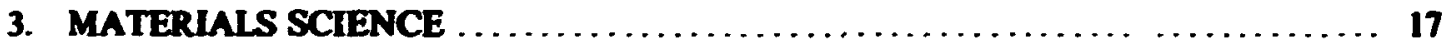

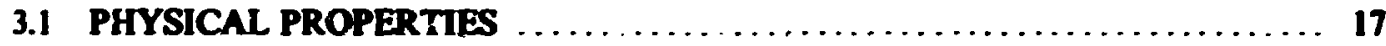

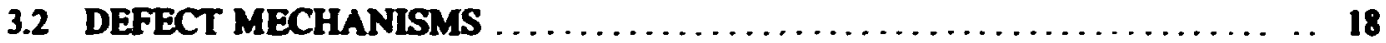

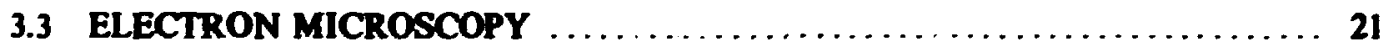

3.4 STRUCTUR AL MATERIALS GROUP ........................ 22

3.5 LABORATORY TECHNIQUES AND SUPPORT FACILITIES GROUP ...... 24

3.6 SURFACE AND SOLID STATE REACTIONS $\ldots \ldots \ldots \ldots \ldots \ldots \ldots \ldots \ldots \ldots \ldots \ldots \ldots$

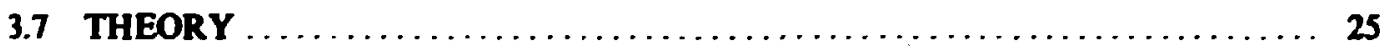

3.8 X-RAY RESEARCH AND APPLICATIONS $\ldots \ldots \ldots \ldots \ldots \ldots \ldots \ldots \ldots \ldots \ldots \ldots \ldots$

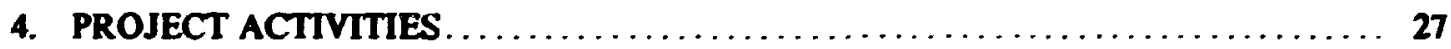

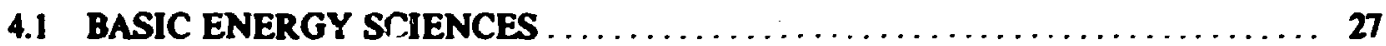

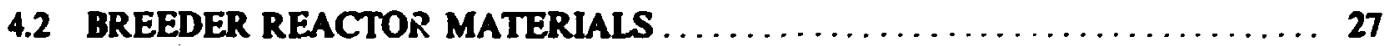

4.3 CONSER VATION TECIINOLOGY $\ldots \ldots \ldots \ldots \ldots \ldots \ldots \ldots \ldots \ldots \ldots \ldots \ldots \ldots, 28$

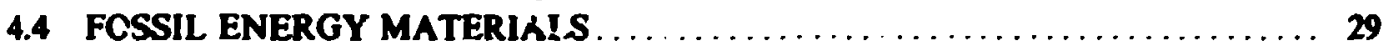

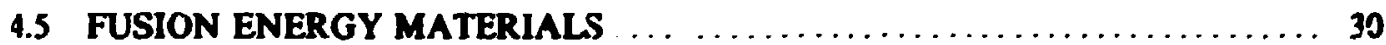

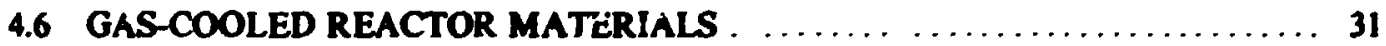

4.7 HEAVY-SECTION STFEL TECHNOLOGY $\ldots \ldots \ldots \ldots \ldots \ldots \ldots \ldots \ldots \ldots \ldots, 31$

4.8 ADVANCED SPACE NUCLEAR SYSTEMS MATERIALS . $\ldots \ldots \ldots \ldots \ldots, 32$

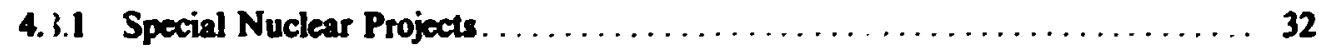

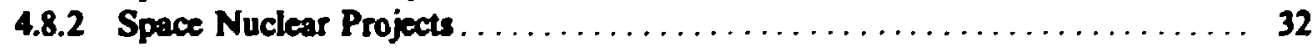

5. SPECIALIZED KESEARCH FACILITIES AND EQUIPMENT $\ldots \ldots \ldots \ldots \ldots \ldots \ldots$ 35

S.I OAK RIDGE SY NCHRO'RON ORGANIZATION FOR

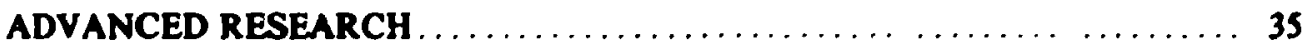

5.2 SHARED RESEARCH EQUIPMENT PROGRAM $\ldots \ldots \ldots \ldots \ldots \ldots \ldots \ldots$, 35

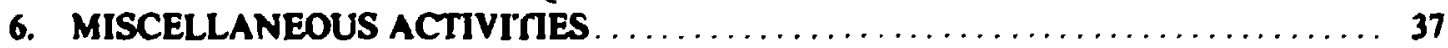

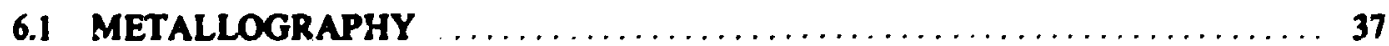

6.1.1 General Metallography and Poatirradiation Examination ............. 37

6.1.2 Electron Beam Microanalysis ............................. 37

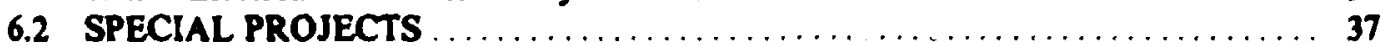
APPENDIXES

A. BUDGET AND FINANCIAL CHANGES $\ldots \ldots \ldots \ldots \ldots \ldots \ldots \ldots \ldots \ldots$

B. PERSON NEL SUMMARY $\ldots \ldots \ldots \ldots \ldots \ldots \ldots \ldots \ldots \ldots \ldots \ldots \ldots, 43$

C. ORGAN:ZATIONAL STRUCTURE AND CHART $\ldots \ldots \ldots \ldots \ldots \ldots \ldots \ldots$ 45

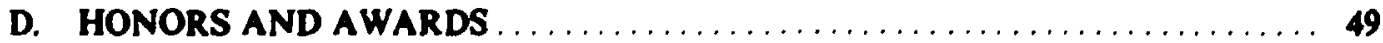

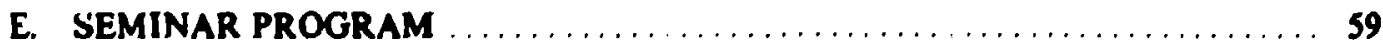

F. INFORMATION MEETING AND ADVISORY COMMITTEE $\ldots \ldots \ldots \ldots \ldots, 67$

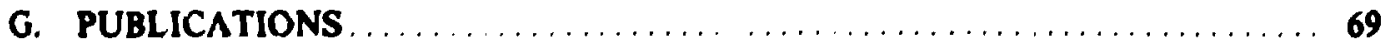

H. PRESENTATIONS AT TEC INICAL MEETINGS $\ldots \ldots \ldots \ldots \ldots \ldots \ldots \ldots, 91$ 


\section{EXICUTTVE SUMMARY}

This progress report covers the research and development activities of the Metals and Ceramics Division from January 1, i983, through Jane 30, 1984. In kecping with tradition the format of the report fothws rather clocky the organimational tructure of the division. Short anmmaries of technical work in progres in the various experimeatal gromps are presented in ix perta. Chapter 1 deals with the research and development sctivities of the Engineering Materials Section, Chap. 2 with the Processing Science and Technolozy Section, Chap. 3 with the Materials Science Section, Chap. 4 with Project Activities, Chap. 5 with Specialized Research Fecilities and Equipment, and Chap. 6 with Miscellaneous Activities.

Persistence in our quest to strengthen materials research at elevated temperature has brought the proposed High-Temperature Materials Laboratory muct clocer to reality. Final decign of the new facility is esentially complete, and funding to commence conatrection woxk in FY 1985 has becn appropriated by Congress. The new materials buboratory, which has been desiganted a national rewearch center, is designed to opersite in user-dedicated mode. Furthermore, the thruat and direction of research will be oriented to accommodate both basic and applied work When completed in 1987, the new facility will provide a gross floor area of $5992 \mathrm{~m}^{2}\left(64,500 \mathrm{ft}^{2}\right)$ for collaborative research with scientists from other research laboratories and with representatives from industry and academia.

Another noteworthy development that augurs well for technological advance on the local materials front is the permanent location of the American Welding Tahnology Application Center (AWTAC) in the Oak Ridge-Knoxville area. The center wss established to promote the succesuful transfer of advanced joining technologies from the laboratory to indusery and to serve as an exchange point for information generated in the fielJ by industry, government agencies, universities, and technical associations. The AWTAC intends to draw on expertise at the University of Tennessec, Tunesce Valley Authority, and Oak Ridge National Laboratory (ORNL) to develop and apply sdvanced technolog; for the benefit of the industrial sector. Incidentelly, the Metals and Ceramics Division Welding and Brazing Group, which was atrongly inatrumental in having AWTAC locate in the Oak Ridge area, recently obtained a Leybold-Heraeur electron beam welder. This unit of 15-kW capacity is capable of penetrating 50-mm-thick steel.

In March of this yeai, a unique contract was negotiated between Cabot Corporation and Union Carbide Nuclear Division to allow Cabot to purvse materiale research at ORNL. The $\mathbf{2 4 0 0 , 0 0 0}$ agrees i int permits Cabot to hold the patent rights to any innovations resulting from research specified in tile contract. Initially, the collaborative reucarch effort will concentrate $m$ the development of two kinds of corrosion-resistant alloys: a nickel-molybdenum alloy and a series of nickel-silico, alloys for application in hostile corrosive environments. The plan is that Cabot will support an additional $\$ 600,000$ of ceramics research in the next. fiscal year. 
Laboratory and division management continues to explore altermative routes for divemination of technical information to American indextry. In particular, we to translate basic findings cmarating in the hboratory into effective indestrial applications. Amoag the varions sctivities of this mature parswed in the past six moaths are

- A Technolozy Trander Meeting on New Oxide Varistor Materials was held on January 11-12, 1984, to discuss recent developments at ORNL in the synthesis and processing of zinc oxide. These developments represent sigaificant improvements in the manufacture and properties of varistors to protect high-voltage lines from destructive orerloeds.

- A joint ORNL-The Metallurgical Society of AIME Confereace on High-Temperature Alloys: Theory and Dexign was held in Detheade, Maryland, on April 9-11, 1984. The mecting provided a forum for reporting, reviewine, and discresieg recent progress in solid state theory, materials science, and applied alloy dacion.

- The Eighth Semiannual Meeting of U.S. Department of Energy (DOE) Materials Directors was held at Lawrence Berkeley Laboratory on April 5-6, 1984. The meeting focused on rendering ascietance to the abtomotive industry. The DOE directors will interact with the petrochemical industry at their fall meeting.

- Division staff members played a key role in organizing and reporting at the Conference on Materials for Future Energy Sysems held in Washington, D.C., of May 1-3, 1984. The conference was sponsored by the American Society for Metals in cooperation with DOE the National Materials Advisory Board, and the White House Office of Science and Technology Policy Committee The role of materials in esergy production was reviewed in context with a broed spectrum of energy sourcer; science and policy iswes that affect materiak science and engineering were discused also.

- The fourth meeting sponsored by the Industrial Research Institute highlighting potential commercial applications of government-sponsored research and new technological developments was beld in Oak Ridge on May 22-24, 1984. The three-day program focused particularly on materials science and materials technologies.

- Oak Ridge National Laboratory is one of two national laboratories working with the steel industry to make U.S. steel companies more competitive in the marketplace. A meeting was held in Oak Ridge on May 23, 1984, to identify critical problems and to discuss potential areas in which ORNL could make meaningful contributions.

Budget data and information on personsel and organizational structure are presental in Appendixes A through C. Data on Honors asd Awards, Information Meeting and Advisory Committee, Publicaticns, and Oral Presentations are presented in Appendixes D through $H$. Previous reports iscued in this series are cited on the following page. 
Reparts previously iswed in this series are as follows:

\begin{tabular}{|c|c|}
\hline ORNL-28 & Period Ending March 1, 1948 \\
\hline ORNL-69 & Period Ending May 31, 1948 \\
\hline ORNL-407 & Period Ending July 31, 1949 \\
\hline ORNL-511 & Period Ending October 31, 1949 \\
\hline ORNL-583 & Period Ending January 31, 1950 \\
\hline ORNL-754 & Period Ending April 30, 1950 \\
\hline ORNL-827 & Period Ending July 31, 1950 \\
\hline ORNL-910 & Period Ending October 31, 1950 \\
\hline ORNL-987 & Period Ending January 31, 1951 \\
\hline ORNL-10.33 & Period Ending April 30, 1951 \\
\hline ORNL-1108 & Period Ending Jaly 31, 1951 \\
\hline ORNL-1161 & Period Ending October 31, 1951 \\
\hline ORNL-1267 & Period Ending January 31, 1952 \\
\hline ORNL-1302 & Period Ending April 30, 1952 \\
\hline ORNL-136؟ & Period Ending July 31, 1952 \\
\hline ORNL-1437 & Period Ending October 31, 1952 \\
\hline ORNL 1503 & Period Ending January 31, 1953 \\
\hline ORNL-1551 & Periad Ending April 10, 1953 \\
\hline ORNL-1625 & Period Ending October 10, 1953 \\
\hline ORNL-1727 & Period Ending April 10, 1954 \\
\hline ORNL-1875 & Period Ending October 10, 1954 \\
\hline ORNL-1911 & Period Ending April 10, 1955 \\
\hline ORNL-1988 & Period Ending Octobe: 10,1955 \\
\hline ORNL-2080 & Period Ending April 10, 1956 \\
\hline ORNL-2217 & Period Ending October 10, 1956 \\
\hline ORNL-2422 & Period Ending October 10, 1957 \\
\hline ORNL-2632 & Period Ending October 10, 1958 \\
\hline ORNL-2839 & Period Ending September 1, 1959 \\
\hline ORNL-2988 & Period Ending July 1, 1960 \\
\hline ORNL-3160 & Period Ending May 31, 1961 \\
\hline ORNL-33: 3 & Period Ending May 31, 1962 \\
\hline ORNL-\$470 & Period Ending May 31, 1963 \\
\hline ORNL-3670 & Period Ending June 30, 1964 \\
\hline ORNL-3870 & Period Ending June 30, 1965 \\
\hline ORNL3970 & Period Ending June 30, 1966 \\
\hline ORNL-4170 & Period Ending June 30, 1967 \\
\hline ORNL-4370 & Periol Ending June 30, 1968 \\
\hline ORNL-4470 & Period Ending June 30, 1969 \\
\hline ORNL-4570 & Period Ending June 30, 1970 \\
\hline ORNL-4770 & Period Ending June 30, 1971 \\
\hline ORNL-48.20 & Period Ending June 30, 1972 \\
\hline ORNL-4870 & Period Ending June 30, 1973 \\
\hline
\end{tabular}


ORNL-4970

ORNL-5579

ORNL-5670

ORNL-5810

ORNL-5943
Period Ending June 30, 1974

October 1, 1978-June 30, 1979

Period Ending June 30, 1980

Period Ending June 30, 1981

Period Ending December 31, 1982 


\title{
1. ENGINEERING MATERIALS
}

\author{
G. M. Slaughter
}

This section is responsible for determining and evaluating the suitability of engineering materials for use in various energy systems, for developing new alloys, and for determining and developing improved joining and nondestructive testing techniques to ensure the structural integrity of materials and components in specific applications. It comprises approximately 65 staff memiers, about $50 \%$ of whom are professionals. Research and development activities are carried out in five different laboratories, which bear the functional names Materials Compatibility, Mechanical Properties, Nondestructive Testing, Pressure Vesel Technology, and Welding and Brazing. Additionally, divisicial support for the Heavy Section Steel Technology (HSST) program and the Space Nuclear Projects is administered through this section. Brief descriptions of work performed by and major accomplishments of these groups are presented.

\subsection{MATERIALS COMPATIBH.TTY-J. H. DeVan}

The Materials Compatibility Group conducts corrosion studies in direct support of fusion energy, fossil energy, waste management, fuel reprocessing, and gas-cooled reactor projects. During this reporting period, related corrosion stu lies were alec conducted under subcontract to Lewrence Livermore National Laboratory and General Electric Company.

Activities under the fusion energy program deal with the corrosion behavior of potential heat transfer and tritium-breeding fluids. Our objective is to identify the mechanisms by which these fluids attack potential first-wali materials at 400 to $600^{\circ} \mathrm{C}$. We completed a kinetic analysis of the mass transfer of type 316 stainless steel in thermally convective lithium and oblained initial results for the weight loss behavior of representative first-wall materials in the more aggressive leadlithium environment. A preliminar; investigation showed that the oxidation of vanadium alloys in high-temperature water was not serere.

Corrosion studies supporting the development of fossil energy resources are divided between two tasks: corrosinn of current collector materials in molten carbonate fuel cells and mechanisms of abrasive vear. Under the formur task, thermochemical calculations were completed to define equilibrium phase relationships in the $\mathrm{Fe}-\mathrm{LiKCO}$ and $\mathrm{Cr}$ - $\mathrm{LiKCO}_{3}$ systems. The predicted phase relationships are being compared with experimental results obtained from reaction rate studies of stainless steel current colleck? materials in molten $\mathrm{LiKCO}_{3}$. The second task, aimed at wear mechanisms, involves the modification of a scanning electron microscope to permit direct observation of impingement damage to selected metal substrates by particles of silicon carbide. The particles are injected into the microscope at controlled velocities and trajectories to impact within a region of a substrate, which is being continuously scanned. Both sulfidizing and oxidizing conditions can be induced over the substrate in provide additional data on corrosion-erosion interactions. 
A long-standing corrosion program in support of the High-Temperature Gas-Cooled Reactor (HTGR) was phased out last September. During the reporting period, studies were completed on the docarburization of $21 / 4 \mathrm{Cr}-1$ Mo steel by HTGR-He and on the solid state reactions occurring between alloy 800 and graphite impregnated with $\mathrm{B}_{4} \mathrm{C}$.

The remainder of the group's project activities concerned corrosion problems in the areas of waste management, fast reactor fuel reprocessing, and adsorption refrigeration. In the first area we conducted a critical assessment of potential failure mechanisms for metallic containers that have been identified for containment of high-level waste. The results were provided to the Nuclear Pegulatory Commission (NRC) to aid their performance evaluation of waste packages. In the area of reprocessing, demronstrations are being planned in the Bresder Reactor Engineering Test at Hanford. Our contribution in this area has been in the selection of corrosior-resistant materials for prucess equipment in the remotely operated facility. Lastly, we are assisting the Oak Ridge National Laboratory (ORNL) Energy Division in improving the efficiency of absorption refrigeration cycles by the development of more efficient absorbers and refrigerants. We are conducting corrosion tests to determine the best materials for use in these new systems.

During the past year we completed a "seed money" project to investigate the electrochemical etching of titanium alloy castings. We demonstrated that under some conditions it is possible to delineate the dendritic structures of such castings electrochemically, which standard chemical etchants are unable to do.

\subsection{MischarICAL PROPERT TS - C. R. Brinkman}

The Mechanical Properties Gruup develops and analyzes data, qualifies new materials, and provides materials engineering support for ongoing national energy- and defense-related programs. During the past 18 months we received support from the following programs: breeder reactor, 40\%; defense, 14\%; gas-cooled reactor, 14\%; fossil, 11\%; conservation, 8\%; fusion, 3\%; and miscellaneous service, $10 \%$. The overall effort on these programs was in characterizing the elastic, plastic, creep, and fatigue (uniaxial, biaxial, and crack growth) behavior of base metals, weldments, stramics, and polymers. After statistical and parametric analyses of the data, we present them in a form useful to engineers or code developers for design.

Fast breeder reactor work continued efforts to obtain various mechanicil properties such as long-term creep and fatigue data for types 304 and 316 stainless steel, alloy $7: 8,2$ i, 4 Cr-1 Mo steel, and modified $9 \mathrm{Cr}-1 \mathrm{Mo}$ steel. Increased effort is currently directed to characterization of cast and weld metals of austenitic stainless steel because of their complex microstructures in comparison with wrought materials. We continue to investigate the influence of combined stress and temperature on the subsequent mechanical properties of thin-wall type 316 stainleas steel largediameter prototypic piping containing welds. This work is based on differences in the microstructure between stresed and unstresced regions of long-term creep specimens and the degradation of room-temperature toughness properties by prolonged exposure to elevated temperatures. Biaxial fatigue tests continued at elevated temperature on several wrought metals, including $21 / 4 \mathrm{Cr}-1$ Mo and type 316 stainless steel. These teats included combinations of in-phase push-pull and torsional cyclic loading, with all tests conducted is strain control by use of a unique extenssineter developed at ORNL.

Several domestic and foreign utilities, steel suppliers, and design organizations have shown considerable interest in the recent development of modified $9 \mathrm{Cr}-1$ Mo ferritic steel. This new structural material for use at elevated temperatures offers several advantages, including increased 
strength and chromium conservation, compared with some austenitic stainless steek. Two foreign (United Kingdom and Canada) and three domeatic utilities and several foreign laboratories are cooperating in the evaiuation of this material. Anerican Society for Testing and Materials specifications for various product forms were obtained, including seamless tubing, pressure vessel plate, forged or rolled pipe flanges, and seamless pipe. Materials data were submitted to the American Society for Mechanical Engineers Cude formulating bodies. Code approval for Sect. I was obtained, with Sect. VIII approval expected in the rear future.

Numerous pages of material properties and behavior were prepared by our Data Analysis Center for entry into the Nuclear Systerms Materials Handbook in support of breeder reactor development. This effort has received particular emphasis despite the apparent decreased national effort on large liquid metal breeder reactors.

Data development and analysis for the materials tochnology to design and license HTGR cogeneration and reformer systems emphasized obtaining information on mechanical properties, thermal stability, and behavior of wrought materials and weldments. Structural alloys under investigation included Hastelloy $\mathrm{X}$, alloy 718, 2 1/4 Cr-1 Mo steel, alloy 800H, and several ceramic materials, including silicon dioxide and aiumina.

Work continued in commercial casting characterization in suyport of fossil materials development. This effort included mechanical property (creep, tensile, and impact) and microstructural characterization, including modified $9 \mathrm{Cr}-1$ Mo steel, CF8 and CF8M stainless stecls, and 2 1/4 Cr-I Mo steel. Castings were ubtained from two domestic and one foreign sources.

Surface gasification project-supported work focused on the development of high-strength lowalloy steels for construction of gasifier pressure vessels. A small commercial heat of a new 3\% $\mathrm{Cr}-15 \%$ Mo-V steel was procured, and research was started to deterr.ine the fabricability, strength, and toughness. Industrial participants in the task included AMAX, CarTech, Lukens Steel, Combustion Engineering, and Chicago Bridge and Iron. Work for the Fossil Energy Advanced Research and Technology Development Program nas directed to providing services to the various university participants. Here, ORNL procured and distributed reference steels, weldments, and overlay claddings to the participants and, in some instances, performed heat-treating and various types of characterization tests. The following subcontractors were a:sisted: University of California, Berkeley; University of California, Santa Barbara; Comell University; University of Illinois; Pennsylvania State University; and University of Tennessee.

We continued work on a conservation program to develop a high-voltage gas-cooled transformer. Our objective is to deveiop mechanical properties of candidate polymers and to investigate longterm degradation in the presence of anticipated transformer materials in $\mathrm{SF}_{6}$ at temperatures up to about $100^{\circ} \mathrm{C}$. This work will supplement efforts of others to establish (1) the optimum polymer for use in sheet-wound transformers and shunt reactors and (2) the compatibility of propoced materials of construction. Efforts were aimed at obtaining low-temperature creen properties on several polymers tested in various environments.

\subsection{NONDESTRUCTIVE TESTING $-R$. W. McClung}

The Nondestructive Testing Group develops new or improved methods of nondestructive testing (NDT) and provides technical support for nondestructive examination. The activities range from long-term studizs of physical mechanisms and theory for development of advanced techniques and equipment to near-term development and technical support for various applied programs. The effort 
is broad based in terms of both the technologies involved (including penetrating radiation, eddycurrent, ultrasonic, thermal, and penetrant techniques) and the varied interests of sponsoring agencies, especially those of the Department of Energy (DOE) and the NRC.

The major activity $f$ or DOE has been on the breeder reactor program. Ultrasonic signal processing techniyues were investigated for improved flaw characterization in steel welds. Eddy-current studies emphasizing multiparameter multifrequency techniques, a special computer-controlled scanner, and modular instrementation are planned for use on welds following initial studies on stainless steel plate. For the Clinch River Breeder Reactor (CRBR) steam generator, we provided technical support for ultrasonic techniques and equipment for in-service inspection (ISI) of the tubing and completed a report on development of eddy-current techniques for ISI of the tubing. Work was completed on the refurbishment of four production microfocus rod-anode $X$-ray units for use by the Westinghouse Nuclear Components Division (W-NCD) for its manufacturing examination of the CRBR steam generators.

Development and technical support were provided for both ultrascnic and eddy-current ISI techniques for double-wall tubing for a Westinghouse alternative steam generator design. Technical support to W-NCD for training for the operation of a microfocus rod-anode X-ray unit for radiography of tube-to-tubesheet joints was also provided. Other DOE nuclear work included lowvoltage radiographic studies on graphite oxidation for the gas-conled program.

For the DOE Office of Fusion Energy, we developed multifrequency eddy-current techniques and equipment for examining JBK-75 seam welds for the sheath of superconductor cable as part of the Large Coil Program. We also provided technical support for on-line computer-based eddycurrent equipment installed at Airco for its use in examining the sheath seam weld of the superconductor to be fabricated into a large coil by Westinghouse. For the DOE Division of Energy Storage Systems, we applied advanced eitrasonic techniques that we developed for evaluating properties of fiber-reinforced plastic composite flywheels at intervais after spin testing. For the DOE Office of Space Nuclear Propulsion, we conducted feasibility studies and initial technique dzrelopment in ultrasonics and radiography for examination of miniature the moelectric devices for extraterrestrial space probes and provided technical support for examining alloys and graphite components for space nuclear systems.

Brief studies and applications of NDT to various ceramic materials and components were made for several DOE programs.

Technical consultation and support were provided to the program management staff for the fossil energy materials development program and for an analysis of spent fuel element casks. Initial studies were begun on electroslag castings for the fossil energy program. Technical assistance in multifrequency eddy-current instrumentation and technology was provided to several DOE weapons laboratories.

A majur activity for NRC reactor safety research was development and improvernent of multiparameter multifrequency eddy-current techniques for the ISI of light-water reactor steam generators. Another activity was interaction with American Society of Mechanical Engineers (ASME) Boiler and Pressure Vessel Code committees for ultrasonic and radiographic techniques. We also provided consultation to the regulatory nifice in evaluating nondes: ructive examinations on commercial nuclear reactors.

Several items of "work for others" included fabrication of prototype multifrequency instruments for three requesters and eddy-current feasibility studies for electrical conductivity measurements on thin coatings for an Army laboratory. 


\subsection{PRDSSURE VR3SR TBChNOLOGY-R. K. Nanstad}

The Pressure Vessel Technology Group investigates the fracture resistance of structural materials, particularly stoels for pressure vessel applications. This requi $x$ expertise in experimental fracture mechanies and metailurgy. Programs are sponsored by both NRC and DOE. We are curreatly emphasizing the materials property needs for the HSST, fossil energy materials, HTGR, magaetic fusion energy, and space reactor p.ograms.

Fracture toughness testin's of prestressed concrete reactor vessel (PCRV) liner and penetration steels was completed with the examination of weldments and with particular emphasis on dynamic and crack arrest fracture toughness during FY 1983. We analyzed that information to apply candidate PCRV liner steels and weldments to a reference fracture toughness framework in Appendix C: of the ASME Boiler and Pressure Vessel Code. A draft report was prepared and will be published following final review. We have initiated a program to study elevated-temperature fracture toughness of structural materials for the HTGR.

Under the HSST thermal shock program, material prop-rty data were obtained for thermal shock experiment 7 (TSE-7) and pressurized iuermal shock experiment 1 (PTSE-1). Investigations are coninuing on lower bound fracture toughness, with the ultimate goal of rediction of thicksection component fracture toughness with small laboratory test specimens.

A new program to investigate effects of stainless steel cladding on flaw propagation in lightwater reactors began in December 1981. The program was motivated by the possible consequences of thermal shocks in pressurized-water reactors (PWRs) and now includes the study of irradiation effects on cladding. The initial laboratory phase involved four-point bend testing of plates $(914 \times 406 \times 51 \mathrm{~mm})$ clad on one face with types 308 and 309 stainless stecl. The initial results indicate that, at a toughness level that may exist in long-time operating PWRs, the unirradiated stainless steel has a limited capacity to arrest the extension of a riynamic naw. The testing program is continuing and includes procurement of plates clad by a commercial fabricator by use of the three-wire series arc process. Phase I of the stainless steel cladding irradiation program (seventh HSST irradiation series) was rompleted with the irradiation and testing of Charpy V-notch and tensile specimens fabricated from a single-wire submerged arc cladding of types 309 and 308 stainless steel. The cladding irradiation program will continue in FY 1985 with the irıadiation of specimens from the three-wire series arc material.

The fourth HS ${ }^{-}$irradiation experiment was started at the Bulk Shielding Reactor in December 1979. The experimen: consists of four capsules containing Charpy impact, tensile, and 25-mm compact specimens. The materials are HSST plate 02 (A 533, grade B, class 1, steel) for reference purposes, four current-practice submergec arc welds with copper contents from 0.04 to $0.12 \%$, and low upper-shelf material from the Federal Republic of Germany. Capsule irradiations were completed in July 1982. Charpy V-not:h and tensile testing was completed, and fracturé toughness testing is scheduled for coinpletion by the end of FY 1984.

A new HSST irradiation project was initiated to examine the upward temperature shift of the $K_{l c}$ and $K_{l a}$ curves in the ASME Code. The project includes irradiated compact specimens up to $102 \mathrm{~mm}$ thick ard unirradiated specimens up to $204 \mathrm{~mm}$ thick. Irradiations being perfort id in the Oak Ridge Research Reactur began in May 1984. 
Studies on the Fossil Energy Materials Program have emphasized mechanical property characterization of 2 l!/4 Cr- $\mathrm{I}$ Mo and 3\% $\mathrm{Cr}-1.5 \% \mathrm{Mo}-\mathrm{V}$ steels for gasification pressure vessels. Tensile properties and Charpy $\mathrm{V}$-notch impact toughness were determined over a wide temperature range for various heats, with specific interest in the high-strength classis of both steets. The materials nave bee.? postweld beat treated (P NHT) for varying times to determine the effects of extended PWHT times cn mechanical properties.

A substantial amount of testiog with subsize Charpy impact specimens of ferritic first-wall materials for the Magnetic Fusion Energy Program was completed. A zew automated impact machine was installed in :he hot cell; testing of irradiated specimens began in June 1984.

A program to fabricate T-11l refractory alloy tubing for the Space Nuclear Materials Program was initiated, and the seed money-funded effort to in restigate plastic zone formation continued.

\subsection{WELDING AND BRAZING - S. A. David}

The Welding and Brazing Group continues to conduct materials joining research and deveiopment for basic energy sriences, fossil energy, conservation, gas-cooled reactor, fast breeder reactor, and Navy projects.

The basic energy sciences welding study continued to investigate the solidification and phase siability of austenitic stainlezs steels and ferritic steels. Significant contributions were made toward understanding ts: solidification behavior and phase stability of austenitic stainless steel welds and the mechanism by which controlled residual element (CRE) additions improve the creep strength and ductility of stainles steel welds. For austenitic stainless steel welds containing CRE additions, we propose that the elimination of a continuous getwork of carbides is responsible for the improved eievated-temperature properties.

The fossil energy program emphasizes the development of welding consumables and characterization of their depssit properties for heavy-section weldments in it: $3 \% \mathrm{Cr}-1.5 \% \mathrm{Mo}-\mathrm{V}$ alloy for large-scale coal conversion vesseis. Filler wire for submerged arc welding and conated electrodes for shielded metal arc welding are being developed and evaluated. Successful welds with acceptable mechanical properties were achieved for the shielded metal arc welding process. Jointly with the conservation program, activities are also under way to evaluate the weldability of ductile aluminides. The, $\mathrm{Ni}, \mathrm{Fe}$ aluminide has sometimes been prone to cracking during welding. Efforts are under way to identify the cracking mechanism and to develop procedures to weld this alloy successfully.

The censervation program activities center around improving the efficiency of automotive heat engines and thereby conserving fuel costs. Acceptable ceramic-to-metal joints are being developed for this application. A novel technique was developed to braze partially stabilized zircunia to nodular cast iron by a direjt brazing technique or by brazing with a transition piece.

The gas-cocled reactor program aims at the development of internal bore welding techniques for superheater tube-to-tubesheet welds. High-quality weldments are required between a weld-clad alloy $800 \mathrm{H}$ forging and alloy $800 \mathrm{H}$ superheater tubing with a relatively heavy wall thickness. A versatile internal bore welding head was designed and fabricated for the welding development program.

The breeder reactor prog:an in the past has demonstrated commercialization of CRE stainless stcel filler metals and continues to study the weldability of modified $9 \mathrm{Cr}-1$ Mo alloy. 


\title{
2. PROCESSING SCIENCE AND TECHNOLOGY
}

\author{
J. O. St egler
}

The Processing Science and Tectnology Section aims at exploiting processing variables to control microstructures and thereby properties of metallic and ceramic materials. Emphasis is primarily on materials for high-temperature applications, and groups in the section play a key role in the High-Temperature Materials Program at Oak Ridge National Laboratory (ORNL).

During the reporting period, sen s:ral developments strengthened our position. Our development of ductile intermetallic alloys baset on the composition $\mathrm{Ni}_{3} \mathrm{Al}$ attracted wide interest from the industrial community. We recently entered into joint agreements with several producers to develop a capability for producing heats of these alloys by commercial practices. Within a few months we iope to have significant quantities of these materials under evaluation by industrial organizations. This fall we will hold a workshop for produce:s to evaluate progress toward commercial production of the ailoys, and in the spring of 1985 we wili hold a techrology transfer meeting to acquaint potential users of the materials with their properties and capabiiities.

We recently signed a contract with the Cabot Corporation to conduce research on several ordered alloy systems of interest to Cabot. We expect to expand that effort during the coming year to include other materials.

We initiated work on several paths to produce ceramic matrix composites combining both highstrength and high-fracture toughness. The room-temperature fracture toughness of alumina was shown to be doubled by the incorporation of about $20 \mathrm{vol} \%$ silicon carbide whiskers. The flexural strength, which was also increased substantially, showed little decline out to $1000^{\circ} \mathrm{C}$. Composites were also produced by infiltration of fibrous preform by chemical vapor deposition or by the simultaneous deposition of two phases.

Members of the section are involved in both the managemeit and research areas of the conservation prngrams on Ceramic Technology for Advanced Heat Eagines and Materials for Energy Conversion and Utilization Technology and of the Fossil Energy Materials Program. In-house work, which comprises about one-third of the funding, includes efforts on development of toughened ceranics, joining, environmental effects, coating technology, and alloy development. In addition to subcontracting about two-thirds of the funding, management activities include close coordination with a sister rrogram on Ceramic Technology sponsored by the National Aeronautics and Space Administration.

\subsection{ALLOYING BEHAVIOR AND DESIGN-C. T. Liu}

The primary goal of the Alloying Behavior and Design Group is developing and understanding the principles of alloying bchavior and of structure-property relationships and their application to 
the creation of new materials to meet energy technology needs. The group focuses on three major programs: (1) high-temperature alloy design and development, (2) deformation and fracture of high-temperature materials, and (3) metastable materials and processing development. The three programs are closely related, with emphasis on design of new high-temperature structural materials by control of alloy composition, microstructure, and processing iechniques.

The alloy design program is concerned with understanding and developing new structural materials based on ordered intermetallic alloys. Many ordered intermetallies possess attractive high-temperature properties; however, low ductility and brittle fracture restrict their ise for structural applications. Both macroalloying and microalloying processes were used to inprove the ductility and fabricability of several intermetallic alloy systems. Macroalloying is aimed at controlling orciered crystal and bulk properties in $\left(\mathrm{Fe}, \mathrm{CO}, \mathrm{Ni}_{3} \mathrm{~V}, \mathrm{Ni}_{3}(\mathrm{Al}, \mathrm{V}), \mathrm{Fe}_{3} \mathrm{Al}\right.$, and $\mathrm{Ni}_{3} \mathrm{Si}$ alloys, whereas microalloying is directed to alleviating both intrinsic and extrinsic grain-boundary weakness in nickel aluminides based on $\mathrm{Ni}_{3} \mathrm{Al}$. The significant achievement this year wis the understanding of ductilizing effects of boron additions and the development of advanced nickel aiuminides. The ductility of polycrystalline $\mathrm{Ni}_{3} \mathrm{Al}$ can be dramatically improved by adding a few hundred parts per million of boron, which tends to segregate strongly to grain boundaries and enhances grain-boundary cohesion. Alloy stoichiometry strongly influences the intensity of boron segregation and the amount of grain-boundary aluminum, which, in turn, affect the fracture behavior and overall ductility of boron-doped $\mathrm{Ni}_{3} \mathrm{Al}$. The mechanical and metallurgical properties of boson-doped $\mathrm{Ni}_{3} \mathrm{Al}$ and $(\mathrm{Ni}, \mathrm{Fe})_{3}(\mathrm{Al}, \mathrm{Fe})$ can be further improved by hafnium and zirconium additions at levels of less than 2 at. \%. Aluminum additions substantially improve the high-temperature strength and corrosion resistance of long-range ordered alloys based on $(\mathrm{Fe}, \mathrm{Co}, \mathrm{Ni})_{3} \mathrm{~V}$. These ordered intermetallic alloys, with a combination of good ductility, low density, high-temperature strength, and oxidation resistance, constitute a new class of structural materials for potential uses at elevated temperatures.

The goal of the deformation and fracture program is understanding the mechanisms of deformation and fracture of structural alloys at elevated temperatures. The model alloy systems used included $\mathrm{Ni}-20 \% \mathrm{Cr}$ (for nickel-base superalloys), Fe-Cr-Ni alloy (for ausienitic stainless steels), a!d $\mathrm{Ni}_{3} \mathrm{Al}$-base alloys (for high-temperature aluminide alloys). Both experimental and theoretical approaches are used to investigate the effects of impurities on grain-boundary cavitation. Effects of trace elements on grain-boundary cavitation under creep and fatigue test conditions are studied by Auger spectroscopy. The 30-m Small-Angle Neutron Scattering (SANS) Facility is employed to obtain data on the nucleation and growth of grain-boundary cavities during deformation. The I-MV high-voltage electron microscope is used to provide direct microstructural information to aid the SANS study. Quantitative measurements are made of grain-boundary sliding and grain-boundary diffusion. Recent theoretical modeling progress includes thermodynamics of solute segregation; a two-component cavity nucleation model; a time-dependent cavity nucleation model; and kinetics of solute segregation, stress concentration, and cavity stability.

The current emphasis of the metastable materials program is on structure-property relationships in metastable materials prepared by rapid quenching from the liquid or vapor states. Lowtemperature specific heat measurements of liquid-quenched zirconium-nickel glass revealed the occurrence, in some compositions, of two separate superconducting transitions, indicating the presence of two glass phases. Compositional variat ins of the transition temperature and other physical properties derived from differential scanning calorimetry of crystallization indicated that the two phases arise from short-range structures characteristic of the glass at two specific compositions, 60 and 66.7 at. \% $\mathrm{Zr}$. Efforts to understand annealing embrittlement in $\mathrm{Fe}_{80} \mathrm{~B}_{16} \mathrm{Si}_{2} \mathrm{C}_{2}$ melt-spun 
metallic glass ribbons involved Auger studies of fracture surfaces of as-quenched and annealed ribbons. The results indicate that embrittlement involves phase separation and the development of an inhomogeneous distribution of oxygen. Addition of small amounts $(\sim 100$ at. ppm) of cerium to decrease the mobility of oxygen slowed annealing embrittlement significantly. Microadditions of cerium also affect strongly the magnetic properties of as-quenched ribbons. The results on both zirconium-nickel and $\mathrm{Fe}_{60} \mathrm{~B}_{16} \mathrm{Si}_{2} \mathrm{C}_{2}$ metallic glasses indicate the importance of the medium-range structure of the glass in determining its properties and suggest that microalloying to control the distribution of trace impurities can significantly affect both structure and properties.

\subsection{CERAMIC TECHNOLOGY - A. J. Moorhead}

We have initiated some very important work on the development and characterizatic $\mathrm{n}$ of SiCwhisker-reinforced oxide matrix composites for improved mechanical performance. These whiskers, produced from rice hulls, are only about $50 \mu \mathrm{m}$ in length and $0.5 \mu \mathrm{m}$ in duameter, allowing $\mathrm{h} h \cdot \mathrm{m}$ to be incorporated into a composite by standard powder processing techniques. Most of the work has dealt with alumina as the matrix because it was deemed a promising material in an initial study. However, other matrix materials are also being explored as a way to tailor the composite for specific applications. Our approach is, first, to use hot pressing to identify compositions that exhibit imprcved tougheness and then to explore pressureless sintering for fabrication of near-net-shape pieces. At this early stage of development, our $\mathrm{il}_{2} \mathrm{O}_{3}-20$ vol $\% \mathrm{SiC}$ whisker composite has a fracture toughness $K_{I c}$ of $8.5 \mathrm{MPa} \cdot \mathrm{m}^{1 / 2}$ and a room-temperature flexural strength of $650 \mathrm{MPa}$. Flexural strength at $1000^{\circ} \mathrm{C}$ is greater than $550 \mathrm{MPa}$. This material also has excellent slow crack growth behavioi. Our current efforts are aimed at altering the bond between the whiskers and alumina matrix to maximize the energy absorbed at that interface during crack propagation, thereby resulting in further increases in $\boldsymbol{K}_{I_{c}}$.

Research continues on the development and characterization of very fine-grained $\mathrm{ZnO}$ varistors. The sol-gel process was used to synthesize highly active powders that can be densified at low temperatures $\left(800^{\circ} \mathrm{C}\right)$. Varistors having breakdown fields as high as $4000 \mathrm{~V} / \mathrm{mm}$ have been prepared in this way. Ongoing studies of their electrical and thermal properties will relate these properties to microstructural and process variables.

The sodium-sulfur battery is a candidate for application to electric vehicles and utility load leveling. The electrolyte in this battery, 8 -alumina, often fails by fracture, which in many cases is initiated by electrolytic degradation. Furthermore, the conductivity of the electrolyte is very low at the operating temperature of some advanced cells. We have initiated research to (1) explore other compositions that promise better low-temperacure conductivity and (2) examine ways in which to improve the toughness of the electrolyte and to minimize degradation and premature failure.

Silicon carbide $\left(\mathrm{S}^{\mathrm{C}} \mathrm{C}\right)$ is a candidate material for both heat engine and recuperator components. Our efforts to develop a process for synthesis of high-purity ultrafine sinterable SiC powder continued during this reporting period. We also made considerable progress in the development of an $\mathrm{SiC}$ matrix composite to increase the reliability of this structural ceramic.

Silicon carbide powders were synthesized with the inexpensive and easily processed raw materials carbon black and mineral : lica. High specific surface areas $\left(10-20 \mathrm{~m}^{2} / \mathrm{g}\right)$ were obtained; these areas are equivalent to those previously obtained with fumed silica and pitch or phenotic resin as the powder precursors and to commercially available $\mathrm{SiC}$ powders. A powder-processing procedure adaptable to industrial scaleup was developed for this material. 
Composites of $\mathrm{SiC}$ and $\mathrm{TiC}$ hot pressed with carbon and alumirum additions exhibit roomtemperature strength and frasture toughness values up to about $50 \%$ nigher than that of the base $\mathrm{SiC}$ matrix. High-temperature strength for the SiC-TiC composite is also guod. At $1000^{\circ} \mathrm{C}$ this material retains about $90 \%$ of its sum-tempe:atyre strength, whereas the base SiC retains only about $45 \%$ of its room-temperature strength. At $1200^{\circ} \mathrm{C}$ the strength of the SiC-TiC composite declines to about $65 \%$ of the room-temperature value; this decline if strength is believed to be due to oxidation of the TiC particles, which introduces flaws into the surface of the composite. It has been shown that this oxidation is self-limiting; that is, after the surface TiC grains baye been oxidized, no further or.jdation ocrurs.

The carbon-bonded carbon-fiber (CBCF) insulation team has developmental efforts under way to identify and characterize a new source of rayon fiber, to evaluate fibers from more isctropic precursors such as phenolics, and to establish more definitive process controls for the new raw materials. The molding equipment was automated and instrumented to control and conitor the slurrying and molding operations. A new source of carbonized rayon ribers was identified and partially evaluated. Only thermal conductivity measurements are required to certify the new fiber for future CBCF insulation production. Three different isotropic fibers (all phenolic) are being evaluated for comparison of their graphitizing potential with that of the fibers fror the rayon precursor.

Fracture mechanies studies of graphite have been very useful in understanding how fabrication variables influence mechanical behavior under service conditions. The criticai defects in various graphites were identilied, and the effects of processing, oxidation, and irradiation in altering the critical defect size were determined. Irradiation reduces the defect size as the density increases; however, the strain energy release rate was reduced as differential anisotropic growth increased the number of much smaller boundary defects. The overall result is that fracture toughness of irradiated graphite does not increase even though the strength is doubled $5 ;$ irradiation. Fracture toughness is also independent of preferred orientation, even for those graphites having strength satios greater than 1.5. The significant difference in strength is due to the preferred orientation in defect size. We also showed that the sensitivity to strength loss by disparate flaws could be reduced by th- addition of a fine microcracked structure that permits a significant growth in the initial defect before stable crack growth occurs. We are actively engaged in implementing these results in two cooperative development programs with graphite manufacturers to produce significantly improved graphites.

The high hardness and toughness of titanium diboride $\left(\mathrm{TiB}_{2}\right)$ ceramic make this material an attractive candidate for armor and other applications. An ORNL-developed process that uses nickel as a bot-pressing aid lo:vers the hot-pressing temperature required to prepare high-density bodies from 2000 to $1550^{\circ} \mathrm{C}$. This development lowers the fabrication cost but, more important, results in improved properties, particularly the high toughness needed for ar.usur applications. We successfully developed a modified procedure for hot pressing $\mathrm{TiB}_{2}$ in an inert atmosphere and transferred this technology to two industrial fabricators. Each prepared five $15.24 \times 15.24 \times 2.5 \% \mathrm{~cm}$ tiles that are awaiting ballistics testing. An even larger scaleup is in process to prepare $25.4 \times 25.4 \times$ $5.1 \mathrm{~cm}$ tiles. In conjunction with this development, we are studying the effect of various processing variables on the hardness, fracture toughness, and flexural strength of this material. 
Our research on the development of brazing filker metals that will wet and bond directly to structural ceramics and metals for high-performance applications at elevated temperatures, at high stre:s levels, and in oxidizing euvironments has continued. The wetting of a ceramic matrix by a metallic brazing filler metal and the extent and strength of a bond between the two are affected by a number ci complex interrelated factors, including those of a chemical, mechanical, or zeometric nature.

During this report period we continued the sessile drcp wettability studies on substrates of Coors AD-99 and AD-998 alumina, DeGussit AL-23 alumina, and Nil $n$ MgO-stabilized partially stabilized zirconia. The room-temperature shear stength of the bond between niany brazing filler metal sessile drops and ceramic substrates was measured. With severai combinations of filler metal and ceramic, we found shear strengths greater than $100 \mathrm{MPa}$. We alsu had some of our experimental brazing filler metals fabricated into narrow foil strips by m.elt spinning and produced bend har specimens by preplacing these foils in the joint between two ceramic coupons. Both room- and elevated-temperature (up to $400^{\circ} \mathrm{C}$ ) flexural strength tests were conducted.

\subsection{COATINGS AND TRIBOLOGY - W. J. Lackey}

This group has completed a transitioy from mostly nuclear-fuels-related activities to inostly nonnuclear tasks involving cuatings and tribology. Emphasis is on chemical vapor deposition (CVD) of coatings for fossil, heat engine, cutting tool, and low friction wear-resistant materials in general. During this reporting period, we achieved particular success in Jepositing wear-resistant TiB $_{2}$, preparation of fiber-reinforced ceramic composites by chemical vapor infiltration, and deposition of a dispersoid-type SiC matrix composite. The major goai of the tribology effort is to understand the mechanisms of wear of ceramics, including thennochemical considerations.

Erosion-resistant coatings of $\mathrm{TiB}_{2}$ prepared by CVD were investigated for use in highly erosive environments such as coal líquefaction plants. Properly deposited coatings exhibited little or no erosion during accelerated testing with a coal-oil slurry. Deposition: temperature was the most important process variable affecting the coating performance. Coatings that were deposited at $900^{\circ} \mathrm{C}$ and exhibited very low erosion rates had low chlorine content $(<0.5 \mathrm{wt} \%)$ and high Knoop microhardness $(33 \mathrm{GPa})$. Coatings that were deposited at $800^{\circ} \mathrm{C}$ and exhibited high erosion rates had higher chlorine content ( $\sim 6 \mathrm{wt} \%)$ and lower microhardness (15 GPa).

Ceramic fiber-ceramic matrix composites are receiving increasej interest because of their higher strength and toughness. However, the high temperatures and -pressures frequently encountered in conventional ceramic fabrication tend to damage the fibers. Thus, the objective of this vork is to form the ceramic matrix by a practical lo v-stress low-temperature CVD infiltration process that will not damage the high strength ceramic fibers. Low-to-medium-density ceramic fiber (15-50 vol \% fibers) preforms were prepared either by stacking layers of SiC cloth or by a vacisum-forming technique with a slurry of chopped $\mathrm{SiC}$ fibers and an SiC-type binder. The preforms of $\mathrm{SiC}$ fibers were then infiltrated with either $\mathrm{CVD} \mathrm{Si}_{3} \mathrm{~N}_{4}$ or $\mathrm{SiC}$ to form the ceramic matrix by use of a new approach that combines the advantages of a thermal gradient and a gas flowthrough scheme to reduce infiltration times to hours. Process feasibility was established for infiltrating disks, and a system for infiltrating tubes was conceived. Densities as high as $93 \%$ of theoretical were achieved for small samples. Although the process is not optimized and current strengths (150 $\mathrm{MPa}$ ) are not yet as high as desired, specimens have exhibited the desired ability to carry a load after crack initiation. 
Toughened $\mathrm{SiC}^{-\mathrm{TiSi}_{2}}$ dispersoid-type composites were produced by the simultaneous CVD of two phases. Fincture toughness values were nearly double the value of $\mathrm{SiC}$ when $\mathrm{CH}_{3} \mathrm{SiCl}_{3}$ and $\mathrm{TiCl}_{4}$ rapors were used to produce the composites. Other systems consisting of $\mathrm{SiC}$ and the metal or metal carbides of $\mathrm{Ni}, \mathrm{Cr}, \mathrm{W}$, and Mo were examined. Eyuilibrium thermochemical analyses of these systems were performed as a function of the CVD variables: temperature, total pressure, and reactant concentration.

A system is beivg developed for the plasma-activated CVD of extremely hasd cubic boron nitride coatings. A staole argon plasma was produced by use of a radio-frequency generator, however, small flows of coating gases extinguished the plasma. Theiefore, a commercial plasma torch is being purchased to optimize the amount of energy transferred from the genstator to the plasma.

Stabilized zirconia coatings applied by CVD are being developed to provide thermal, wear, oxidation, and corrosion protection to a variety of advanced heat engine components. Experimental runs produced high-quality monoclinic $\mathrm{ZrO}_{2}$ powder with no noticeable contaminants. Unforturately, the reaction produced homogeneous nucleation within the gas phase instead of heterogeneous nucleation on the substrate.

An effort was recently undertaken to investigate the poor adherence of stabilized $\mathrm{ZrO}_{2}$ coatings to metallic substrates. We are investigating the effect of ion mixing zirconium ions into the surface of the metallic substrate to promote better adherence. Numerous ion-mixed samples are being coated with stabilized zirconia at various locations, and adherence testing will be performed later.

Tribological studies of refractory materials has become an additional function of the group. $h$ tribology laboratory being developed for wear testing at present includss a controlled scratch device and a pin-un-disc sliding wear system. Chemical effects in wear are also under study, and for this purpose a controlled atmosphere glove box and test chamber were made operative.

The pin-on-disc system was used to study the sliding wear mechanism of nickel-bonded $\mathrm{TiB}_{2}$. The wear path failed by the disintergration of individual surface grains. Transmission electron microscopy showed a high concentraticis of dislocations in the subsurface region beneath the wear track and led to the accumulation of strain and failure of individual grains by reduction to fine particles.

Unlubricated pin-on-disc tests were also performed with five ceramics in nitrogen at room temperature and 205 and $425^{\circ} \mathrm{C}$, sliding against themselves and each of the other sample types. The test ceramies were alumina, a zirconia-toughened alumina, silicon carbide, silicon nitride, and partially stabilized zirionia. In general, a highly deformed interfacial debris was present or. severely worn surfaces, and the friction coefficients for the tests ranged from 0.7 to 1.0 . Tests in partially stabilized zirconia at lower loads yielded minimal damage. Saanning electron microscopy and transmission e. etron microscopy study of the less severely wo.n zirconia samples showed the formation of fine surface fissures, a r.redominance of the cubic and monoclinic phases, and no evidence of dislocation formaticn. Further studies are in progress to amplify these observations.

Grouts used for disposal of nuclear wast is by hydrofracture are being characterized to verify that radionuclides have not migrated into the shale repository. Autoradiographs of cored grout samples showed no detectable migration. Isolation of the various cement phases revealed that the radionuclides cesium and strontium were adsorbed by the clay additives but not by the cement phases. A sample of grout was taken during an actual injection; its hydration was retarded several days because of boron present : $:$.he waste 


\section{METALS PROCtSSING-R. L. Heestand}

Activities in support of space and terrestrial power systems continu-d on fabricating iridium containmeat for genc al purpose heat sources through September 1983, when sufficient material was completed for projected use. The production task was then put in a standby condition, and a program on iridium process improvement was initiated to address casting iridium by consumable arc meltiing and to investigate a fabrication schedule modified to reduce delamination defects.

An new effort was started to produce refractory alloys for the SP-100 program for $100-\mathrm{kW}(e)$ reactors. Initially, we are supplying $\mathrm{Nb}, \mathrm{Ta}$, and $\mathrm{W}$ allo;s for irradiation experiments and are preparing process procedures and specifications for refractory metal fabrication.

Postirradiation evaluation of irradiated high-uranium-loaded oxide, aluminide, and silicidealt ninum fuel plates and elements continued. This program is directed to an effort to reduce enrichment leveis of test reactor fuels to less than $20 \%{ }^{235} \mathrm{U}$, thus requiring an increase in the total uranium loading. Examinations during this reporting period indica -1 satisfactory performance of experimental Oak Ridge Research Reactor elements to $70 \%$ average burnup.

Work sontinued in support of the fusion renitor program with the Structural Materials Developmerit Group, inwiving preparation and processing of experimental stainless and ferritic steels for microstructural and radiation damage evaluation. These alloys are of interest for poteritial applic ation as the first-wall structural material of a fusion system. The experimenial alloys included modifications of the current prim.e candidate austenitic stainless steel, high-manganese-containing stainless steels, and modifications of T-9 and HT-9 ferritic steels.

As assistance to the Alloying Behavior and Design Group, a program for the scaleup of nickel aluminides was outlined and initiated with Cabot Corporation. Nineteer control rod plates were fabricated for the High Flux Isotope Reactor. Fabrication of these plates into control rods should provide su fficient reactor control for the next six years. During this reporting period, requests for over 750 fabrications and 700 melts were fulfilled.

\subsection{STRUCTURAL CERAMICS -P. F. Becher}

The research efforts in the Structural Ceramics Group are organized to study ceramic powder characteristics and densification behavior in the tailoring of mirrostructure and composition of dense ceramics. This is coupled with studies of the explicit effects of microstructure and composition on toughening and slow-crack-growth mechanisms in ceramics. The mechanical behavior of ceramics that can be used in heat engines, high-temperature fossil-fuel-fired systems, and highpower microviave plasma heating devices for fusion systems is also being investigated.

One of the severest limitations of ceramics is low critical fracture toughness (i.e., $\left.K_{l c} \leqslant S \mathrm{MPa} \cdot \sqrt{\mathrm{m}}\right)$ due to the absence of $f$ astic deformation in the crack tip rep,ion. One must then consider novel toughening mechanisms that are applicable to ceramics. We thereby showed that ceramic composites containing second-phase particles or whiskers are substantially tougher than conventional ceramics. Alumina ceramics containing $\mathrm{ZrO}_{2}$ particles, which undergo a phase transformation in the region adjacent to a crack, exhibited fracture toughnesses at least 3 times those of monolithic ceramics. Analytical electron microscopy revealed that the ability to transform such $\mathrm{ZrO}_{2}$ par...eles is controlled by the stabilizer content of the $\mathrm{ZrO}_{2}$ but not by particle size for particle diameters less than $0.1 \mu \mathrm{m}$. Related studies revealed that the critical applied stress for this phase transformation decreases and, thus, that the resultant toughness increases as the temperature 
and stabilizer content of the $\mathrm{ZrO}_{2}$ decrease and as particle-particle interactions increase at higher $\mathrm{ZrO}_{2}$ content. Associated studies of transformation-toughened partially stabilized $\mathrm{ZrO}_{2}$ and composites address the elevated-temperature toughening and fatigue behavior in these materials, which are being considered for heat engine components.

The above findings indicate that greater tonghening can be achieved by judicions tailoring of microstructure and composition. This requires that the unique role of ponder characteristics and densification be well understood. Colloid chemistr, including sol-gei processes (jointly with the Chemical Technology Division), combined with analysis of surface and particle charac aristics are being used to achieve this.

Our studies of ceramic composites revealed that toughening is also achieved by incorporating other second phases that interact with propagating cracks. For example, SiC ceramics containing TiC particles are toughened by cract defloction. We also showed that even stronger toughening effects occur when very strong SiC single-crystal whiskers are incorporated into alumina ceramics and that such composites exhibit high fracture strengths and toughness at $1000^{\circ} \mathrm{C}$.

An analytical model of the microstructural effects on slow crack growth of polycrystalline noncubic ceramics was developed. The model accounts for grain size dependences of both residual stresses and microcracking mechanisms, which then influence cract growth parameters. This model shower that noncubic polycrystalline ceramics such as $\mathrm{TiB}_{2}$ must bave a fine grain size to achieve high fatigue resistance. Joint studies with the Chemistry Division on the densification of fine $\mathrm{TiB}_{2}$ powder show that carbon additions retard grain grown during densification but that the introduction of oxygen promotes coarsening and detrimentally affects densification. Liquid-phase-assisted densification, which reduces the processing temperatures, also minimizes grain growth, as illustrated by studies of $\mathrm{TiB}_{2}$ containing nickel, $\mathrm{Ni}_{3} \mathrm{Al}$, or platinum. However, formation of very brittle boride second phases (e.g., with $\mathrm{Ni}$ and $\mathrm{Ni}_{3} \mathrm{Al}$ additions) limit the maximum toughness (and strength) that can be achieved in such $\mathrm{TiB}_{2}$ ceramics. Analytical electron microscopy indicated that platinum additions basically yield a metallic boundary phase that should plastically deform and improve the toughness and resistance to slow crack growth of TiB ceramics.

The thermochemical environment also strongly influences how slow crack growth affects the fatigue life of ceramies, as revealed by studies of alunina and beryllia ceramics used as windows in microwave heating devices. Concise thermal stress analysis for windows subjected to dielectric heating was developed for the multitude of potential device operating parameters and the dielectric properties of the winc $2 w$. Recent studies indicate that both fine-grained alumina and transformation-toughened inmposites are attractive window materials for very high-power highfrequency arplications.

In the area of fossil energy materials, analysis of the change in mechanical roperties of $\mathrm{SiC}$ and other ceramies, when exposed to oxidizing environments or to coal slags, is continuing by use nf recently developed test facilities in which the effecs of applied stress and teniperature can be explicitly determined. Recent results for high-temperature $\left(1100-1300^{\circ} \mathrm{C}\right.$ ) exposures of $\mathrm{SiC}$ ceramics to an acidic coal slag revealed that the slag layer thickness affects the oxygen partial pressures at the slag-SiC interface. Both the oxygen partial pressure, an the temperature control the corrosion mechanisms and hence the rotained strength $\mathrm{at}$ these temperatures. Long-term (up to $5000-h$ ) exposures of $\mathrm{SiC}$ ceramics to a $1200^{\circ} \mathrm{C}$ oxidizing environment showed that surface oxidation and retained strengths are also quite sensifive to additives or impurities. Current studies are aimed at defining the processes that dominate the applied stress-temperature dependence of the static fatigue behavior of SiC ceramics. 


\title{
3. MATERIALS SCIENCE
}

\author{
E. E Blcom
}

Research in the Materials Science Section is focused on (1) obtaining a fundamental understanding of the behavior of materials through theory and experiment, (2) developing tools and techniques necessary for obtaining an improved understanding of the relationship between the microstructure and microchemistry of materials and their physical and mechanical properties, and (3) developing improved materials for advanced energy systems.

The section develops and provides important facilities for microstructural and microchenical characterization (transmission, analytical, and leigh-voltage electron microscopy, X-ray diffraction; and fluorescence) and for physical property determination (thermal conductivity, electrical resistivity, thermal expansion, specific heat, and emittance).

About $70 \%$ of our support is from the Office of Basic Energy Suiences, about $20 \%$ from the Office of Fusion Energy, and the remaining !O\% from the Offices of Fossil Energy and Conservation and Renewable Energy. Research prograns on alloy theory, characterization of the structure and iremistry of materials with $X$ rays, diffusion and reaction kinetics, radiation effect on materials, physical properties, and electron micrescopy are centered in the Materials Science Section, as are programs for development of alloys for breeder reactor cladding and duct applications and fusion reactor first-wall and structural applications. The staff of the section interacts extensively with the other divisional sections and programs, primarily through materials characterization capabilities. Many of the materials characterization facilities are available io universities and industry through the Shared Research Equipment (SHaRE) Program (Chap. 5). Brief descriptions of astivities and accomplishments of groups in the section are given in the following pages.

\subsection{PHYSICAL PROPERTIES-D. L. McElroy}

The research of the Physical Properties Group focuses on measuring and explaining charge and heat transport pher.omena acting in materials of interest to specific programs. The measurements are analyzed with theoretical techniques to obtain the magnitude of electron and phonon scattering components acting in a speciíu system. This guides further research.

Abcirt 30\% of this effort was for the Office of Basic Energy Sciences to examine the effects of temperature and composition on he electrical and thermal conductivities of alloys in several systems, including $\mathrm{Ni}_{3} \mathrm{Al}, \mathrm{TiB}_{2}, \mathrm{Pd}-\mathrm{Mo}$, and bec iron. This effort revealed the thermal conductivity of $\mathrm{Ni}_{3} \mathrm{Al}$ to be quite sensitive to stoichiometry, with a maximum at about 74.8 ai. $\% \mathrm{Ni}$. The calculated and experimentally derived phonon component agreed and indicated that phonons are responsible for about 25\% of the room-temperature thermal conductivity. The electronic Lorenz function is essentially equal to the Sommerfeld value. Our electrical resistivity study on pmlycrystalline $\mathrm{TiB}_{2}$ is the first in the range 4.2 to $300 \mathrm{~K}$ and revealed a minimum in electrical resistivity near $40 \mathrm{~K}$. 
This is caused by the Kondo effect, and, although weli known in metals, this is the first data showing this effect in a polycrystalline electrically conducting ceramic. In addition to these studies, we are completing a thermal conductivity review with P. G. Klemens, Uaiversity of Connecticut.

About $60 \%$ of our effort, aimed to improve the technical data base for insulating materials, is supported by the Building Energy Research and Development Division. In-house facilities and subcontracts are used to evaluate building materials. Results are reported to the insulation community, particularly the American Society for Testing and Materials Committee C16 on thermal insulations, for use in developing improved materials and tests. Our simple flat insulation testing device that uses an unguarded nichrome screen wire heater yielded thermal conductivit: results within 1\% of National Bureau of Standards values. This testing device provided experimental thermal diffusivity values that are only $50 \%$ of expected values. These values indicate that radiative transport is acive in low-density thermal insulations but is not includes in the transient heat conduction equation. Other parts of this effort include modeling heat transfer measurement equipment and measuring the amount of settling of loose-fill attic insulations after installation. For the Building Equipment Program, we were asked to explore ways to improve the thermal resistance of insulating materials used for appliances. An annual energy savings of 1 EJ (1 quad) would result if a material with a specific thermai resistance about 2.5 times that of the best in current use were applied. Our results on evacuated panels containing fumed silica particles indicate a twofold improvement, and results for evacuated amorphous silica powders suggest that a fourfold improvement is technically feasible.

Our measurement capabilities were used to obtain specific materials properties behayior for other systems, including the current voltage behavior of $\mathrm{ZnO}$-base varistors, high-temperature thermal conductivity insulations of fibrous $\mathrm{Al}_{2} \mathrm{O}_{3}$ and fibrous carbon, and the room-temperature thermal conductivity of rocks, roof insulations, and heat engine insulations.

\subsection{DEFECT MECHANISMS- -L. K. Mansur}

The main theme of the Defect Mechanisms Group is the characterization and understanding of microstructural and atomic processes as they relate to the behavior of materials in the demanding environments of advanced energy production systems. Based on this work, principles are developed for the design of improved alloys. The work covers an extensive basic program in radiation effects on materials; development of tools and techniques for research, including ion beam techniques and surface analysis techniques; and plasma-materials interaction studies of relevance to fusion reactor applications. The radiation effects and ion beam work is supported mainly by the Office of Basic Energy Sciences, and the surface and plasma-materials interaction work is supported mainly by the Office of Fusion Energy. The group combines both theoretical and experimental research to attack major problem areas. It interacts extensively with other groups working in related areas, including structural materials development for fusion and fission reactcr applications, electron microscopy, and facilities and techniques suppori. Our approach is to study the effects of radiation and to apply it as a unique tool to produce extreme changes in microstructure and microcomposition, which are generally unattainable by conventional thermal or mechanical treatments.

The experimental program in radiation effects consists of both neutron and charged-particle irradiations. To characterize and measure radiation effects, substantial use is made of our extensive analytical transmission electron microscopy facilities, our high-resolution Auger electron spectroscopy surface Alorlysis facility, and our mechanical testing devices. For neutron irradiations, we 
recently started using the Fasi Flux Test Facility (FFTF) at Hanford, Washington, and continue to make use of the High Flux Isotopes Reactor (HFIR) and the Oat Ridge Research Reactor (ORR) at Oak Ridge, Tennessee, and the Experimental Breeder Reactor-II (EBR-II) at Idaho Falls, Idaho. Charged-particle work is done mainly on our $5 \mathrm{MeV}-400 \mathrm{keV}$ dual- or triple-ion-beam Van de Graafi accelerator facility.

Part of our recent experimental work centers on the concept of a critical radius and critical number of gas atoms for cavity swelling. Theory suggests that cavity swelling can begin only when a critical cavity radius is achieved by stochastic processes or when a critical number of gas atoms is accumulated in a cavity. The critical quantities can be measured when the cavity size distribution breaks into a bimodal distribuiion, with the smaller cavities defining the critical size. Such measurements were made in an ion-irradiated swelling-resistant ferritic $\mathrm{Fe}-10 \% \mathrm{Cr}$ alloy to determine (1) whether a large critical size is responsible for the low-swelling behavior and (2) by theoretical calculation based on measured values, the bias and other fundamental parameters of the alloy. To obtain further insight into the peculiarities of ferritic material, the microstructure of pure iron was compared with that of pure vanadium after neutron irradia.ion. Similar measurements were made on both high-swelling (low-nickel) and low-swelling (high-nickel) austenitic Fe-Cr-Ni alloys. Preliminsiy results suggest the remarkable result that the critical radii for these two alloys differ by an order of magnitude. This work may therefore offer part of the long-sought-for explanation of the mechanism responsible for the large differences in swelling with nickel content. An extensive experiment, together with analyses of the eifects of helium in neutron-irradiated aluminum, confirmed the critical radius-critical number of gas atoms concept and gave a moie complete picture of microstructural evolution. Other experiments on phosphorous-containing stainless steels suggested a mechanism based on these concepts for swelling suppression with increasing phosphorous. By increasing the phosphide-matrix interfacial area, the transmutation-produced helium in the alloy is diluted among more interfacial cavity sites, thereby delaying the time to the aci. ievement of the critical number of gas $a ! n m s$ in a cavity and, therefore, the onset of swelling. This work produced a principle for the design of alloys resistant to swelling.

Work on the effects of pulsed irradiation showed the new result that pulsing can drastically alter the sequence of radiation-induced phase transformations in a complex alloy. Pulsing offers a way to separate time-dependent evolution processes and some insight into possible effects in fusion reactors operated in a pulsed mode. Irradiations at very high pulsing frequencies $\left(10^{3}-10^{5} \mathrm{~Hz}\right)$ were recently completed. A new series of alloys based on Fe-13\% $\mathrm{Cr}-15 \% \mathrm{Ni}$ with controlled additions was designed to study th.e mechanistics of phase stability during irradiation. Data from thermal aging studies and the first ion irradiations ar now being analyzed. Wore than $\mathbf{4 0 0}$ specimens of these alloys are under irradiation in the FFTF. Experiments began for the fracture of neutron-irradiated austenitic and ferritic alloys in our high-vacuum high-resolution Auger system to study the effects of solute segregation on mode of failure and to relate this to irradiation conditions and alloy composition.

A major contribution of this task continues to be the development of the theory of microstructural evolution. The theories of swelling, irradiation creep, and some aspects of precipitation effects have received the most emphasis. We recently completed extensive work on our cascade diffusion theory of point defect absorption at dislocations, cavities, and other sinks. This theory goes beyond the almost universally used uniform production models to determine mure realistic defect concentrations. The concentrations show extreme fluctuations from point to point and time to time. 
Through it we have discovered a new phenomenon of irradiation creep caused by the cascadeinduced fluctuations is jinned dislocations. We completed a review and further development of the theory of the interactions of helium with radiation effects. On the basis of this work, a number of new experiments were planned and analyzed to better urderstand the mechanisms of swelling suppr ssion in swelling-resistant alloys. 'omprehensive derivations of the relationships between swelling and irradiation creep by four majer mechanisms of irradiation creep were completed. A mechanism for the observed peaetration of damage further into ion-irradiated polyatomic specimens (ceramics) than the range of the bombarding particle was proposed and analyzed by more sophisticated damage production computer calculations. The origin of the effect lies in the energetu displacement of lighter target elements by the heavier bombarding ion, thereby creating more highly penetrating prujectiles.

Development of tools and facilities for research on defect behavior continues as an important part of our efforts. Capabilities for both low-frequency and high-frequency pulsing of the heavy ion beam are now in place. We also improved our capabilities to deliver a wider number of heavy ior: beams. A new method was developed to overcome the difficulties of producing large and reliable curr.nts of zirconium and molybdenum. We increased our use of the accelerator for ion beam implantation, ion bean mixing, and nuclear microanalysis studies. Apparatus for the fracture of irradiated specimens, followed by high-resolution compusitional fractography with Auger electron spectroscopy under ultrahigh vacuum conditions, was completed. Work began on a new ion irradiation apparatus designed to permit irradiations on specimens under stress with protons whose range is larger than the specimen thickness.

Our research in plasma-wall interacions for fusion energy applications focused on the measurement of changes in the surface composition of the wall during plasma wall conditioning, a relativeiy poorly understood process for removiag oxygen and some other impurities while also charging the walls with hydrogen. Surface analysis equipment from Oak Ridge National Laboratory (ORNL) was used on (1) TEXTOR, a tokamak at the Institute fur Festkörperforschung der Kernforschungsanlage in Jülich; (2) JET, a very large tokamak built by the Joint European Community at Culham, England; and (3) ISX-B, the ORNL toikmak being used to test beryllium as a limiter material.

The stucies on TEXTOR showed clearly that it is very difficult to get the base metal to represent more than $6 n$ at. \% of the surface composition; O, C, N, S, Cl, and other surface-active impurities make up the balance. On the other hand, it is easy to get the impurity levels as low as 50 at. $\%$ and to substitute one impurity for another. This makes it possible to reduce or remove the oxygen, for example, by replacing it with carbon, which is a less objectionable impuricy. We monitored the initial wall conditioninz of JET. The results of the TEXTOR study were applied to JET, that is, carbon was added to speed the removal of oxygen. This was very effective, and the first JET tokamak plasmas not dominated by impurities were obtained. Measurements in ISX-B were used to characterize the wall conditions and materials transport during the beryllium limiter experiment. Beryllium is transported by sputtering during wall conditioning and as ions in the plasma cdge during tokamak shots. Beryllium acts as a strong getter for oxygen and covers the walls; as a result tokamak plasmas low in oxygen are obtained. 


\subsection{ELECTRON MICROSCOPY -J. Bentley}

The research of the Electron Microscopy Group centers on obtainino -iusotructural information on a wide range of metallic and ceramic materials to make reliable stricture-property correlations that are necessary in developing advanced materials with superior properties. In the past year we again emphasized the application of new methods asd techniques for materials characterization, with efforts to develop and evaluate new initrumentation being confined :o a field ion microscopeatom probe. Some of the applications involved collaboration with researchers from industry and universities through the SHaRE program.

$\mathrm{X}$-ray microanalysis research included the first clear demonstration of the magnitude of secondary fluorescence effects [which were shown to produce errors of up to $10 \%$ in compositions obtained by X-ray microanalysis in an analytical electron microscope (AEM)]; the further refinement of techniques for the measurement of concentration profiles in backthinned surfase-modified materials; and preliminary measurements of atom lucations in ion-implanted ceramics with the use of electron channeling analysis (first developed by the staff of the ORNL. Solid State Division). As part of a continuing effort to improve the reliability of electron energy loss spectroscopy analysis, measurements of absolute partial ionization cross sections were made to compare with the calculated values used in our data quantification computer programs. The ability to measure lattice parameter changes of $10^{-4}$ from convergent besm electron diffraction patterns was used to measure thermal expansion coefficients from 100 -nm regions. The technique appears to work well and will be applied to a range of phases in ceramic materials. Energy-filtered electron intensities of diffuse and Bragg maxima in electron diffraction patterns from ordered and modulated alloys were measured, and reasonable estirnates of the long-range-order parameters for $\mathrm{Ni}_{3} \mathrm{Al}$ were obtained from analysis of the data by kinematic theory.

Application of AEM rechniques to the measurement of chemical segregation profiles at high spatial resolution began. The effort involves the use of the Monte Carlo pregrams to account for beam broadening and Fourier transformation techniques for deionvolution. Experimental $m$ rsurements are also being made. An example is the measurement of grain-boundary antimony c nichment factors of 3 to 4 times the matrix in a doped model stainless steel.

A variety of in situ experiments were performed in the high-voltage electron microscope. The dynamic recording system was completed and fully evaluated. The work on strain localization in precipitation-hardened aluminum-lithium alloys was also completed. A noteworthy result was the formation of dislocation tangles along the edges of grain-boundary precipitate-free zones, resulting in large misorientations $\left(>10^{\circ}\right)$.

A major emphasis of the group involved collaborative applications. In structural ceramics, AEM investigations of zirconia-toughened alumina revealed gross inhomogeneities in the yttrium dopant distribution. Grain-boundary segregation of impurities and $\beta$-alumina grains were also observed. All the observed features can degrade the mechanical properties of these complex systems. Identification by $\mathrm{A}: \mathrm{M}$ of $r$-boride intergranular phases in $\mathrm{TiB}_{2}$ ceramics sintered with nickel or hotpressed with $\mathrm{Ni}_{3} \mathrm{Al}$ allowed significant progress in our understanding the sintering mechanisms in such alloys. The microstructural characterization of ion-implanted ceramics involved implant concentration profile measurements and identification of secondary defects and prscipitates. In siiu annealing experiments were also performed. Materials studied included $\mathrm{Al}_{2} \mathrm{O}_{3}$ implanted with zirconium, $\mathrm{TiB}_{2}$ implanted with nickel, and $\mathrm{SiC}$ implanted with chromium. 
Collaborative AtM investigations of rapidly solidifed $\mathrm{Ni}_{3} \mathrm{Al}$ alloys revealed the presence of a previously unknown metastable tetragonal phase and showed the development of antiphase domain boundaries on $\{100\}$ as a result of both bulk and thin-foil in situ annealing. The microstructural characterization of aluminum implanted with molybdenum, which involved identification of $\mathbf{A l}_{12} \mathbf{M o}$ precipitates in lamellar and continuous-film morphologies and in situ observation of the phase transformation processes, was completed.

The SHaRE projects included examination of creep-deformed SiC (where $\mathrm{B}_{4} \mathrm{C}$ intragranular and intergranular precipitates were identified) and the surprising observation of extensive intragranular cavitation in oxidized and riduced lanthanum-doped $\mathrm{SrTiO}_{3}$. The cavities may be the defects that accommodate the nonstoichiometry. Finally, further observations of supported metal catalysts were made. Video recordings of diffraction patterns obtained from operation in the scanning transmission mode with probes of less than $2 \mathrm{~nm}$ revealed the internal crystallography of the catalyst particles.

\subsection{STRUCTURAL MATERIALS GRUUP-A. F. Rowcliffe}

The work of the Structural Materials Group centers around understanding the effects of radiation damage on the physical and mochanical properties of complex alloys and on the development of alloys for fusion and fission reactor components subjected to high levels of displacement damage. Eighty percent of the group's support is from the Alloy Development for Irradiation Performance Program funded by the Office of Fusion Energy. The program is primarily concerned with the development of materials that will withstand the temperatures, stresses, chemical environment, and neutron damage levels expected in commercial power-producing reactors, which are several generations away from current experimental fusion machines.

Helium produced by transmutation has a major influence on radiation-induced swelling, microstructural evolution, and mechanical p-operty degradation. Consequently, helium effects are the focus of much of our work. Alloy compositions and reactor spectra are varied to achieve ratios of helium to displacements per atom (He:dpa) similar to fusion reactor conditions; in some experiments helium is introduced into the material before neutron irradiation.

In the austenitic stainless steel class, we snncluded that the lifetime of components fabricated from 20\%-cold-worked type 316 is limited by void sirelling to iluences of 40 to $50 \mathrm{dpa}$ in the range 450 to $600^{\circ} \mathrm{C}, 50$ to $70 \mathrm{dpa}$ in the range 300 to $450^{\circ} \mathrm{C}$, and 80 to $100 \mathrm{dpa}$ for temperatures below $300^{\circ} \mathrm{C}$. Grain-houndary helium embrittlement provides another linitation at 40 to $50 \mathrm{dpa}$ for temperatures above $575^{\circ} \mathrm{C}$. Attention is now being focused on austenitic steels with various types of particle dispersion designed to control the scale of helium bubble nucleation. A titanium-modifiei steel (prime candidate alloy) is showing improved swellin $_{b}$ and embrittlement resistance compared with AIS1 316 in the presence ef very high concentrations of helium ( -3000 at. ppm) produced by irradiation in HFIR. The He:dpa ratio achiced in the experiments is 4 to 5 times higher than that anticipated for a fusion machine. To achieve a more realistic end-of-life situation, a sequential HFIR-FFTF irradiation was initiated, which will be used to compare the swelling and embrittlement resistance of some 20 new developmental alloys. The effects of the He:dpa ratio on voic nucleation ase ien:is studied in a variety of austenitic stainless steels irradiated to $15 \mathrm{dpa}$ in FFTF (he:dpa, 0.4), HFIR (He:dpa, 60), and ORR (He:dpa, 15). 
An assessment of the potential of ferritic stainless steels continued with work on an Fe-12\% Cr-1\% Mo steel (HT-9), an Fe-y\% Cr-1\% Mo steel (ORNL Mod $9 \mathrm{Cr}-1 \mathrm{Mo}$ ), and a 2 ! $44 \mathrm{Cr}$-Mo steel. Both the $9 \mathrm{Cr}$ and $12 \mathrm{Cr}$ stecls showed outstanding resistance to void swelling in breeder reactor program irradiation experiments. Increasing the He:dpa ratio to approximately 3 by irradiating in HFIR produced an increase in cavity density, although total swelling remainer very low. The effects of higher helium generation rates on swelling and tensile properties are being explored by irradiating alloys with deliberate additions of nickel, the major source of helium in HFIR irradirtion being a two-step reaction of nickel with thermal neutrons.

A cruciai question in the application of these materials is the radiation-induced upward shift in ductile-brittle transition temper:-ure. The phenomenon is currently being explored with miniaturized Chan;; specimens irradiated in both HFIR and EBR-II at temperatures from 400 to $600^{\circ} \mathrm{C}$. Further low-dose experiments in HFIR are being planned to explore this phenomenon at irradiation temperature from 200 to $300^{\circ} \mathrm{C}$.

Efforts were initiated this year to control the very high levels of neutron-induced radioactivity in alloys for fusion reactor first-wall and blanket components. Concentratior imits were established for certain elements (principally $\mathrm{Ni}, \mathrm{Mo}, \mathrm{Nb}, \mathrm{N}, \mathrm{Al}$, and $\mathrm{Cu}$ ) that would result in radioactive decay rapid enough to permit shallow land burial of discharged components. Both ferritic and austenitic stzels were produced, in which the critical elements were ubstituted with alternative alloying additions. The principal metallurgical properties of these new alloys are being investigated, and an initial irradiation experiment is in place in FFTF.

The ques: for reduced activation levels has revived interest in vanadium and its alloys. Current work focuses on the effects of helium concentration on sweling and on ductility. Helium is not produced in vanadium alloys at fusion reactor levels during neutron irradiation in fission reactors. To circumvent this difficulty, a "tritium trick" facility was developed in collaboration with the ORNL Isotopes Division. Tritium is diffused into the vanadium alloys at the planned irradiation temperature; the required fraction is allowed to decay to ${ }^{3} \mathrm{He}$, and the residual tritium is pumped out under vacuum. This technique is being used to explore the sensitivity of mechanical properties in a range of vanadium alloys to various distributions of helium. Helium-doped alloys are currently being irradiated in FFTF to assess the combined effects of helium and neutron damage on phase stability, swelling, and mechanical propertics.

The past year was distinguished by the signing of a collaborative agreement on fusion materials developiment between the United States and Japan. This agreement provides irradiation space fo, Japanese materials in both the HFIR and ORR. Eight capsules, with space equally shared between the United States anc Japan, will be irradiated in HFIR from 400 to $600^{\circ} \mathrm{C}$ to doses of 30 and 50 dpa. In addition, two spectrally tailored capsules will be equally shared, operating at temperatures of $60,200,300$, and $400^{\circ} \mathrm{C}$. Currently four of the capsules are in position in HFIR, with the remaining four on schedule for insertion by the end of 1984. All the mechanical testing will be carried out at ORNL, and a new analytical electron microscope provided by Japan is shortly to be installed. As part of the agreement, two Japanese scientists will join the Structural Materials Group.

Other projects in the group involve the application of electron microscopy techniques to the structure of welds in ferritic and austenitic steels and to the structure of oxide films in oxidedispersion-strengthened inaterials. Work also began tnis year in support of the SP-100 Space Reactor Materials Program. The tantalum alloys T-111 and ASTAR 811C, which are being 
evaluated by the SP-100 project, were irradiated in EBR-II in 1970 as part of the fast reactor absorber program. These alloys were retrieved from long-term storage and are currently undergoing swelling measurements and high-vacuum tensile testing.

\subsection{LABORATORY TECHNIQUES AND SUPPORT FACILITIES GROUP-C. K. H. DuBOSe}

The work of the Laboratory Techniques and Support Facilities Group centers around specimen preparation for transmission electron microscopy (TEM) studies and related services. Structural characterization of ceramic materials by TEM has increased considerably over the last 18 months. Being nonconductors, ceramics caunot be thinned to electron transparency by electrolytic thinning as can metal samples. New techniques for sample preparation by use of mechanical erosion for prethinning followed by ion milling to electron transparency were developed. Care must be taken not to alter the crystal structure during the mechanical tusnning operation. Even hard materials like $\mathrm{TiB}_{2}$ can be plastically deformed on the surface. Ion implantation of the surface of many ceramics significantly increases the surface hardness and thus reduces wear. Techniques to study the structure of this thin ion-implanted region were developed.

Techniques were developed for preparing very thin splat-cooled material for TEM. An improved process for electrolytic - *:action of precipitates from bulk metal samples is being perfected, and a new technique was developed for preparing fine powder samples.

\subsection{SURFACE AND SOLID STATE REACTIONS-J. V. Cathcart}

The general goal of the research of the Surface and Solid State Reactions Group is to achieve a better understanding of the mechanisms of $g$ as-metal reactions. During this reporting period major emphasis was on studies of the sulfidation r.: iron and iron-base alloys. Two specific questions adOs ssed were (1) the extent to which impurity dtoms change scale defect concentration and, hence, sulfidation (or oxidation) kinetics and (2) the mechanism by which impurity atoms in a growing scale concentrate sufficiently to form a second phase. Systems being studied include Fe and dilute Fe-base alloys containing $\mathrm{Cr}, \mathrm{Mn}$, or $\mathrm{Al}$.

A second major research area involves an investigation of factors controlling the adherence of oxide scales. A dynamic resonance apparatus was designed to study the elastic and anelastic properties of scales and the correlation between these properties and the decohesion of the scale. In addition, we are assessing the importance of impurity atom size and the relative stability of impurityatom oxides on oxide scale adhesion. Collaborative programs are in progress, in which we study the influence of dispersoid particles on the nucleation stage of oxidation of a nickel-base, oxidedispersion-strengthened alloy and in which we characterize the high-temperature oxidation properties of $\mathrm{Ni}_{3} \mathrm{Al}$-base alloys.

Progress in these various areas includes (1) measurement of the defect concentrations in FeS samples doped with $\mathrm{Cr}$ and $\mathrm{Mn}$ as a function of temperature and prissure; (2) characterization of the influence of environment and impurities on the sulfide scale microstructure and on the sulfidation kinetics of $\mathrm{Fe}$; (3) resolution of the cause of apparent nonparabolic kinetics for the sulfidation of $\mathrm{Fe} ;(4)$ determination of tracer diffusivities for $\mathrm{i}$., $\mathrm{Cr}$, and $\mathrm{Mn}$ in FeS crystals; (5) characterization of the effect of $\mathrm{B}, \mathrm{Ce}$, and $\mathrm{Hf}$ additions on the oxidation of $\mathrm{Ni}_{3} \mathrm{Al}$-base alloys; (5) design and construction of a computer-operated dynamic resonance apparatus; and (6) initiation of studies of the influence of selected impurities on scale adherence on $\mathrm{Ni}_{3} \mathrm{Al}$-base alloys. 


\subsection{THEORY - J. S. Faulkner}

The Theory Group develops the techniques of solid state theory and applies them to problems in materiais science.

Our development of a modern theory of metallic alloys has reached the point that it is helpful to people engaged in practical alloy development and to those carrying out more basic studies of such solids. We have recently made a special effort to communicate this fact to a wider audience. We organized the theoretical contributions to a conference on High-Temperatire Alloys: Theory and Design sponsored by the Metals and Ceramics Division and the Committee on Alloy Phases of The Metallurgical Society of AIME in Bethesda, Maryland, on April 9-11, 1984. A course on Phase Stability of Alloys was taught during the winter quarter of 1984 as part of the in-house continuing education program for staff members at ORNL, which was attended by 21 senior scientists. We gave seminars on alloy theory at such institutions as the Bell Telephone Laboratory and the Materials Science Departments of Columbia University and North Carolina State University.

During this reporting period we developed a mathematically sophisticated technique for the calculation of the electronic states in alloys with the coherent-potential approximation, in which energy integrals are carried out along trajectories in the complex plane. This will dramatically reduce the computer time required for such calculations. We derived for the electrical resistivity of alloys a formula that makes no approximation beyond the one used to calculate the electronic states. Our quadratic-band-theory technique is being used to study the energy differences between the phases of pure metals. These are important paramcters in alloy phase diagrams. We are studying the energy of formation of long-range-ordered alloys related to $\mathrm{Ni}_{3} \mathrm{Al}$ in support of the collaborative alloy development program of the Metals and Ceramics Division and the Cabot Corporation.

We made improvements in our ability to calculate forces on the nuclei of atoms in large clusters. We will soon be using these results to enhance our studies on metal-metal bonding and the rnle of impurities in cohesion.

Most alloys of practical interest contain $\mathrm{Fe}, \mathrm{Co}, \mathrm{Ni}, \mathrm{Cr}$, or $\mathrm{Mn}$, which develop magnetic moments spontaneously. We have made progress in understanding the magnetism of these elements at both absolute zelo and finite temperatures.

\subsection{X-RAY RESEARCH AND APPLICATIONS - C. J. Sparks, Jr.}

The research of the X-Ray Research and Applications Group in materials science centers on the application of $X$ rays as a scattering probe and on the interpretation of these $X$-ray scattering measurements to determine the average structures of periodic crystals, the distribution and strain fields of defects in imperfect crystals, and the local atomic arrangements in crystalline and amorphous solids. We study the atomic arrangements that are relevant to their physical and chemical properties and that are important to advancing practical and theoretical concepts for designing new materials.

A new thrust in our program is to use synchrotron radiation to support our materials science research. We lave instrumented a statiou to be installed in the fall of 1984 at the National Synchrotron Light Source (NSLS). Advanced X-ray optics were designed for our beam line, for which we received an IR 100 award. The use of synchrotron radiation will permit the first systematic study of structures comprising those elements that form the base of our most technologically important alloy systems- $\mathrm{Fe}$ with the additions of $\mathrm{Ni}, \mathrm{Cr}, \mathrm{Co}, \mathrm{Mn}, \mathrm{V}$, and $\mathrm{Ti}$. Of major 
interest is the substitutability of these elements for each other in various crystallographic structures and the short-range ordering or clustering among them. A group of university and industrial scientists, organized through the Oak Ridge Associated Universities, have participated in the design and will perform collaborative research at this $\mathrm{X}$-ray station on a variety of materials problems.

The merits of $\mathrm{X}$ rays over elsetrons for microcharacterization of materials by both elementai mapping with fluorescence and structural mapping with diffraction led us to consider the advantages of using synchrotron $X$-radiation as an $X$-ray microprobe source. We designed two energytunable fluorescent microprobe optical designs, which efficiently use $X$ rays available from bending magnets and insertion devices of synchrotron radiation sources. Compared with other proposed optical systc.ns, the gain in intensity is from 3 to 10 at demagnifications of the focus by factors of 8 and greater. From the bending-arc magnets of the NSLS operating at $500 \mathrm{~mA}$ and $2.5 \mathrm{GeV}$, expected flux in a $1-\mu \mathrm{m}$-diam spot is about $2 \times 10^{10}$ photons $/ \mathrm{s}$ at $15 \mathrm{keV}$. With this $X$-ray intensity, concentration levels $10^{-3}$ less than those observed with electron probes are detectable. We are currently working with the NSLS staff and others to implement a microprobe that can be applied to materials science problems.

Studies of X-re-induced resonant and threshold phenomena near absorption edges continued. An understanding of the $X$-ray interaction processes near absorption edges is important to our developing use of anomalous dispersion to interpret diffuse $X$-ray scattering. Furthermore, nearedge resonant $X$-ray spectroscopies can have important attributes such as a sensitivity to the unfilled density of states around a particular atomic species and an ability to resolve structure normally convoluted with the initial hole lifetime width. New and more detailed measurements were made of postcollision interaction and the resonant Raman Auger effect from deep inner-shell holes. These measurements show a discrepancy between existing theory and experiment. Measurements of hard $\ddot{x}$-ray-induced shakeup and shakeoff near threshold were performed for the first time, and a basic theoretical understanding was formulated.

$X$-ray diffraction measurements of nonrandom distribuiion of elements among various coordination sites continues to produce new insights to the crystal chemistry of alloy phases. The presence of minor second phases in steels and other metal alloys can have dramatic effects on the mechanical properties. These effects range from improving certain properties to rendering the alloy unusable in some applications. We have selected for study three second-phase structures that commonly occur: the sigma phase, the spinel, and the tau carbides. Variations in the heat treatment and compositions are used to produce structural changes, follo'ved by diffraction anaiysis. These studies are bringing new information to the understanding of stability for these phase..

Measurements of site occupation parameters were extended to single crystals of binary $\mathrm{W}-57.9$ wt \% $\mathrm{Re}$ and $\operatorname{Min}-21.7$ wt \% $\mathrm{Cr}$ sigma phases. The latter is unique among sigma phases in that indirect evidence exists for both atomic and magnetic ordering. Extensive conventional Mo $K \alpha$ d.ffraction data sets were measured to fix the thermal parameters, but these data could not distinguish between the two kinds of atoms. Synchrotron radiation will be used to determine how the atoms are positioned among the different coordination sites to learn more about the chemical substitutability among these atoms.

Despite the small number of iron atoms per unit cell ( $\sim 3$ out of 92 total metal atoms) in a 7-carbide single crystal of composition $\left(\mathrm{Cr}_{22.26} \mathrm{Fe}_{0.74}\right) \mathrm{C}_{6}$, their their distributions could be estimated from the conventional $X-r$ diffraction data. The accuracy of these site occupation parameters was confirmed by analyses of synchrotron radiation Brags diffraction data collected near $\mathrm{Cr} K$ and Fe $K$ ibsorption edges with the same crystal. The distribution parameters form a reasonable extrapolatior. from the results previously obtained at higher iron contents. 


\section{PROJECT ACTIVITIES}

This section of the report deals with the various project activities in which the division was engaged to a major extent during the report period. Brief statements of the purpose, nature, and scope are presented on the following U.S. Department of Energy (DOE)-sponsored programs: Basic Energy Sciences, Breeder Reactor Materials, Conservation Technology, Fossil Energy Materials, Fusion Energy Materials, Gas-Cooled Reactor Materials, Heavy-Section Steel Technology, and Advanced Space Nuclear.

\subsection{BASIC ENERGY SCIENCES-MATERIALS SCIENCES- C. J. McHargue}

The purpose of the Basic Energy Sciences-Materials Sciences Program is to establish an understanding of the principles governing the behavior of materials. The thrust of the division's efforts can be characterized as the scientific design of materials in the specific areas of structural ceramics, high-temperature metallic alloys based on intermetallic compounds, and radiation-resistant alloys. The progress at Oak Ridge National Laboratcly (ORNL) toward the construction of the HighTemperature Materials Laboratory strongly influenced the choice of these res:arch areas.

The program contains tasks in the areas of theory of alloying, structural characterization, properties, and processing. During this reporting period, new efforts were initiated toward developing a state-of-the-art imaging atom probe facility and toward cooperating with the Solid State Division in ion-beam processing of materials.

The structural ceramics program initiated new studies dealing with the characteristics of powders as they influence the densification process, which interact with studies in the Chemistry and Chemical Technology divisions. The tast on fundamentals of welding is involved with the national efforts to establish the American Welding Technology Application Center and has developed a joint research program with industrial laboratories. The high-temperature alloy design task focused on the nickel aluminide system, and the success in ductilizing the polycrystalline forms of this alloy generated several interactions with applied programs and industrial firms.

\subsection{BREEDER REACTOR MATERIALS-P. Patriarca}

Materials probleins, are central to economic competitiveness, inherent safety, and reliable performance of liquid metal fast breeder reactor (LMFBR) power plants. In recognition of this fact, DOE ias sponsored for many years LMFBR Materials and Structures and Fuels and Materials programs at ORNL. Technology areas in the Metals and Ceramics Division include mechanical properties, fabrication, nondestructive testing, advanced alloys, and support of the Nuclear Systems Materials Handbook. 
Work under mechanical properties ranges from the performance of exploratory tests for characterizing material behavior to the full-scale acquisition of engineering data. Reference data in air and the effects of metallurgical variables are being determined.

Processes and procedures for component fabrication are being developed and evaluated under the heading of fabrication technology. The emphasis is on welding, including testing and evaluation of ferritic and austenitic steel dissimilar-metal joints.

Tasks in nondestructive testing technology are aimed at inspection of materials and components during manufacture and in service, including situations requiring remote, autonated performance. Advanced radiography, ultuasound, and eddy-current techniques are being developed, especially for stainless steel welds, ferritic steel tube-to-tubesheet welds, and high-temperature in-service inspection.

Development of advanced alloys was one of the main achievements of the LMFBR materials programs. A modified $9 \mathrm{Cr}-1 \mathrm{Mo}$ steel with elevated-temperature strengh comparable with type 304 stainless steel to $550^{\circ} \mathrm{C}$ was developed for structural applications. This steel bas good fabricability, high resistance to thermal stresses, and good resistance to stress corrosion cracking. Commercialization strategy has emphasized technology transfer, and cooperative programs involving over $\mathbf{4 0}$ participating organizations are under way.

Serious design problems sar occur in a fast reactor such as the LMFBR if the duct material swells from exposure to irradiation. An alloy deveiupment program led to the design of a type 316 stainless steel alloy with adjusted compositions of $\mathrm{Cr}, \mathrm{Ni}$, and $\mathrm{Ti}$, which is greatly resistant to neutron-induced swelling. This class of titanium-m dified steels is referred to as D-9, and current efforts are aimed at developing the required design data base and at gaining operating experience with full-scale assemblies of fuel pin bundles.

\subsection{CONSERVATION TECHNOLOGY-A. C. Schafthauser}

Our materials research and development programs formergy conservation have grown significantly with the renewed DOE emphasis on increased energy efficiency and the realization that materials are a key technology need for advanced energy conservation systems. We have established lead laboratory roles on major materials support tasks in the following conservation projects: (1) Energy Conversion and Utilization Technologies (ECUT) Materials, (2) ECUT Tribology, (3) Ceramic Technology for Advanced Heat Engines, (4) Building and Equipment Insulation, (5) Industrial Waste Energy Recovery, and (6) Electric Energy Systems. In the first four projects, we are responsible for the planning, implementation, and management of the national DOE program, which involves extensive interfaces and subcontracts with industry, universities, and other fcderal laboratories in addition to research in the Metals and Ceramics Division.

The objective of the ECUT Materials and Tribology projects is to provide the technology base for all advanced energy conservation systems. The projects fund long-range applied research and innovative ideas tiat are beyond the scope of either the applied programs or basic research. The ECUT Materials Project provided the major funding for our development of the ordered intermetallic alloys and for smaller tasks involving innovative research on ceramic powder synthesis, composites, joining, and surface modification. The major in-house effort in Tribology is on understanding the friction and wear behavior of ceramics in a cooperative effort with various universities. Research on lubricants is led by the National Bureau of Standards, and Argonne National Laboratory is leading the effort on tribological coatings. 
The Ceramic Technotogy for Advanced Heat Engines Project was developed in FY 1983 to meet the ceramic technology requirements of the DOE Office of Vehicle and Engine Research and Development (OVERD) automotive technology programs. The objective of the project is to develop the industrial technology base required for reliable ceramics for application in advanced automotive heat engines. The focus is on structural ceramics for advanced gas turbine and diesel engines, ceramic attachments, and ceramic coatings for thermal barrier and wear applications in these engines. An assessment of needs was completed through extensive interaction with industrial ceramic and engine companies, and a five-year project plan was developed. Technical wort began on (1) materials and processing, (2) materials design methodology, and (3) data base and life prediction through ORNL in-house research; subcontracts with industry, universities, and other government laboratories; and an interagency agreement with the Department of Defense. The ORNL inhouse work is on powder synthesis, development and characterization of toughened ceramics, and joining of structural ceramics to metals. The construction and equipment for the High-Temperature Materials Laboratory (HTML) is being funded by OVERD. The Ceramic Technology Project will become an integral part of the HTML.

The objective of the Building and Equipment Insulation Project is to develop a reliable data base, testing techniques, and models for heal transfer mechanisms and other physical properties of insulation and building materials. The current focus is on determining the importance of radiant heat transfer and the transient behavior in low-density building and syuipment insulation. This research is leading to the development of improved insulation systems.

The focus of our materials task on Industrial Waste Heat Recovery is to determine the performance of current ceramics high-temperature corrosive industrial furnace flue environments and to develop improved materials. To achieve the large fuel savings possible with ceramic recuperators reliably, we are determining corrosion limits in various industrial environments and developing cost-effective fabrication methods cooperatively with several industrial suppliers and users.

Materials tasks in support of Electric Energy Systems include development of high breakdown voltage $\mathrm{ZnO}$ varistors for protection of the electric distribution system, development of ductile amorphous metals with optimum electrical characteristics for high-efficiency motors and transformers, and characterization of polymer insulation for gaseous dielectric transforme.s.

The interaction of these projects within the Conservation Technology Prngram and with the Materials Science and Fossil Energy programs at ORNL, other federal agencies, and industry is synergistic and very productive. We anticipate continued growth in these projects but at a somewhat slower rate than in the previous two years.

\subsection{FOSSIL ENERGY MATERIALS-R. A. Bradley}

The Fossil Energy Materials Program at ORNL consists of four major activities (1) technical support to Oak Ridge Operations (ORO) in the management of DOE's Advanced Research and Technology Development (AR \&TD) Fossil Energy Materials Program; (2) technical support to ORO and the Morgantown Energy Technology Center in the management of DOE's Surface Gasification Materials Program; (3) in-hous: research and development on the AR\&TD Fossil Energy Materials Program and the Surface Gasification Materials Program; and (4) research activities for DOE's Major Coal Liquefaction Projects Office, DOE's Office of Coal Liquefaction Technology, and the Pittsburgh Energy Technology Center Coal Liquefaction Instrument and Component Project Office. 
The objective of the AR \&TD Foesil Energy Materials Program is to conduct research and development on materials for fossil energy applications, with a focus on the longer term and generic needs of the various fossil fuel technologies. The program includes research aimed at a better understanding of materials behavior in fossil energy environments and the development of new materials capable of substantial improvement in plant operations and reliability. In addition to performing in-bouse research on materials for casl combustion and conversion of coal to liquid and gaseous fuels, ORNL provides technical support to JOE-ORO in the management of the national AR \&TD Fossil Energy Materials Program. Our responsibilities include preparation of draft program plans for DOE approval and implementation of the research program through subcontracts with industrial research centers, universities, and other government and national laboratories. The in-house research and development on the AR \&TD Fossil Energy Materials Program includes tasks on the development of irsa and aickel aluminides, erasion and corrusion in coal combustion environments, corrosion of materials for moltea carbonate fuel cells, development of structural ceramies, and assessment of materials needs for advanced sten!n cycle pulverized-coal plants.

The objective of the Surface Gasification Materials Program is to conduct research and development on materials for application to the specific needs of coal gasification systems. One of the goals of the program is to evaluate innovative fabrication methods that can potentially lower costs and improve reliability and safety for gasifier vessels and components. Arrother goal is to conduct engineering-scale development and application of materials for coal gasification systems to ensure that the materials of construction for pilot plants and future large-scale plants can be properly selected and specified. Our management responsibilities on the Surface Gasification Materials Program are similar to those for the AR \&TD Fossil Energy Materials Program. In-house activities on the Surface Gasification Materials Program include tasks on advanced pressure vessel materials technology and electroslag component casting.

Research on coal liquefaction includes materials design reviews, assessments of materials performance and selection, pilot plant materials testing, chemical vapor deposition coating studies for erosion-resistant materials, and in-plant and labnratory testing of elastomers.

\subsection{FUSION ENERGY MATERIALS - J. L. Scott}

The objective of the Fusion Energy Materials Program is to develop structural materials for near-term and commercial fusion reactors. By use of several techniques for simulating the effects of 14-MeV neutrons, we have found that austenitic steels, ferritic steels, and vanadi:m alloys show promise as randidate fusion materials. Type 316 stainless steel is marginal from the standpoint of swelling: a modified alloy, prime-candidate alloy (PCA), is therefore being investigated. Results to date show that $25 \%$-cold-worked PCA is remarkably resistant to swelling up to $5 \mathrm{MW}$-years $/ \mathrm{m}^{2}$ and shows promise for a lifetime of at least $10 \mathrm{MW}$-years $/ \mathrm{m}^{2}$. Ferritic steels $\mathrm{HT}-9$ and $9 \mathrm{Cr}$ 1 Mo are very swelling resistant and have excellent tensile properties after exposure to $4 \mathrm{MW}$.years $/ \mathrm{m}^{2}$. A possible disadvantage is the increase of up to $125^{\circ} \mathrm{C}$ in ductile-to-brittle transition temperature. For the longer term, low-activation versions of austenitic, ferritic, and vanadiumbase alloys a:e being developed. 
46 GAS-COOLED REACTOR MATIERIAIS-W. P. Eatherly, M. J. Kania, and P. L Ritteahous:

Increasing attertion is being given to several gas-cooted reactor (GCR) concepts in the size range 100 to $500 \mathrm{MW}(\mathrm{e})$. The primary reason for this interest is the high degree of inherent safety. Such plants possess intrinsic features that should pernit them to recover by passive cooling from worst-accident situations with hessentially no release of fission products from the coatedparticle fuel and with no damage to the plant core or structures. This is accomplished without reactor operator actions or engineered safeguards.

Three areas of technology important to such GCRs-Iuels, graphites, and structural alkoys-are being covered in the division's programs. The hisctive of the fuels work is to provide the technology base for the assurance of safe, reliable, and economic coated-particle fuel. The major current activity is the postirradiation examination of fuels to verify performance margins, including fiel particle failure fraction, and to measure the degree of fission product retention.

Work on graphices is aimed at the development and qualification of nuclear grades for in-core, reflector, and structural applications. Specific tasks within ' $x$ division involve development of improved materials, determination of physical and mechanical properties and oxidation behavior, failure and design criteria studies, and postirradiation examination and evaluation of irradiated graphites.

Objoctives of the structural alloys task are to develop alloys for GCR use and to generate the required materials data base and technology needed for design, construction, and licensing. Work in progress addresses (1) high-temperature mechanical properties including creep, fatigue, and fracture toughness; (2) thermal stability and effects of GCR enviroament; (3) corrosion and compatibility of materials; (4) fabrication and manufacturing iechnology; and (5) new alloys for application at very high temperatures.

\subsection{HEA VY-SECTION STEEL TECHNOLOGY-R. F.. Nanstad}

The Heavy-Section Steel Technology Program is iunded by the U.S. Nuclear Regulatory Commission and is charged with the performance of research aimed at assurance of the integrity of light-water nuclear reactor pressure vessels. The Metals ind Ceramics Division performs materials testing and analyses in support of structural testing tasks sucn as thermal shock, pressurized thermal shock, intermediate test vessels, and widu j!- - crack arrest. We are responsible for performan 2 of a multitask irradiation program to study $t=$ effects of neutron irradiation on the properties (the most important of which is fracture toughness) of reactor pressure, vessel steels and their weldments.

Series 2 and 3 irradiations and testing were completed, and a final report is being prepared. Those irradiations were conducted to examine the effects of irradiation on the welds with relatively low Charpy upper-shelf energy representing early commercial practice. Series 4 is similar except that the materials represent current practice welds. Charpy impact and tensile testing was compieted, and fracture toughness testing will be completed by the end of FY 1984. Series 5 and 6 were conceived to validate the amount and shape of the initiation fracture toughness $K_{l c}$ and crack

arrest toughness $K_{l \sigma}$ curve shifts, respectively, as a consequence of irradiation. Specimens up to $100 \mathrm{~mm}$ thick will be irradiated and tested. The irradiations began in the Oak Ridge Research 
Reactor in May 1984. Series i is designed to determine the effects of irradiation on stainless steel cladding. Phase I was completed with the irradiation testing of Charpy and tensile specimens of single-wire submerged arc types 309 and 308 stainless steel. The program will continue in FY 1985 with the irradiation of three-wire series are austenitic cladding obtained from a commercial vendor.

Activities in the nonirradiation area were the developecent of our crack arrest teating system and the completion of testing for the American Society for Testing and Materials Round Robin Program on Crack Arrest.

We performed extensive metallurgical analyses, iceluding transmission ind scanning electron microscopy, in support of all test proprams and demonstrated the capability for obtaining accurate, reproducible fracture toughness results with a dc-potential drop system for in-flight crack length measurement.

\section{ADVANCED SPACE NUCLEAR SYSTEMS MATERIAL:}

\subsection{Special Neclear Projects-M. M. Martin}

Improved materials and processes for space and terrestrial applications that utilize radioisetope thermoelectric generators (RTGs) are being developed and evaluated. Activities have included production of iridium alloy-cladding blanks, which contain the heat-eenerating radioisotopes, and carbon-bonded carbon fiber (CBCF) insulators, which achieve a design operating temperature of about $1550 \mathrm{~K}$ at the surface of the cladding blanks in the RTGs. In anticipation of resumed production in FY 1986, an inventory of iridium and a production capability for the insulators and bianks are being maintained at ORNL. In the interim, technology improvements being pursued involve a process to produce CBCF from new raw materials, a consumable are-melting technique to produce iridium alloy ingots of minimal porosity for blank production, publication of an Isotopic Space Power Materials Handbook, nondestructive examination support for manufacture of advanced thermoelectric elements, and evaluation of measurements of thermal diffusivity and steadystate thermal conductivity on CBCF products. Ail these efforts will provide an expanding materials and processing data base for future RTGs.

\subsection{Space Noclear Projects-R. H. Cooper, Jr.}

Efforts continue to establish a substantial role for ORNL in the Space Nuclear Reactor Program. At present the program funded by the Department of Defense, DOE, and National Aeronautics and Space Administration is primarily focused on the development by FY 1985 of a viable concept for a $100-\mathrm{kW}(e)$ reactor. Additional funding may be made available as early as FY 1985 for developing the technologies needed to support multimegawatt space nuclear concepts for possible deployment in the year $\mathbf{2 0 0 0}$.

The Metals and Ceramics Division currently has a major role in the fabrication and characterization of the candidate refractory alloys being considered for fuel-cladding and structural applications in $100-\mathrm{kW}(\mathrm{e})$ reactors. Active tasks in FYs 1984 and 1985 include characterization of alloy irradiation effects; determination of the creep properties of Ni-, Ta-, Mo-, and W-base alloys; and fabrication of refractory alloy mill products to support important component testing activities. 
A program for the Navy on titanium alloy weldments involves understanding the solidification microstructure and its stability in Ti-6\% Al-2\% Nb-1\% Ta-0.8\% Mo alloy. Potentiostatic etching and X-ray microradiography eschniques were developed to delineate solidification substructures in titanium alloys. The effect of residual impurities such as boron on the properties of Ti-6211 alloy weldments is being investigated.

Finally, a project was initiated to develop a suitable weldability test for thin sheet materials. A weldability test was developed and used sucoessfiully to characterize the weldability of thin sheets of stainless steels. 
Wide agreement exists in the technical community that development of an effective refractory alloy technology is critical to the successful deployment of high-performance space nuclear power systems. If a significant nationai program oriented to the development of high-performance space nuclear power system develops in FY 1986 as planned, the Metals and Ceramics Division is expected to have a lead role in the development of refractory alloys. 


\section{SPECIALIZED RESEARCH FACILITIES AND EQUIPMENT}

In recent years the division has promoted the establishment of selected research facilities with unique capabilities to be operated in the user-dedicated mode. The underlying objective is to advance materials srience on a broad national front by making this one-of-a-kind equipment available for collaborative and joint research with the industrial sector and the university community. The effort involves two specialized facilities: Oak Ridge Synchrotron Organization for Advanced Research (ORSOAR) and Oak Ridge National Laboratory (ORNL)-Oak Ridge Associated Universities (ORAU) Shared Research Equipment Program (SHaRE). A brief status report on each activity is presented.

\subsection{OAK RIDGE SYNCHROTRON ORGANIZATION FOR ADVANCED RESEARCII- C. J. Sparks, Jr.}

Tuis task provides support for a consortium of prinarily university and some industrial scientists to share the ORNL X-ray research station at the National Synchrotron Light Source (NSLS) under construction at the Brookhaven National Laboratory (BNL). The user group organization will make available to university staff members and industrial scientists a unique research facility and of portunities for scientific collaboration not available in their respect,$\cdot$ home institutions. The task also supports one full-time ORAU staff member, A. Habenschuss, to interface with the users and to develop computer support for collaborative research at the ORNL X-ray station.

We have assembled a scientifically competent and motivated group of university and industrial scientists whose research interests not only match the needs of U.S. Department of Energy (DOE) basic energy sciences but will benefit from the application of synctirotron radiation. Currently, 21 university scientists and members of four industrial laboratories have expressed an interest in participating in our consortium. Our annual meeting was held at BNL during the NSLS user's meeting in June 1984. Even though there has been no radiation availab!e from the $X$-ray ring for our beam line (the NSLS is now three years behind schedule), eight scientists not affiliated with ORNL or ORAU attended the meeting and expressed their continued interest. The date for beginning user experimental research on the X-ray ring at the NSLS was discussed and estimated to be January 1985 at the earliest.

During the delay in completing the X-ray ring at the NSLS, we developed high- and lowtemperature specimen chambers and other ancillary equipment, improved our beam line, and con tinued computer hardware and software development to maximize the utility of the beam line for scientific applications.

\subsection{SHARED RESEARCH EQUIPMENT PROGRAM-E. A. Kenik}

In the past 18 months the SHaRE experienced growth in the number of internal collaborators and research areas. The program allows participants from universities, industrial research 
organizations, and other national laboratories access to the wide range of often unique microanalytical facilities. The program is aimed at collaborative research in materials science in areas pertinent to the DOE-ORNL mission and emphasizes areas under investigation in the Metals and Ceramics Division. Facilities and iechniques included under SHaRE are analytical and highvoltage electron microscopy, Auger spectroscopy, nuclear microanalysis, surface modification by ion beam techniques, and rapid solidification facilities. An atom probe and imaging atom probe facility will soon be included. Several SHaRE projects support advanced materials development programs in the Metals and Ceramics Division, such as long-range-ordered alloys, nickel-base aluminides, high-temperature ferritic alloys, and high-performance ceramics.

During this period, the Division of Materials Sciences, Office of Basic Energy Science, provided funds through ORAU to support the SHaRE activity. Program funds are used for travel and living expenses of SHaRE participants while at ORNL and for the support of G. L. Lehman, an electron microscopist. His responsibility is to fanziliarize SHaRE participants with the electron microscope and computer facilities and to participate in SHaRE research when appropriate. His presence has made possible the high level of SHaRE participation and minimized interference with in-house programs.

A steering committee reviews all proposed SHaRE projects and defines SHaRE program policy. The members in FY 1983 were E. A. Kenik, ORNL; C. L. White, ORNL; D. H. Garber, ORAU; J. J. Hren, Professor, Department of Materials Science and Engineering, University of Florida, Gainesville; and K. R. Lawless, Professor and Chairman, Department of Materials Science, University of Virginia, Charlottesville.

Three changes were made in the FY 1984 steering committee: R. Wiesehuegel, ORAU, replaced D. H. Garber; P. S. Sklad, ORNL, replaced C. L. White; and R. F. Davis, Professor, North Carolina State University, Raleigh, replaced K. R. Lawless.

During this reporting period, 20 SHaRE projects were active, involving about 41 participants. Some 20 to 25 papers based on SHaRE research were published, and about 30 presentations were made at technical meetings. 


\section{MISCELLANEOUS ACTIVITIES}

This chapter presents work in progress in the division other than that discussed in previous chapters.

\subsection{METallograPhy - R. S. Crouse}

The Metallography Gruup of the Metals and Ceramics Division provides technical assistance in general metallography, including psstirradiation examination and electron beam microanalysis. These services are available not only to the division but to the entire Oak Ridge complex and to outside organizations such as Batielle Pacific Northwest Laboratories (PNL). Tennessee Valley Authority, and U.S. Department of Energy. Duting the reporting period, the group processed $\mathbf{4 4 0 0}$ specimens and made 10,000 black-and-white negatives, 600 color negatives, and 4000 slides and viewgraphs.

\subsubsection{General Metallography and Postirradiation Examination-}

R. S. Crouse and B. C. Leslie

In the field, metallography continues to be performed for the Engineering Technology Division at the Y-12 Plant in support of its full-scale creep tests and stress rupture tests. Test pieces are polished, etched, and replicated in situ ait specified intervals during testing to follow the progress of changes in the microstructure.

The hot cell metallography facility is used to analyze stainless steel capsules containing ${ }^{137} \mathrm{CsCl}$ for Battelle PNL as part of its continuing study of the long-term compatibility of container materials with high-radiation-level reactor wastes. Four capsules were sectioned and fully examined during this reporting period.

\subsubsection{Electron Beam Microanalysis-R. S. Crouse and T. J. Henson}

A fully automated electron beam microprobe (probe) $\mathrm{X}$-ray analyzer was installed and became operational. This instrument performs rigorous quantitative chemical analyses on flat polished specimens of metals, ceramics, and minerals about $1 \mu \mathrm{m}$ in diameter. All operations are computer controlled.

The probe was recently used to determine the concentiation and distribution of $\mathrm{Ca}, \mathrm{Mg}, \mathrm{Na}$, and $\mathrm{Sr}$ in dolomite crystals from the Florida aquifer. This enables the geologists to estimate the mode and time of formation of the rock strata.

\subsection{SPECIAL PROJECTS-R. J. Gray}

This activity focuses on projects requiring special applications of metallographic techniques and investigative skills. Most of the work is on failure studies, but examinations are also made on materials behavior under specific circumstances. One study involved the metallographic analysis of 
a number of transition or dissimilar-r.tal weld joint failures that occurred during elevatedtemperature service (fossil find) or during laboratory specimen testing. A report was published, which included the study of crack initiation and propagation in the heat-affected zone adjacent to the fusion line of the weld as shown in microstructures with light optical and scanning elactron microscopy.

Another study determined the cause of a blark-firing adapter explosion that occurred during a security exercise at Oak Ridge National Laboratory. The explosion was credited to the firing of a live round of ammunition containing a recessed projectile that was inadvertently mixed with blank ammunition. A report was published on this work, and an open-literature publication is in press.

An article was published on the microstructural study of series 300 stainless steel sheet welds and tensile specimens. Magnetic etching was used to detect ferromagnetic and paramagnetic conditions in the microstructure as related to welding and testing conditions. 


\section{APPENDIXES}




\section{Appeadix A}

\section{BUDGET AND FINANCIAL CHANGES}

During the past 18 months, the divisional operating budget increased $\$ 1.7$ million for a total FY 1984 budget of $\$ 27.7$ milion. The increase occurred in FY 1983, with a small decrease of $\$ 240$ thousand in FY 1984 the first decrease in total support in many years. These data are tabulated in Table A.1.

A significant change in division funding not included above is the increase in assigned U.S. Department of Energy (DOE) pass-through funds to support subcontracting, Table A.l. These funds have increased from about $\mathbf{\$ 3 . 8}$ million to an estimated $\mathbf{5 6 . 9}$ million; additional personnel are required to manage the activity (see Appendix C). Two projects (conservation and fossil), each representing over $40 \%$, are the primary sources of these funds; however, most programs now support work of this type. The increase over this period has been primarily in conservation, which has increased by more than a factor of 3 to an estimated $\$ 3$ million. This growth is expected to conlinue during the coming year.

In FY 1983 the budget for basic energy sciences, conservation, space, and work for others increased considerably, but waste management and nuclear fission energy suffered large decreases. In FY 1984 a large increase in conservation and a smaller one in basic energy sciences were offset by losses in fission energy, space, waste management, Nuclear Regulatory Commission support, fossil energy, and work for others. The waste management program, which suffered decreases in both years, is now in the process of being transferred to the Operations Division.

The desired diversification of division funds discussed in the previous report has continued. The programs in fission energy, which as late as 1978 constituted over $60 \%$ of the division budget, have continued to decrease and now represent only $14 \%$ of the division effort. The largest program is now basic energy sciences, and, with its rapid growth, conservation is second. Five major programs now corstitute between 10 and $25 \%$ of the budget; no major program supports less than 5\%.

Table A.1. Dividos baleat

Thousands of dollars

\begin{tabular}{ccc}
$\begin{array}{c}\text { Fiscal } \\
\text { year }\end{array}$ & $\begin{array}{c}\text { Oprrating } \\
\text { funds }\end{array}$ & $\begin{array}{c}\text { Subcontracting } \\
\text { funds }\end{array}$ \\
\hline 1982 & 26,020 & 3,786 \\
1983 & 27,941 & 4,570 \\
1984 & 27,701 & 6,900 \\
\hline
\end{tabular}

-Estimated. 


\section{Appandix B}

\section{PERSONNII SUMMARY}

The decline in personnel discussed in the two previous reports was reversed during this period. Increases have occurred in all personnel categories during the period January 1, 1983, through June 30, 1984 (Table B.1). The permanent staff increased by four technical and seven support people. We used two-year appointments to increase the technical staff an additional three for a total increase of seven technical peopie. In the support area, the secretarial staff was increased, and the technician staff was decreased by one.

The increase of 7 in the technical staff was achieved by obtaining 15 new people: 12 were hired, 1 was transferred, and 2 received internal promotions. The high quality of the division was thus maintained with the new hires. All but one of the hires are $\mathrm{Ph}$. D's, and the one has extensive experience in a needed area. Of the 13 people obtained from outside the division, 10 had three years or more experience; the average for the entire group was eight years. A wide range of disciplines is represented by this group, six being trained in metallurgy or materials science, three in physics, two in chemistry, one in both ceramics and engineering mechanics, and two with no degree.

Of the eight people who left the division, only three went to outside jobs, four retired, and one was promoted and transferred to another division. Of this group only three or $37 \%$ had Ph.D's; two had no degree.

The division staff was again augmented by technical guests from the outside. On July 1, 1984, we had 13 assigned to the division compared with 5 on January 1, 1982. During these 18 months a total of 107 long-time guests worked in the division. Their appointments ranged from two months to two years. The wide source of these technical guests is tabulated in Table B.2.

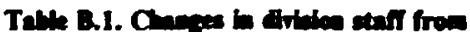

Jemer 1, 1983, itrend Jen 39, 1944

\begin{tabular}{|c|c|c|c|c|c|c|c|}
\hline & \multicolumn{3}{|c|}{ Technical } & \multicolumn{3}{|c|}{ Support } & \multirow{2}{*}{$\begin{array}{l}\text { Tola' } \\
\text { change }\end{array}$} \\
\hline & $1 / 1 / 83$ & $7 / 1 / 84$ & Change & $1 / 1 / 83$ & $7 / 1 / 84$ & Change & \\
\hline Permanent employces & 127 & 131 & +4 & 106 & 113 & +7 & +11 \\
\hline Temporary employees, >ten months & $s$ & B & +3 & 0 & 0 & $\mathbf{0}$ & +3 \\
\hline Losneet to other divisions & 4 & 3.5 & -0.5 & 2 & 4 & +2 & +1.5 \\
\hline Loances from other divisions & 1 & 2 & +1 & 2 & 2 & $\mathbf{0}$ & +1 \\
\hline Part-time employees & 4 & 4 & & 6 & 8 & +2 & +2 \\
\hline Long-time guests & 5 & 13 & +8 & 0 & 0 & $\mathbf{0}$ & +8 \\
\hline
\end{tabular}


Trale R.2 Soroe of necturiod gavets

\begin{tabular}{lr}
\hline \multicolumn{1}{c}{ Sourc: } & Number \\
\hline American universitios & 72 \\
Industry & 7 \\
Foreign conntries & 16 \\
Other natiosal laboratories & 1 \\
Other & 11 \\
Total & 107 \\
\hline
\end{tabular}




\section{Appeadix C \\ ORGANIZATIONAL STRUCTURE AND CHART}

During this reporting period, the organization of the division remained relatively stable. In the implementation of 11 programmatic activities, we continue to operate with three functional research sections comprising 18 functional laboratories and with one service section. An organization chart of the division as of July 1, 1984, is included in this appendix.

The major change in organization was the expansion and formalization of the conservation programs under A. C. Schaffhauser. Under the U.S. Department of Energy assistant secretaries for conservation and renewable energy, the division is now managing two major phases of the national conservation program. The major portion of both these tasks involves supervision of outside subcontracts; however, as an incentive, about $20 \%$ of each program may be kept in house. D. R. Johnson returned from the Oak Ridge Gaseous Diffusion Plant as task leader of ceramic technology for advanced heat engines, the purpose of which is to develop a technology base for reliable application of ceramics for gas turbine and adiabatic diesel engines. J. A. Carpenter leads a task on conversion and utilization technologies aimed at long-range applied research and exploration of materials and tribology for advanced conservation technologies. A joint program under T. S. Lundy with the Energy Division on building thermal envelope systems has continued. A conservation administrative group was established under M. C. Matthews.

In what is expected to be a growth area, a new space nuclear projects task under R. H. Cocper was established. This office will develop materials, primarily refractory metals, for space reactors. The former space power program aimed at developing radioisotopic power sources continues at a decreased rate under $M$. M. Martin.

F. G. Homan, who was manager of both the division Nuclear Regulatory Commission program and waste program, was promoted and transferred to the Operations Division. With decreased suppurt expected in these tasks, no replacement was appointed.

Group leaders of two functional laboratories were replaced. S. A. David is now in charge of welding and brazing, replacing G. M. Goodwin, who has returned to the laboratory to conduct research. P. T. Thornton heads the publications office, replacing F. $R$. Cox, who retired.

During this period the division made a considerable recnvery from the low point in personnel during the preceding period, with an increase of about 20 people. Changes by section are tabulated

in Table $C$. These figures include changes in loanees and in long-time nonstudent guests and therefore do not correspond directly to the figures or division personnel included in Appendix B. Table C.I shows that the staff in most functional laboratories has been quite stable and that the largest increases were in the managers and task leaders and in increased secretarial services for them as a result of the increase in subcontracting demand previously mentioned. The largest increases for individual laboratories were four in each of Alloying Behavior and Structural Ceramics, with increases of three in each of Defect Mechanisms and Electron Microscopy. The largest decrease was six in Coating and Tribology, with three in Materials Compatibility. 


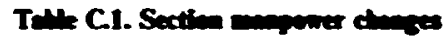

\begin{tabular}{|c|c|c|c|}
\hline \multirow{2}{*}{ Section } & \multicolumn{2}{|c|}{ Manpoure changes } & \multirow{2}{*}{ Total } \\
\hline & Techuical & Sopport & \\
\hline Division services & -1 & +2 & +1 \\
\hline Engincering materinls & +25 & -5 & -25 \\
\hline Materials scieaces & +11 & -2 & +9 \\
\hline Procesene science and techrolosy & $\mathbf{0}$ & +2 & +2 \\
\hline Managers and tat ieaders & +6 & +1 & +7 \\
\hline Secretarial & $\mathbf{0}$ & +5 & +5 \\
\hline Total increase & 18.5 & 3 & 21.5 \\
\hline
\end{tabular}

Four additioaal part-time seretaries were abo adked. 
METALS AND CEAAMICS DIVISION

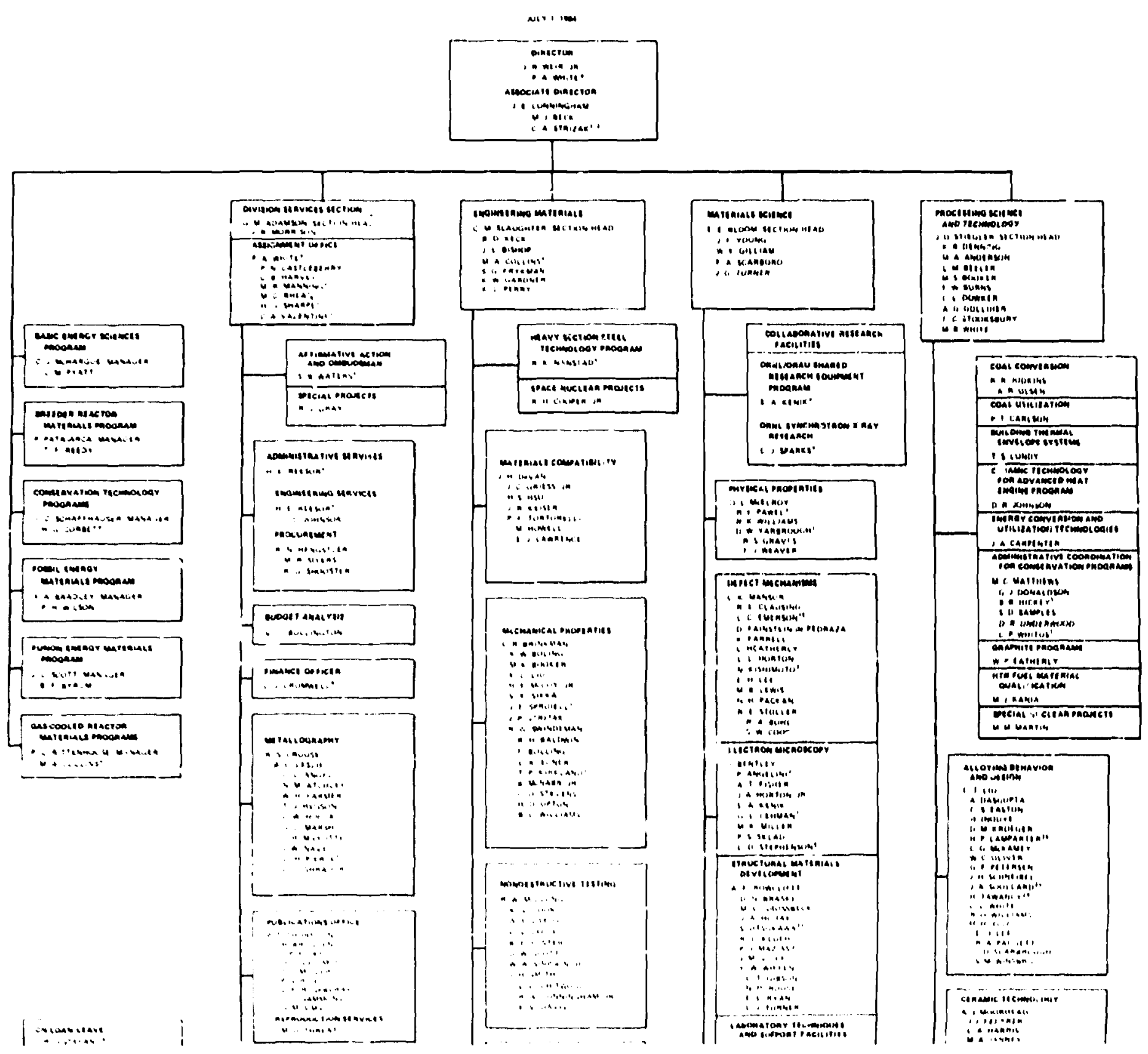




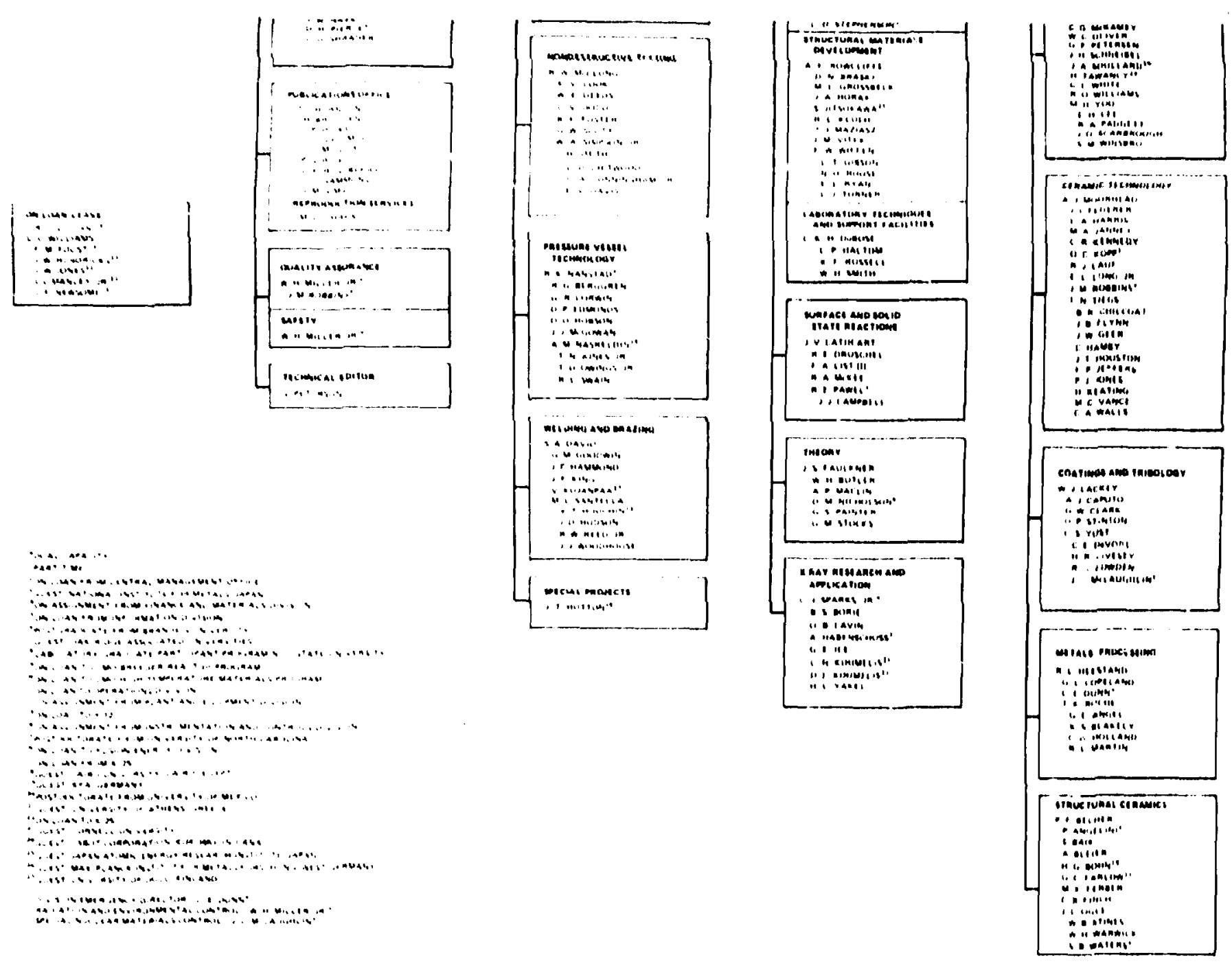




\section{Appeadix D}

\section{HONORS AND AWARDS}

Excellence in research is a constant divisional objective, and reer recognition is one measure of how well staff members of the division perform in meeting that important goal. The division therefore monitors recognition accorded staff members by their peers. Of particular interest is the frequency with which staff members are cited and rewarded for demonstrating outstanding talent and ability in fulfilling their professional roles in the scientific and engineering community. The type of recognition received varies in degree but tends to fall into one of the following generic categories: honorific awards, exhibition prizes, elected officers and members, commendations, cetification and registration, patents issued, conference organizers, conference chairmen, session chairmen, and appointments $A$ listing of citations by generic category during the past 18 months follows.

\section{HONORIFIC AWARDS}

B. Aswown (editor) and D. P. Stimen, W. J. Lackey, and R. D. Speace (writers) won the Award of Merit (third place) in the Journal Articles and Conference Papers category of the Society for Technical Communication, East Tennessec Chapter, 1983 Competition, for the article "Production of Spherical $\mathrm{UO}_{2}-\mathrm{UC}_{2}$ for Nuclear Fuel Applications Using Thermochemical Principles," published in the Journal of the American Ceramic Society 65(7), 321-24 (1982).

E. E. Bloon was elected a Fellow of the American Society for ' :etais.

Ireac Brogdea (editor), J. E. Comingtan and J. R. Weir (coauthors), and D. L. LeComte (composition and makeup) won the Award of Merit (third place) in the Periodic Activit; Reports category of the Society for Technical Communication, East Tennessee Chapter, 1984 Competition, for the Metals and Ceramics Division Progress Report for the Period Ending December 31, 1982.

Irese Brogdea (editor) and D. P. Stiniom, P. Angelini, A. J. Capmo, and W. J. Lackey (writers) won the Award of Distinction (first place) in the Journal Articles and Conference Papers category of the Society for Technical Communication, East Tennessee Chapter, 1983 Competition, for the article "Coating Crystalline Nuclear Waste Forms to Improve Inertsess," published in the Journal of tir American Ceramic Society 65(8), 394-98 (1982).

C. V. Dodd and L. D. Chitmood (with W. F. Deeds of the University of Tennessec) won an IR.100 Award from Industrial Research for their development of a Multiple-Frequency EddyCurrent Testing Instrument.

W. P. Eatherly received the George Skakel Memorial Award from the American Carbon Society in recognition of his outstanding contributions to the science and technology of carbon. 
C. T. Liv and C. C. Koch won an IR-100 Award from Industrial Research for their development of NIFE Alumiaide.

L. K. Mansw was elected a Fellow of the American Nuclear Society.

L. K. Manser, K. Farrell, L. L. Horton, E. H. Lee, M. B. Lewis, and N. H. Pacton won in the category of Significant Implication for Energy Technology of the U.S. Department of Energy Materials Sciences Research Competition for their entry, "The Effect of Helium Gas and Pulsed Irradiation on Materials Behavior in Fusion Reactors."

R. W. MeClang received the American Society for Testing and Materials Longevity Award for 25 years of continuous service in ASTM standardization.

B. MeNa b, Jr., received the American Society for Metals Engineering Associate's Achievement Award for 1983.

C. J. Sparks, Jr, and G. E. Ice (with Metria Willey of the Fusion Energy Design Center) won an IR-100 Award from Industrial Research for their development of an X-Ray Monochromator. High-Performance X-Ray Focusing Optics for Synchrotron Radiation.

G. M. Stocks was elected a Fellow of the American Physical Society.

P. F. Tortorelli was selected as the Outstanding Young Member by the Oak Ridge Chapter of the American Society for Metals.

\section{EXHIBITION PRIZES}

G. M. Goodwin and C. P. Haltom (with P. A. Sanger, Airco) won honorable mention in Class 1-Optical Microscopy; Iron, Steel, Stainless Steel, Nickel, and Nickel Alloys, of the International Metallographic Exhibit of the International Metallographic Society, July 1983, for their poster "Unintentional Carburizing Treatment Improves a Semiconductor."

C. P. Haltom, C. L. Angel, J. W. Nave, and G. M. Goodwin received 14th prize in the 1983 Nikon International Small World Competition for their entry "Superconductor Containing Bundles of $\mathrm{Nb}_{3} \mathrm{Sn}$ Filaments in a Copper Matrix." This picture illustrates the month of August on Nikon's 1984 Small World calericiar.

V. K. Sikka, C. W. Houck, and J. M. Vitek (with K. S. Modrell, Iniormation Division) won first place in Class 1-- Optical Microscopy; Iron, Steel, Stainless Steel, Nickel, ard Nickel Alloys, of the International Metallographic Exhibit of the International Metallographic Sxciety: July 1983. for their poster "Recrystallization in a Long-term Creep Specimen."

D. P. Stinton and N. M. Atchley were awarded first place in the Different or Combined Techniques Category of the Ceramographic Contest held in conjunction with the American Ceramic Society innual Meeing in Chicago, Illinois, April 24-27, 1983, for a poster describing the characterization of hydrofracture grout.

G. C. Wei and J. R. Mayotte were awarded second piace in the Optical Microscopy category of the Ceramographic Contcst held in conjuntion with the American Ceramic Society Annual Meeting in Chicago, Illinois, April 24 27, 1983, for a poster on "SiC Sintering Behavior." 


\section{ELECTED OFFICERS AND MEMBERS}

J. Beatley was elected to serve on the Board of Review of Metallurgical Transactions for a three-year term, starting in 1984.

W. J. Lackey was elected Vice-Chairman of the Nuclear Division of the American Ceramic Society for 1983-84.

D. L. McElroy was elected to serve a second term as Chairman of the Governing Board of the International Thermal Conductivity Conference, 1984-85.

C. M. Slaughter was elected a Trustec of tine American Society for Metals for a three-year term.

C. J. Sparks, Jr., was elected Charman of the Executive Comnitte of the Users National Synchrotron Light Source (Brookhaven National Laboratory; for a two-year term.

R. W. Swindernn was elected to serve as a member of $\mathrm{t}^{\mathrm{t}}$. Executive Committee of the Pressurc Vessels and Piping Division of the American Society of Mecisanical Engineers for a five-year term, effective June 1984.

P. T. Thornton was elected Vice-Presitent-Membership of the Association of Information Systems Professionals for the 1984-85 term.

C. S. Yust was elected Chairman of the Nuclear Division of the American Ceramic Society for 1983-84.

\section{COMMENDATIONS}

G. M. Adamson received a letter of appreciation for excellent service on the ORNL High Pressure Equipment Review Cominittee during 1983.

E. S. Bomar, Jr., received a letter of appreciation for excellent service on the Radioactive Operations Committee of Oak R.Jge National Laboratory during 1983.

R. E. Clausing received a certificate of appreciation from Oak Ridge National Laboratory for time and effort in serving as instructor for the course on Fundamentals of Vacuum Technology.

J. E. Conningham received a Certificate of Governance from the American Nuclear Society in recognition of special services rendered to the Society.

J. E. Cunningham received a certificate of appreciation from Oak Ridge National Labol tory for time and effort in serving as instructor for the course on Fundamentals of Vacuum Technology.

D. S. Easton received a certificate of appreciation from Oak Ridge Na:i:n I Laboratory for time and effort in serving as instructor for the course on Fundamentals of Vacuum Technology.

D. P. Edmonds received a letter of commendation from the Clinch River Breeder Reactor Project Office for outstanding work in reviewing the project's mechanical designs and in spearheading the Steam Generator Program. 
J. I. Federer, R. L. Heestand, H. Loaye, C. T. Lia, and A. C. Sclafinamer (with R. G. Doanelly and K. H. Galloway) received a commendation from the U.S. Department of Energy and the Jet Propulsion Laboratory for their significant contributions to the success of the Voyager Outerplanetary program. The citation and framed photograph showing Jupiter and its moon were presented to H. Postma on their behalf in ceremonies at ORNL.

R. J. Gray received the President's Award of the International Metallographic Society in appreciation of his outstanding contribution to the society through his leadership and assistance in all the society's many activities.

J. C. Griess received a letter of appreciation for excellent service on the Reactor Experiments Review Committee of Oak Ridge National Laboratury Juring i 983.

L. Heatherly received a certificate of appreciation from Oak Ridge National Laboratory for time and effort in serving as instructor for the-course on Fundamentals of Vacuum Technology.

R. L. Heestand received a certificate of appreciation from Oak Ridge National Laboratory for time and effort in serving as instructor for the cuurse on Fundamentals of Vacuum Technology.

R. R. Jodkins received a letter of appreciation for excellent service on the Reactor Operations Review Commitlee of Oak Ridge National Laboratory during 1983.

M. Matthews received a certificate of appreciation from Oak Ridge National Laboratory for time and effort in serving as instructor for the course Guide for Executive Secretaries and Administrative Assistants.

J. L. Scott received a Certificate of Appreciation from the American Nucleat Society for serving as the General Chairman of the Fifth Topical Meeting on the Technology of Fusion Energy, Knoxville, Tennessee, April 26-28, 1983.

P. F. Tortorelli received the President's Citation from the Oak Ridge Chapter of the American Society for Metals for 1982-83.

\section{CERTIFICATION AND REGISTRATION}

K. V. Cook received recertification (for five years), Level III (professional level) in ultrasonics and liquid penetrants, from the American Society for Nondestructive Testing.

C. V. Dodd received recertification (for five years), Level III (professional level) ia eddy currents, from the American Society for Nondestructive Testing.

B. E. Foster received recertification (for five years), Level III (professional level) in radiogiaphy, from the American Society for Nondestructive Testing.

R. W. McClung received recertification (for five years), Level II: (professional level) in ultrasonics, radiography, eddy currents, and liquid penetrants, from the American Society for Nondestructive Testing.

J. H. Smith icceived recertification (fo: five years), Level III (professional level) in ultrasonics and eddy currents, from the American Society for Nondestructive Testing. 


\section{PATENTS ISSUED}

D. P. Stinton, "Mixed Uranium Dicarbide and Uranium Dioxide Microspheres and Process of Making Same," U.S. patent 4,367,184, Jan. 4, 1983.

B. E. Foster and E. V. Davis, "Pentrameter Positioner for Bore-Side Radiography of Tubes," U.S. patent 4,368,996. Jan. 18, 1983.

P. Angelini, W. J. Lackey, D. P. Stintom, R. E. Blanco, W. D. Boad, and W. D. Arnold, Jr., "Method for Primary Cuntainment of Cesium Wastes," U.S. patent 4,376,792, Mar. 15, 1983.

K. V. Cook, R. A. Conningham, and H. T. Miurin, "Ultrasonic Probe for Inspecting DoubleWal. Tube," U.S. patent 4,391,143, July 5, 1983.

R. J. Lauf and C. S. Morgan, "Solid Electrolytes Strengthened by Metal Dispersions," U.S. patent 4,393,124, July $12,1983$.

C. S. Morgan, "Method for Fabricating Cermets of Alumina-Chromium Systems," U.S. patent 4,397,963, Aug. 9. 1983.

J. H. DeVan and J. E. Selle, "Method for Inhibiting Alkali Metal Corrosion of NickelContaining Alloys," U.S patent 4,3:9,967, Aug. 16, 1983.

R. L. Heestand and B. Heshmatpoar, "Method for Refining Contaminated Iridium," U.S. patent 4,406,693, Sept. 27, 1983.

P. A. Haas and W. B. Stines, "Method for Improved Decomposition of Metal Nitrate Solutions," U.S. patent 4,409,157, Oct. 11, 1983.

C. T. Liu, H. Inouye, and A. C. Schafimauser, "Long-Range-Ordered Alloys Modified by Group IV-B Metals," U.S. patent 4,410,371, Oct. 18, 1983.

\section{CONFERENCE ORGANIZERS}

A. Bleier served as organizing chairman for the American Chemical Society's 58th Colloid and Surface Science Syniposium on Siructures in Concentrated Suspensions, Pittsburgt. nonnsylvania, June 10-13, 1984.

R. A. Bradley served as an crganizer fo: the U.S. Department of Energy Symposium on ilectroslag Component Casting, Morgantown, West Virginia, June 1-2, 1983.

R. A. Bradley served on the organizing commitlu for the Conference on Materials for Future Energy Systems, Washington, D.C., May 1--3, 1984.

J. E. Cunningham served on the organizing committee for the Conference on Materials for Future Energy Systems, Washington, D.C., May 1-3, 1984.

F. J. Homan served on the organizing committee for the Conference on Materials for Future Energy Systems, Washington, D.C., May 1-3, 1984.

R. R. Judkins served as an organizer for the U.S. Department of Energy Symposium on Electroslag Component Casting, Morgantown, West Virginia, June 1-2, 1983. 
P. Patriarca served on the organizing committee for the Conference on Materials for Future Energy Systems, Washington, D.C., May 1-3, 1984.

A. C. Setufinamer served on the organizing committee for the Conference on Materials for Future Energy Systems, Washington, D.C., May I-3, 1984.

J. L. Scott served on the organizing committee for the Conference on Materials for Future Energy Systems, Washington, D.C., May 1-3, 1984.

P. F. Tortorelli served as organizer of the Symposium on Advances in Materials Analysis, Oak Ridge, Tennesse, sponsored by the Oak Ridge Chapter of the American Society for Metals, April 15, 1983.

F. W. Wiffea served as organizer for the Office of Fusion Energy, U.S. Department of Energy Workshop on Copper and Copper Alloys for Fusion Reactor Applications, Washington, D.C., April 14-15, 1983.

D. W. Yartrongt was appointed organizer of the Symposium on Properties, Testing, and Utilization of Materials for Energy Conservation in Industrial Applications for the National Meeting of the American Iustitute of Chemical Engineers to be heid in Philadelphia, Pennsylvania, August 20-23, 1984.

\section{CONFERENCE CHAIRMEN}

J. E. Cunningham served as program chairman of the American Society for Metals Conference on Materials for Future Energy Systems, Washington, D.C., May 1-3, 1984.

D. W. Yarbrough was selected as chairman of the 19th International Thermal Conductivity Conference to be held in 1985 at Tennessee Technological University.

\section{SESSION CHAIRMEN}

P. Angelini served as chairman of the session on Novel Techniques of Surface Modification for the Fourth Annual Meeting of the Tennessee Valley Chapter of the American Vacuum Society, Knoxville,Tennessee, May 3, 1984.

P. F. Becher served as chairman of the session on Solid State Studies of Ceramics at the Gordon Research Conference, New London, New Hampshire, July 24-29, 1983.

J. Bentley served as session chairman of the Symposium on Advances in Materials Analysis, Oak Ridge, Tennesses, sponsored by the Oak Ridge Chapter of the America i Society for Metals, April 15, 1983.

R. A. Bradley served as session chairman of the American Society for $\mathbf{M}$ tals Conference on Materials for Future Energy Systems, Washington, D.C., May 1-3, 1984.

F. J. Homan served as session chairman of the American Society for Metals Conference on Materials for Future Energy Systems, Washington, D.C., May 1-3, 198?..

L. L. Horton served as sission chairman of the $\Sigma, \ldots$... pusium on Advances in Materials Analysis, Oak Ridge, Tennessee, sponsored by the Oak Ridge Chapter of the American Society for Metals, April 15, 1983 
R. R. Jedlies served as session chairms a of the Diamond Jubilee Meeting of the Amer:can Institute of Chemical Engineers, Washington, D.C., November 2, 1983.

P. Patriarea served as session chairman of the American Society for Metals Conference on Materials for Future Energy Systems, Washington, D.C.. May 1-3, 1984.

A. C. Schafinuaser served as session chairman of the American Society for Matals Conference on Materials for Future Energy Systems, Washington, D.C., May I-3, 1984.

J. L. Scott served as session chairman of the American Society for Metals Conference on Materials for Future Energ\} Systems, Washington, D.C., May 1-3, 1984.

D. W. Yerbroegh was appointed session chairman of the Symposim on Properties, Testing, and Utilization of Materials for Energy Conservation in Industrial Applications for the National Meeting of the Americau Institut: of Chemica! Engineers to be held in Philadelphia, Pennsylvania. Iuglist 20-23, 1984.

\section{APPOINTMENTS}

P. Becher was appointed Chairman of the Sosman Memorial Lecture Committee, Subcommittee on Show and Conference, of the American Welding Society.

J. Bentley was appoint:d Associate Professur, part-time, Department of Chemical, Metallurgical, and Polymer Engineering, University of Tennessee, Knoxville.

J. Bentley was reappointed Adjunct Professor of Materials Science, Vanderbilt University, Nashville, Tennessee, for a three-year term beginning with the fall 1983 semester.

A. Bleier served as group moderator of the U.S. Department of Fnergy meeting on Characterization and Behavior of Submicron Carbide and Nitride Powder, Albuquerque, New Mexico, February 26-March 2, 1984.

E. E. Bloom was appointed to the Metals Engineering Institute Committee of the American Society for Metals for a three-year term.

J. E. Cunningham was appointed a member (past Chairman) of the Advisory Technical Awareness Council of the American Society for Metals.

S. A. David was appointed Adjunct Associate Professor of Metallurgical and Materials Engineering in the School of Engineering, Department of Metallurgical and Materials Engineering, University of Pittsburgh, Pennsylvania.

B. E. Foster was appointed to serve as a member of the E7.01 Committee on Radiography of the American Society ror Testing and Materials.

R. J. Gray was selected to judge an international photographic competition, Nikon's Small World Competitior, at Nikon House in New York City, July 14, 1983.

D. O. Hobson was appointed Chairman of the newly formed Texture and Anisutropy Committee of the Materials Science Division of the American Society for Metals for a two-year term. 
R. R. Jentins was appointed Vice-Chairman of The Metal Properties Council Phase Group VII (Materials for Liquefaction, Processes, Abrasion, and Slurry Erosion) of Subcommittec 9 (Materials for Fossil Fuel Conversion and Utilization).

E A. Kenil was reappointed Adjunct Associate Professor, Department of Mechanical and Materials Engineering, Vanderbilt University, Nashville, Tennessee, for a three-year term beginning in September 1983.

W. J. Lackey was appointed a member of the American Ceramic Society Programs and Meetings Committee for a four-year term.

M. M. Martin was appointed a member of the American Society for Metals Membership Committee for a three-year term.

R. W. McClos was appointed Chairman of the Finance Committee to assist the U.S. Technical Advisory Group for the International Standards Organization Technical Committee 135 of the American Society for Testing and Materials.

R. W. MeClang was selected to serve as a member of the Nominating Committee for the E7 Committec on Nondestructive Testing of the American Society for Testing and Materials.

A. J. Moortead was appointed to serve as Chairman of the C3H Subcommittee on Show and Conference of the American Welding Society.

R. K. Nanstad was appointed Chairman of the Subcommittee on Thermal and Mechanical Effects of the Pressure Vessel Research Committec, Welding Research Council.

A. R. Olsen was appointed to serve as a member of the Subcommittee of the Reactor Operations Review Committee for the Oak Ridge Research Reactor for a one-year period.

P. S. Stlad was reappointed Adjunct Associate Professor, Department of Mechanical and Materials Engineering, Vanderbilt University, Nashville, Tennessee, for a three-year term beginning in September 1983.

P. S. Sklad was reappointed to the Education Committee of the Electron Microscopy Society of America as audiovisual coordinator from August 1983 to July 1984.

J. H. Smith was appointed to serve during 1983-84 as the Board of Directors representative to the Section Management and Membership Committee of the American Society for Nondestructive Testing.

J. H. Smith was appointed to the committee to select the recipient of the 1984 American Society for Nondestructive Testing Achievement Award.

C. J. Sparks, Jro, was appointed a member of the Policy Advisory Board, National Synchrotron Light Source, Brookhaven National Laboratory.

G. M. Stocks was appointed a member of the U.S. Department of Energy's Research Computer Users Advisory Committee. 


\section{Appendix E}

\section{SEMINAR PROGRAM}

Because effective communication is vital to scientific and technological advancement, the division sponsors and maintains an active seminar program to promote the exchange of ideas and the discussion of common problems amcag researchers working in the field of materiak science and technology and allied disciplines. Most of the talks deal with scientific and engineering subjects and are presented by invited speakers from various organizations in North America and abroad. The actual number of talks scheduled in any given week varies bit over the year averages slightly less than two per week.

The Seminar Program is administered by a committee appointed by division management. The Seminar Committee for the reporting period consists of J. A. Carpenter (chairman), J. P. Hammond, P. S. Sklad, and J. A. Horton.

The speakers and topics of seminars presented in the past 18 months are listed below. It is interesting that 37 of the 132 talks were made by individuals affiliated with institutions outside the United States. An alternative breakdown shows $\mathbf{5 7}$ talks by university faculty members and graduate students, 28 by representatives from industrial firms, and the balance from governmental and other research institutions. In function, the program achieves the desired objectives of maintaining close relationships with the university community and of enhancing the diffusion of knowledge.

B. R. Dewey, University of Wyoming, Laramie, "Finite Element Modeling of Ultrasonic Inspection of Weldments," January 6, 1983.

L. E. Willertz, Westinghouse Electric Corporation, Pittsburgh, Pennsylvania, "ElevatedTemperature Corrosion Fatigue Using Ultrasonic Techniques," January 12, 1983.

N. S. Stolof, Rensselaer Polytechnic Institute, Troy, New York, "Ordered Alloys for Structural Applications," January 13, 1983.

G. R. Odette, University of California, Santa Barbara, "Helium Effects on Microstructural Evolution and Swelling," January 25, 1983.

G. R. Odette, University of California, Santa Barbara, "Modeling the Effects of Gas and Grain Boundary Microstructure on Mechanical Behavior in Several Environments," January 26, 1983.

C. B. Fiech, Metals and Ceramics Division, ORNL, "CVD $\mathrm{TiB}_{2}$ and Glimpses of South Africa," January 28, 1983.

J. Fong, National Bureau of Standa:ds, Washington, D.C., "On-line Retrieval and Analysis of Materials Data for Critical Decision Miaking," February 7, 1983. 
J. G. Hamoech, Norton Company, Worcester, Massachusetts, -Modeling of Ceramic-Ceramic and Ceramir-Metal Joints," February 9, 1983.

M. Stecks, Metals and Ceramics Division, ORNL, -A Hitchhiker's Guide to SERC, Daresbury, Concentration Waves, Metallic Magnetism, and the Fumious Bandersnatch," February 11, 1983.

R. Herschitz, Cornell University, Ithaca, New York, -Atom Probe Field Ion Microscope Study of Solute Atom Segregation to Stacking Faults in Cobalt-Base Alloys and the Study of RadiationInduced Precipitation in Tungsten-Rhenium Alloys," February 15, 1983.

W. Lowe, Stanford University, Stanford, California, "Structure and Superconductivity of Metallic Multilayers," February 15, 1983.

R. A. Inda, Consultant, formerly with Allegheny Ludlum Steel Corporation, -Recent Developments in Duplex Austentitic/Ferritic Stainless Stecl," February 16, 1983.

R. Cmaseor, University of Illinois, Urbana, "Structural Studies of Hydrides with Diffuse X-Ray Scattering," February 28, 1983.

S. Antalorich, University of Cincinnati, Ohio, "Fatigue Crack Propagation and Low-Cycle Fatigue in Nickel-Ease Super Alloys," March 11, 1983.

W. K. Croo, Korea Advanced Institute of Science and Technology, Seoul, South Korea, "Phase Stability of Fe-Mn-Al-C Alloys," March 14, 1983.

G. W. Wellan, University of Kansas, Manhattan, "Application of the CTOD Test Method to the Fracture Resistance Design of Pressure Vessels," March 17, 1983.

J.-G. Wasg, Cornell University, Ithaca, New York, "Super Plastic Flow in Glass-Ceramics Under Multiaxial Loading." March 17, 1983.

W. A. Jemian, Auburn University, Auburn, Alabama, "Welding and Weldability Aluminides," March 2I, 1983.

Y. Fu, University of California, Berkeley, "Micrncrack Toughening of Ceramics," March 2I, 1983.

M. Böhmer, Institute for Materials Research, West German Space Agency, Cologne, Federal Republic of Germany, "German Advanced Heat Engine Program and Ceramics Development," March 23, 1983.

M. K. Miller, U.S. Steel Research Laboratory, Monroeville, Pennsylvania, “Application of the Atom Probe to Phase Transformations," March 28, 1983.

J. Naraya, Solid State Division, ORNL, "Laser Annealing of Ceramics," March 29, 1983.

D. W. Ricksson, Garrett Turbine Engine Company, Phoenix, Arizona, "Advanced Gas Turbine Engine Program: A Review of and Status Report on Structural Ceramic Technology at Garrett," April 5, 1983.

R. L. Coble, Massachusetts Institute of Technology, Cambridge, "Reanalvsis of the 'Rules' for Sintering to High-Density Paradigms," April 6, 1983. 
A. E. Pasto, GTE Laboratories, Waltham, Massachusetts, "Microstructural Effects Influencing Strength of Silicon Nitride," April 8, 1983.

E. A. Kenil, Metals and Ceramics Division, ORNL, "Shared Research Equipment Program or How to Get Your SHaRE," April 8, 1983.

G. Grimvall, Royal Institute of Technology, Stockholm, Sweden, -High-Temperature Resistivity and a New Thermal Defect," April 8, 1983.

W. Dobsom, Teledyne Engineering Services, Waltham, Massachusetts; "Testing and Analysis of Materials at Cryogenic Temperatures as Low as $4 \mathrm{~K}, "$ April 12, 1983.

C. R. Honsta, Virginia Polytechnic Institute and Staie University, Blacksburg, "X-Ray Diffraction Methods for Investigations of Near-Surface Regions of Solids," April 14, 1983.

C. J. Abtetter, University of Illinois, Urbana, "Hydrogen Embrittlement of Stainless Steel," April 14, 1983.

J. Bitello, State University of New York at Stony Brook, "Applications of Synchrotron X-Ray Topography to the Study of Deformation and Fracture of Materials," Aprii 14, 1983.

M. L. Sentella, Olin Corporation, New Haven. Connecticut, "Reheated Microstructure and Hot Rolling Behavior of Austenite," April 14, 1983.

K. U. Saorden, Australian AEC Research Establishment, Lucas Heights, New South Wales, "Creep Cavities, Cracks, and Conundrums," April 25, 1983.

W. C. Moshier, Massachusetts Institute of Technology, Cambridge, "Effect of Heat Treatment on Fatigue Crack Growth of Inconel 600," April 28, 1983.

S. Somiya, Tokyo Institute of Technology, Yokohama, Japan, "Sunthesis of Ceramic Poviders," April 29, 1983.

S. M. Wiedertorn, National Bureau of Standards, Washington, D.C., "Structural Reliability of Ceramics," May 2, 1983.

I. Freach, CSIRO, Australia, "Welding Research at Commonwealth Scientific and Industrial Research Organization of Australia," May 11, 1983.

J. A. Panitz, Sandia National Laboratories, Albuquerque, New Mexico, -The Imaging AtemProbe," May 11, 1983.

R. Giddings, General Electric Research and Development Center, Schenectady, New York, "Development and Staius of Beta Silicon Carbide," May 18, 1983.

C. Johnson, General E'ectric Research and Development Center, Schenectady, New York, "Statistics of Fracture in Brittle Materials" May 31, 1983.

L. J. Schioker, Army Materials and Mechanics Research Center, Watertown, Massachusetts, "Structure-Conductivity Relations in the Fast-Ion Conducting NASICON Solid Solution System," June 1, 1983.

H. Moelver, Babcock \& Wilcox Research Center, L.ynchburg, Virginia, "Study of Crack Growth in Ceramics Using Acoustic Emission Location Techniques," June 6, 1983. 
T. L Amersen, Colorado School of Mines, Golden, and National Bureau of Standards, "Fracture of Steels in the Ductile-to-Brittle Transition Region," June 7, 1983.

B. A. Nagaraj, GEC Power Engineering, Leister, England, -Application of High-Temperature Heat Exchangers to Coal-Burning Gas Turbine Systems," June 9, 1983.

P. Sutor, Midwest Research Institute, Dayton, Ohio, -Friction and Wear Testing of Bearing Ceramics at High Temperature," June 29, 1983.

J. Mefoman, University of Alabama, Tuscaloosa, -A Microprocessor-Based System for Determining Mear-Threshold Fatigue C. .ck Growth Rates," July 7, 1983.

D. D. Butten, Norton Company, Worchester, Massachusetts, "Sintering of Glass," July 7, 1983.

M. A. Jamey, Kennametal, Inc., Latrobe, Pennsylvania, "Plasticity of Ceramic Systems," July 8, 1983.

J. H. Sebreibe, Metals and Ceramics Division, ORNL, "Grain Boundary Sliding in Nicke-The Influence of Small Alloying Additions," July 8, 1983.

S. Verma, Illinois Institute of Technology Research Institute, Chicago, Illinois, “HighTemperature Corrosion of Commercial Alloys in Coal Gasification Environments," July 11, 1983.

S. Nett, National Bureau of Standards, Washington, D.C., -Microstructure of SiC-Al Composites," July 11, 1983.

W. L. Hawkins, The Plastics Institute of America, Hoboken, New Jersey, 'Recycling of Plastics from Scrapped and ShredJed Automobiles," July 11, 1983.

J. Sankar, North Caroiina State University, Raleigh, "The Effat of Submerged Arc Welding Variables on the Structure of Mechanical Behavior of Pressure Vessel Steel Weldments," July $20,1983$.

J. G. Luctenan, Exxon Research and Engineering Company, Linden, New Jersey, "Chemisorption and Gas-Solid Reaction Kinetics in Carburization and Oxidation," July 20, 1983.

C. Wascilew, Kernforschungszentrum, Karlsruhe, Federal Republic of Germany, "Twin Planes in FCC Metals as Relaied to Helium Embrittlement," July 26, 1983.

D. F. Petraza, University of Connecticut, Storrs, "The Martersitic Transformation in Ferrous Alloys," August 4, 1983.

G. Czjzek, Kernforschungszentrum, Karlsruhe, Federal Repulic of Germany, "Structural Studies of Amorphous Solids by Mossbauer Spectroscopy." August 8, 1983.

J. E. Gould, Carnegie-Mellon University, Fittsburgh, Pennsylvania, "The Effect of Composition and Weld Process on the Titanium Alloy Welds," August 8, 1983.

P. Weiaberger, University of Vienna, Austria, "Electronic States of Actinides and Actinide Compounds," August 10, 1983.

J. E. Allison, Brown Loveri, Switzerland, "Fatigue Crack Growth in Titanium Alloys," August , 1983. 
R. E. Steller, University of California, Santa Barbara, -Modeling the Influence of Transmutant Helium un Neutron-Irradiated Austenitic Stainless Steel," August 18, 1983.

A. Lawley, Drexel University, Philadelphia, Pennsytvania, "Metal Matrix Composites-Status and Potential," August 22, 1983.

W. C. OHner, United Technology Research Center, Sunnyvale, California, "The Influence of Surface Image Forces on Very Shallow Hardness Measurements," August 24, 1983.

P. B. Alen, State University of New Yor' at Stony Brook, -Quasi-Particle and Non-QuasiParticle Transport in Solids," August 24, 1983.

T. Hehealtane. Institut for Metallphysit, Universitat Goutingen, Federal Republic of Germany, "Vacancy Formation and Diffusion in Alpha-Range Alloys," Angust 25, 1983.

D. Peat, Y-12 De:elopment, Y-12 Plant, Oak Ridge, Tennessec, "Methods Used to Fabricate Components from Composite Materials,' August 25, 1983.

E. M. Seluben, Dartmouth College, hianover, New Hampshire. "Strength and Ductility of Polycrystalline IJickel Aluminides ( $\mathrm{Ni}_{3}+\mathrm{I}$ and $\mathrm{NiAl}$ )," August 29, 1983.

P. Langarter, Max-Planck Institut für Metallforschung, Stuttgart, Federal Republic of Germany, "Atomic Structure of Metallic Glasses," September 1, 1983.

G. Colfiner, Metals and Ceramies Division, ORNL, "How Big Am I Now," September 7, 1983.

D. M. Nichobon, Oak Ridge Associated Universities, Oak Ridge, Tennessec, "Self-Consistent Total Energy Calculations with the Quadratic KKR," September 9, 1983.

D. F. Adans, University of Wyoming, Laramie, "Analytical Predictions and Experimental Measurements of Composite Materials Propertie," September 12, 1983.

J. Hack, Southwest Research Institute, San Antonio, Texas, "Hydrogen-Assisted Sustained Load Cracking in Structural Alloys," September 13, 1983.

B. L. Gyorfify, H. H. Wills Physics Laboratory, University of Bristol, ėngland, "Theory of Magnetic Phase Transitions in Metals," September 14, 1983.

J. K. Tiea, Columbia University, New York, -Alloy Redesign of Superalloy, September 15, 1983.

K. Khria, National Swedish Board for Technical Development, Stockholm, Sweden, "Metallic Materials Research in Sweden," September 2.2, 1983.

H. Ullanier, W. Kesternich, and P. Batfalaky, Institut filr Festkörperforschung, Kernforschungsanlage. Jullich, Federal Republic of Germany, "Recent Research on Helium Effects on Microstructure and Properties," September 27, 1983.

D. Kaletta, Kernforschungszentrum, Karlsruhe, Federal Republic of Germany, “Fusion Materials Research at Karlsruhe," September 27, 1983.

A. J. Ptador, University of Toronto, Carada, -KKR-CPA Calculations of the Electronic Structure of Hydrides," Seplember 28, 1983 
F. A. List II, Cornell University, Ithaca, Vew York, "The (jxidation of Carbon on Nickel Surfaces, October 3, 1983.

D. S. Tecker, Atlantic Richfield, Chatsworth, Caliiomia, -Transfermation Mochanism for Spherical Alumina Powders Precipitated from a Sulphate Solution," Octobe: 5, 1983.

M. Schbter, Bell Laboratories, Murray Hill, New Jersey, - Quiantrine Theory of Localized Defect," October 5, i983.

J. Mumer, Institut fur Festkorperforschung, Kernforschungsanlage, Julich, -Cluster Study of the Interaction of an $\mathrm{H}_{2} \mathrm{O}$ Molecule with the $\mathrm{A}(100)$ Surface," October I9, 1983.

M. Benett, Atomic Energy Research Establishment, Harwell, England, -New Techniques for Examining Micron-Thick Oxide Scales," Octoler 24, 1983.

J. F. Callen, E Leitz, Inc, Roctleigh, New Jersey, -Current Perspectives on Image Analysis-Its Capabilities and Applications," October 26, 1983.

D. J. Grifintha, Oregon State University, Corvallis, "Small-Angle X-Ray Scattering in Amorphous $\mathrm{TbCu}$, " October 27, 1983.

D. J. Ronclifie, Stanford Research Institute, Stanford, California, -Structure and Deformation Behavior of the Transition Metal Carbides," October 31, 1983.

D. C. Cranaer, Massachusetts Institute of Technology, Cambridge, -Friction and Wear of Monolithic Ceramics," October 31, 1983.

Y. Othe, University of Florida, Gainesville, -An Alternative Description of Molecular Electronic Spectra Using Electron Pair Functions," November 4, 1983.

D. G. Morris, Atlas Copco Corporate Research Laboratory, Institut Cerac, Switzerland, "Some Developments in Rapid Solidification Techrology for Mechanical Applications," November 7, 1983.

J. Lantford, Southwest Research Institute, San Antoniv, Texas, "Fracture and Deformation of Partially Stabilized Zirconia," November 8, 1983.

R. A. Page, Southwest Research Institute, San Antonio, Texas, -Study of Creep Cavitation in $\mathrm{Al}_{2} \mathrm{O}_{3}$ and $\mathrm{SiC}$ by SANS," November 8, 1983.

E. Kisker, Kernforschungsanlage, Jülich, Federal Republic of Gerinany, "Spin-Split Electronic Stater in Fe and $\mathrm{Ni}$ and Their Temperature Dependence," Novemiver 14, 1983.

J. B. Postbill, University of Oxford, England, -Precipitation Reactions in the $90 \mathrm{~W}-5 \mathrm{Ni}-5 \mathrm{Fe}$ Heavy-Alloy System," November 2J, 1983.

H. G. Corbet, Metals and Ceramics Division, ORNL, "Behind the Iron Curtain-Personal Glimpses of Czechoslovakia," November 22, 1983.

Y. Shimazaki, Georgia Institute of Technology, Atlanta, "Steady-State Frictional Behavior of Thin Films," December 5, 1983.

J. M. Sanchez, Henty Krum School of Mines, Columbia University, New York, "Modeling of Alloy Phase Equilibrium," December 14, 1983. 
M. Menrith, Systems Research Laboratories, Dayton, Ohio, "Flow and Fracture Behavior of Iron Aluminides," January 10, 1984.

T.-1. Mal, Systems Rescarch Laboratories, Dayton, Ohio, "Ceramic Fiber-Reinforced Ceramic Matrix Compositex," January 10, 1984.

J. Heaverty, Massachusetts Institute of Technology, Cambridge "Powder and Thin-Film Synthesis by Laser-Induced Gas-Phase Reaci "ons," January 12, 1984.

J. Steveas, Stanford University, Stanford, California, -Creep and Fracture Bebavior of MA 754 at Elevated Temperature, January 16, 198 ;.

B. Carter, Cornell University, Ithaca, New York, "Phase and Grain Boundaries in Ceramics," January 17, 1984.

C. R. Brooks, University of Tennessee, Knoxville, -Physical Metallurgy of Nickel and Molybdenun! Alloys," February 22, 1984.

O. Byycozth and E-S Ora, Massachusetts Institute of Technology, Cambridge, "ThreeDimensional Finite-Element Analysis of Thermomechanical Stresses in Brittle Materials (Refraciories for Coal Gasifiers)," March 22, 1984.

D. G. Pettifor, Imperial College of Science and Technology, London, England, "The Structural Stability of Metals and Compounds," April 2, 1984.

F. Gantier, Université Louis Pasteur, Strasbourg, France, "Electronic Structure, Order, and Stability of Transition Metal Alleys and Compounds," April 4, 1984.

R. Raj, Cornell University, Ithaca, New York, “Sintering Behavior of Bimodal Powder Compact," April 5, 1984.

R. G. Jortan, University of Birmingham, England, "Use of Angle-Resolved UV Photoelectron Spectroscepy in the Study of Alloys," April 6, 1984.

P. J. Alberry, Central Electricity Generating Board, Marchwood Engineering Laboratory, Marrt.wood, England, -Prediction of HAZ Structure and Hardness for PWR Repair Welds," April 13, 1984.

R. L. Berger, University of Illinois, Urbana, "A Potpourri of Observations on the Characteristics of Hydrofracture Grouts," April 26, 1984.

H. Hieber, Philips GmbH Research Laboratory, Hamburg, Federal Republic of Germany, -Degradation of Hybrid Interconnectic:s," May 2, 1',84.

F. W. Clieard, Los Alamos National Labor 1tory, Los Alamos, New Mexico, "Radiation Effects on Ceramics," May 4, 1984.

Y. Tajian, NGK Spark Plug Co., Led., Aichi, Japan, "Effects of Substituting AIN for $\mathrm{Al}_{2} \mathrm{O}_{3}$ on the Sintering Behavior and Properties in the $\mathrm{Si}_{3} \mathrm{~N}_{4}-\mathrm{Al}_{2} \mathrm{O}_{3}$ System," May 8, 1984.

Y. Katayama, NGK Spark Plug Co., Ltd., Aichi, Japan, "Strength/Flaw-Size Relationship for Sintered $\mathrm{Si}_{3} \mathrm{~N}_{4}=$ May 8. 1984. 
J. Bahi, Cornell University, Ithaca, New York, -X-Ray Diffraction Studies of Grain Boundaries and of Hexatic Order in Liquid Crystals," May 10, 1984.

P. Von der Hart, Joint Research Center, Petten, Netherlands, -Fusion-Materials Irradiation and Vessel Repiacement is the High Flux Reactor in Petten, Netherlands," May 15, 1984.

J. B. Wagner, Jr, Center for Materials Science, Arizona State University, Tempe, "Studies on the Sulfidation of Metals," May 24, 1984.

J. A. Carpenter, Metals and Ceramics Division, ORNL "Personal Glimpes of India and Nepal," Sune 1, 1984.

W. E. Lee, Case Western Reserve University, Cleveland, Ohio, "A TEM Study of Heavy-Ion Radiation Damage in Alpha-Alumina With and Without Helium Preimplantation," June 11, 1984.

J. H. Erans, Atomic Energy Research Establishment, Harwell, England, "Precipitaition of Helium in Metals," June 15, 1984.

C. H. Heanger, Jr., Battelie Pacific Northwest Laboratory, Richland, Washington, "Irradiation Creep Mechanisms in Pure Nickel at Low Fluence," June 15, 1984.

A. Pasto, GTE Laboratories, Waltham, Massachusetts, "Causes and Effects of Iron-Bearing Inclusions in Silicon Nitride," June 15, 1984.

K. P. Singh. Indian Institute of Technology, Kanpur, India, Oxidation and Mechanical Behavior of Cr-Mo Steels," June 19, 1984.

D. P. Pope, University of Penasyivania, Philadelphia, "A Strengthening Mechanism in Ordered Intermetallic Alloys," June 21, 1984.

R. McEtroy, Atomic Energy Research Establishment, Harwell, England, "Irradiation Creep and Growth During Proton Bombardment," June 25, 1984. 
P. T. Thernton was appointed Vice President-Membership of the Association of Information Systems Professionals for the 1983-84 term.

F. W. Wiffe was appointed a member of the Journal of Metals Advisory Board, representing the Nuclear Metallurgy Commintee of The Metallurgical Society of AIME. 


\section{Appendix F \\ INFORMATION MEETING AND ADVISORY COMMITTEE}

The next divisinnal information meeting and concurrent advisory committee review will occur December 12 through 14, 1984. An overview of the general condition of the division and reports of technical progress, changes in thrust and direction, and new initiatives on the programmatic effort will be presented.

The Advisory Committee to the Metals and Cera.niss Division currently consists of six members appointed by the laboratory director. Members are a.jpuinted for staggered four-year terms so that two new members replace two retiring members. The committee meets as a body during the information meeting and review, and each member visits the division separately during the 18-month period. The main function of the committee is to review divisional ongoing research and development activities and faciil' ies and to render independent judgments on the generai condition, ability of staff, and progress in various operations and missions of the division. Members are chosen from governmental, industrial, educational, and research institutions in the United States and are selected on the basis of demonstrated ability in management, research, and technology. Members of the 1984 Metals and Ceramics Division Advisory Committee are listed below.

Professor Tadeusz B. Massalski

(Committee Chairman)

Department of Metallurgy and Materials Science

Carnegie-Mellon University

5000 Forbes Avenue

Pittshurgh, Pennsylvania 15213

Dr. Richard J. Charles

Corporate Research and Development

General Electric Company

Post Office Box 8

Schenectady, New York 12301

Dr. Marry F. Cook

Scientific Research Laboratory

Ford Motor Company

P.O. Box 2053

Dearborn, Michigan 48121
Professor Alan Lawley

Department of Materials Engineering

Drexel University

Philadelphia, Pennsylvania 19104

Dr. James C. Williams

Dean of Engineering

Carnegie-Mellon University

Schenley Park

Pittsburgh, Pennsylvania 15213

Dr. Klaus M. Zwiisky

Executive Director

National Materials Advisory Board

National Acaciemy of Sciences

2101 Constitution Avenue

Washington, D.C. 20418 


\section{Appeadix G}

\section{PUBLICATIONS}

\section{Compiled by Faye Roseberry}

G. J. Abbaschian and S. A. David, eds., Grain Refinement in Castings and W'elds, proceedings of symposium sponsored by Solidification Committee of The Metallurgical Society of AIME held in St. Louis on Oct. 25-26, 1982, The Metallurgical Society of AIME, Warrendz!s, Pa., 1983.

P. Angelini, J. Bentley, C. B. Finch, and P. S. Sklad, "Microstructure of TiB ${ }_{2}$ Liquid Phase Sintered with $\mathrm{Ni}_{3} \mathrm{Al}$," pp. 62-63 in Proceedings of 41 st Annual Meeting of the Electron Microscopy Society of America, Phoenix, Arizona, August 8-12, 1983, ed. G. W. Bailey, San Francisco Press, San Francisco, 1983.

P. Angelini, G. L. Lehman, and J. Brynestad, "Microsi.ucture of Highly Reactive Submicrometer $\mathrm{TiB}_{2}$ Powders," pp. 64-65 in Proceedings of 4/st Annual Meeting of the Electron Microscopy Society of America, Phoenix, Arizona, August 8-12, 1983, ed. G. W. Bailey, San Francisco Press, San Francisco, 1983.

B. R. Appleton, H. Naramoto, C. W. White, O. W. Holland, C. J. McHargue, G. Farlow, J. Narayan, and J. M. Williams, "Ion Implantation, Ion Beam Mixing, and Annealing Studies of Metals in $\mathrm{Al}_{2} \mathrm{O}_{3}, \mathrm{SiC}$, and $\mathrm{Si}_{3} \mathrm{~N}_{4}, "$ Nucl. Instrum. Methods Phys. Res. B1, 167-75 (1984).

V. B. Baylor, J. R. Keiser, and E. H. Lee, "Corrosion Studies in $\mathrm{ZnCl}_{2}$-Air-HCl Envirenments at 500 to $1000^{\circ} \mathrm{C},{ }^{n}$ pp. 483-90 in High Temperature Corrosion, proceedings of International Conference held in San Diego, Calif., on Mar. 2-6, 1981, ed. R. A. Rapp, Natior 1 Association of Corrosion Engineers, Houston, 1983.

J. A. Beavers, W. E. Berry, and J. C. Griess, "Materials Performance in Moist Iodine Vapors at Luw Temperatures," pp. 274-81 in International Congress on Metallic Corrosion, proceedingis of mee.ing held in Toronto on June 3-7, 1984, vol. 3, National Research Council of Ottawa, Canada, 1984.

P. F. Becher, "Dependence of Toughness and Slow Crack Growth Behavior on the Stability of Teiragonal $\mathrm{ZrO}_{2}$ Pariticles in $\mathrm{Al}_{2} \mathrm{O}_{3}$, abstract, Am. Ceram. Soc. Bull. 61(3), 338 (March 1982).

$\mathrm{P}$. 5. Becher, "Slow Crack Growth Behavior in Transformation-Toughened $\mathrm{Al}_{2} \mathrm{O}_{3}-\mathrm{ZrO}_{2}\left(\mathrm{Y}_{2} \mathrm{O}_{3}\right)$ Ceramics," J. Am. Ceram. Soc. 66(7), 485-88 (July 1983).

P. F. Becher, "Strength Retention in SiC Ceramics After Long-Term Oxidation," J. Am. Ceram. Soc. 66(8), C-120-2i (August 1983).

P. F. Becher, "The Mechanical Reliability of Ceramics for Fusion Systems: Windows for Gyrotrons in Elmo Bumpy Torus," Am. Ceram. Soc. Bull. 61(3), 389-91 (March 1982).

P F. Becher and M. K. Ferber, Mechanical Reliability of Current Alumina and Beryllia Ceramics Used in Microwave Windows for Gyrotrons, ORNL/TM-8555, Fev:uary 1983.

P. F. Becher and V. J. Tennery, "Fracture Behavior in Composites Containing $\mathrm{ZrO}_{2}$ Particulates," abstract, Am. Ceram. Soc. Bull. 60(3), 377 (March 1981).

P. F. Becher and V. J. Tennery, "Fracture Toughness of $\mathrm{Al}_{2} \mathrm{O}_{3}-\mathrm{Z}_{5} \mathrm{O}_{2}$ Composites," pp. 38.3-99 in Fracture Mechanics of Ceramics, vol. 6, ed. R. C. Bradt, A. G. Evans, D. P. H. Hasselman, and F. F. Lange, Plenum Press, New York, 1983. 
J. Bentley, L. D. Stephenson, R. B. Benson, Jr., and P. A. Parrish, "In Situ Annealing of Aluminum Ion Implanted with Molybdenum," pp. 260-61 in Proceedings of 11 st Annual Meeting of the Electron Microscupy Society of America, Phoenix, Arizona, August 8-12, 1983, od. G. W. Bailey, San Francisco Press, San Francisco, 1983.

D. H. Bilderback, B. M. Lairson, T. W. Barbee, Jr., G. E. Ice, and C. J. Spaiks, Jr., “Design of Doubly Focusing, Tunable ( $5-30 \mathrm{keV}$ ), Wide Bandpass Optics Made from Layered Sunthetic Microstructures," Nucl. Instrum. Methods 208, 251-61 (i983).

E. E. Bloom, comp., Alloy Development for Irradiation Performance Semiannial Progress Report for Period Ending September 30, 1982, DOE/ER-0045/9, February 1983.

E. E. Bloom, comp., Alloy Development for Irradiation Performance Semiannual Progress Repoit for Period Ending March 31, 1983, DOE/ER-0045/10, October 1983.

E. E. Bloom and J. O. Stiegler, "Implications of Radiation-Induced Segregation and Phase Instability on Alloy Design," pp. 331-55 in Phase Transformations During Irradiation, ed. F. V. Nolfi, Jr., Applied Science Publishers, New York, 1983.

G. C. Bodine and R. E. McDonald, "Laboratory and Pilot Commercial Process/Froduct Development of Modified 9 Cr-1 Mo Ferritic Alloy," pp. 9-20 in Ferritic Steels for HighTemperature Applications, proceedings of ASM International Conference on Production, Fabrication, Properties, and Application of Ferritic Steels for High-Temperature Applications held in Warren, Pa., on Oct. 6-8, 1981, ed. A. K. Khare, American Society for Metals, Metais Park, Ohic, 1983.

M. K. Booker, Analysis of the Creep Strain-Time Behavior of Alloy 800, ORNL/TM-8449, May 1983.

M. K. Booker, V. K. Sikka, and B. L. P. Booker, "Comparison of the Mechanical Strength Properties of Several High-Chromium Ferritic Steels," pp. 257-73 in Ferritic Steels for HighTemperature Applications, proceedings of ASM International Conference on Production, Fabrication, Properties, and Application of Ferritic Steels for High-Temperature Applications held in Warren, Pa., on Oct. 6-8, 1981, ed. A. K. Khare, American Society for Metals, Metals Park, Ohio, 1983.

B. S. Borie and H. L. Yakel, “The Short-Range Structure of Ti and Zr B.c.c. Solid Solutions Containing the $\omega$ Phase. III. Extension of the Diffraction Theory to Partially Transformed Systems," Acta Crystallogr., Sect. A, A39, 287-98 (1983).

R. A. Bradley, comp., AR\&TD Fossil Energy Materials Program Quarterly Progress Report for Period Ending December 31, 1982, ORNL/FMP-83/1, February 1983.

R. A. Bradley, comp., AR\&TD Fossil Energy Materials Program Quarterly Progress Report for Pericd Ending March 31, 1983, ORNL/FMP-83/2, May 1983.

R. A. Bradley, comp., AR\&TD Fossil Energy Materials Program Quarterly Progress Report for Period Ending June 30, 1983, ORNL/FMP-83/3, August 1983.

R. A. Bradley, comp., AR\&TD Fussil Energy Materials Program Quarterly Progress Report for Perind Ending September 30, 1983, ORNL/FMP-83/4, November 1983.

R. A. Bradley, comp., AR\&TD Fossil Energy Materials Program Quarterly Progress Report for Period Ending December 31, 1983, ORNL/FMP-84/1, March 1984.

R. A. Bradlcy, comp., AR\& 7 D Fossil Energy Materials Program Quarterly Progress Report for Period Ending March 31, 1984, ORNL/FMP-84/2, May 1984.

R. A. Bradley, comp., Surface Gasification Materials Program Semiannual Progress Report for Period Ending March 31, 1983, ORNL/SGMP-83/1, May 1983.

R. A. Bradley, comp., Surface Gasification Materials Program Semiannual Progress Report for Period Ending September 30, 1983, ORNL/SGMP-83/2, November 1983. 
R. A. Bradley, comp., Surface Gesification Materials Program Semiannual Progress Report for Period Ending March 31, 1984, ORNL/SGMP-84/1, June 1984.

R. A. Bradiey and P. T. Carlson, Advanced Researct and Technology Development Fossil Energy Materials Program Plan for Fiscal Years 1983 Through 1987, ORNL/TM-8737, June 1984.

R. A. Bradley, R. R. Judkins, and J. P. Hammond, "Materials for Coal Conversion Systems," pp. 71-90 in Symposium on High Temperature Materials for Coal Conversion and Utilization. proceedings of meeting held in Mol, Belgium, on Nov. 17, 1983, ed. J. Nihoul and W. R. A. Goossens, Studiecentrum Voor Kernenergie, Mol, Belgium, 1983.

D. N. Braski and S. A. David, "Weld Microstructure of $(\mathrm{Ni}, \mathrm{Fe})_{3}(\mathrm{~V}, \mathrm{Ti})$ Long-Range-Ordered Alloy," Metall. Trans. A 14A, 1785-91 (September 1983).

D. N. Braski, P. D. Goodell, J. V. Cathcart, and R. H. Kane, "The Oxidation of Inconel Alloy MA754 at Low Oxidation Potential," pp. 218-19 in Proceedings of 4/st Annual Meeting of the Electron Microscopy Society of America, Phoenix, Arizona, August 8-12, 1983, ed. G. W. Bailey, San Francisco Press, San Francisco, 1983.

C. R. Brinkman, "Creep-Fatigue Effects in Structural Materials Used in Advanced Nuclear Power Generating Systems," pp. 241-63 in Fatigut Environment and Temperature Effects, proceedings of Sagamore Army Materials Research Conference held in Lake George, N.Y., on July 14-18, 1980, ed. J. J. Burke and V. Weiss, Plenum Press, New York, 1983.

P. Bull, comp., . . P. F. Tortorelli, "Chemical Aspects of Fusion Technology-1982," Nucl. Fusion 23(7), 955-73 (1983).

W. H. Butler, "Calculated Low-Field Hall Coefficieni of $\mathrm{Ag}_{\mathbf{x}} \mathrm{Pd}_{\mathrm{I}-\mathrm{x}}$ Alloys," Phys. Rev. B 29(8), 4224-29 (April 1984).

W. H. Butler, -Theory of Electronic Transport in Random Alloys: Korringa-Kohn-RostokerCoherent Potential Approximation," abstract, Am. Ceram. Soc. Bull. 29(3), 446 (March :984).

W. H. Butler and G. M. Stocks, "Calculated Elect:-ial Conductivity and Thermopower of Silver-Palladium Alloys," Phys. Rev. B 29(8), 4217-23 (April 1984).

W. H. Butler and G. M. Stocks, "Hall Coefficient of $\mathrm{Ag}_{\mathbf{x}} \mathbf{P d}_{1-x}$ Alloys," abstract, Bull. Am. Phys. Soc. 28(3), 559 (March 1983).

B. C. Cai, A. DasGupta, and Y. T. Chou, "A New Technique for the Growth of Bicrystals of Refractory Metals," J. Less-Common Met. 86, 145-51 (1982).

B. C. Cai, A. DasGupta, and Y. T. Chou, "Etch Pits on Single Crystals and Biciystals of Niobium," J. Less-Common Met. 90, 37-47 (1983).

B. C. Cai, A. DasGupta, Y. T. Chou, J. O. Scarbrough, and C. C. Koch, "Fluxoid Pinning by Grain Boundaries in Bicrystals and Polycrystals of Niobium," pp. 421-25 in Proceedings of International Cryogenic Materials Conference, Kobe, Japan, 1982, ed. K. Tachikawa and A. Clark, Butterworths, London, 1983.

A. J. Caputo, "Fabrication of : uel Pins Using the Gel-Sphere-Pac Process," abstract, Am. Ceram. Soc. Bull. 59(3), 391 (1980).

A. J. Caputo, F. Angelini, and D. P. Stinton, "Drying and Characterization of Sol-Gel Produced SYNROC Waste Forms," abstract, Am. Ceram. Soc. Bull. 59(8), 834 (1980).

A. J. Caputo, W. J. Lackey, and I. G. Wright, Cinemical Vapor Deposition of ErosionResistant TiB 2 Coatings, ORNI/TM-9042, April 1984.

J. V. Cathcart, R. E. Druschel, L C Manley, and G. F. Petersen, “A Technique for Growing Massive Single Crystals of FeS," J. Cryst. Growth 62, 299-308 (1982).

O. B. Cavin, "Use of the APD-3600 in a Multifunction X-Ray Diffraction Laboratory at Oak Ridge National Laboratory," Norelco Rep. 30(2), 12-16 (September 1983). 
I-Wei Chen, "Mechanisms of Cavity Growth in Creep," Scr. Metall. 17(1), 17-22 (1983).

A. Chowdhary, D. M. Nicholson, and L. Schwartz, "Electronic Structure of Amorphous NiP and CoP Alloys," abstract, Bull. Am. Phys. Soc. 29r(3), 424 (March 1984).

G. J. Clark, J. E. E. Baglin, F. M. d'Heurle, C. W. White, G. Farlow, and J. Narayan. "Ion Beam Irradiation of Metal Films on $\mathrm{SiO}_{2}{ }^{*}$ pp. 55-60 in Materials Research Society Symposium Proceedings, vol. 27, meeting held in Boston in November 1983, Elsevier, New York, 1984.

W. A. Coghlan and L. K. Mansur, "Irradiation Creep in the Fusion Reactor First Wall," Res Mech. 7, 85-124 (1983).

W. A. Coghlan and M. H. Yoo, "Radius Dependence of the Sink Strength of a Dislocation Loop," pp. 152-57 in Dislocation Modelling of Physical Systems, procedings of International Conference held in Gainesville. Fla., on June 22-27, 1980, ed. M. F. Ashby, R. Bullough, C. S. Hartley, and J. P. Hirth, Pergamon Press, New York, 1981.

R. W. Conn, E. E. Bloom, J. W. Davis, R. E. Gold, R. Little, K. R. Schuitz, D. L. Smith, and F. W. Wiffen. "Lower Activation Materials and Magnetic Fusion Reactors," Nucl. Technol./Fusion 5, 291-310 (May 1984).

R. H. Cooper, Jr., and E. E. Hoffman. eds., Refractory Alloy Technology for Space Nuclear Power Applications, procedings of symposium held in Oak Ridge, Tenn., on Aug. 10-11, 1983, CONF-8308130, U. S. Department of Energy, 1984.

R. H. Cooper, Jr., and E. E. Hoffman, "Tantalum and Niobium Alloys for Space Nuclear Applications," pp. 336-37 in 1984 Annual Meeting of the .4:-rerican Nuclear Society. New Orleans, Louisiana, June 3-7, 1984, ed. L. Palagi, Anuerican Nuclear Society Transactions, vol. 46, 1984.

G. L. Copeland, "The Aluminum- $\mathrm{U}_{3} \mathrm{O}_{8}$ Exothermic Reaction," pp. 149-52 in Proceedings of the International Meeting on Research and Test Reactor Core Conversions from HEU to LEU Fuels, Argonne, Illinois, November 8-10, 1982, ANi/RERTR/TM-4, CONF-821155, Argonne National Laboratory, Argonne, Ill., September 1983.

G. L. Copeland, R. L. Heestand, C. R. Kennedy, J. F. King, M. F. Marchbanks, and R. K. Williams, comps., Isotopic Space Power Materials Handbook, ORNL/TM-8949, December 1983.

G. L. Copeland and M. M. Martin, "Fabrication of High-Uranium-Loaded $\mathrm{U}_{3} \mathrm{O}_{8}$-Al Developmental Fuel Plates," pp. 67-80 in Proceedings of the International Meeting on Development, Fabrication and Application of Reduced Enrichment Fuels for Research and Test Reactors. Argonne. Illinois, November 12-14, 1980, ANL/RERTR/TM-3, CONF-801144, Argonne National Laboratory, Argonne, Ill., Augus* 1983.

G. L. Copeland and J. L. Snelgrove, "Examination of Irradiated High-U-Loaded $\mathrm{U}_{3} \mathrm{O}_{8}$-Al Fuel Plates," pp. 79-87 in Proceedings of the International Meeting on Research and Test Reactor Core Conversions from HEU to LEU Fuels, Argonne, Illinvis, November 8-10, 1982, ANL/RERTR/TM-4, CONF-821155, Argonne National Laboratory, Argonne, Ill., September 1983.

B. A. Cramer, G. M. Fuller, J. R. Haines, V. D. Lee, F. W. Wiffen, and Y. Gohar, “An Electrically Conducting First Wall for the Fusion Engineering Device-A (Fed-A) Tokamak," Nucl. Technol./Fusion 4, 1095-1100 (September 1983).

R. E. Crooks, E. A. Kenik, and E. A. Starke, Jr., "HVEM In Situ Deformation of Al-Li-X Alloys," Scr. Metall. 17, 643-47 (1983).

G. W. Curningham, P. Patriarca, and E. E. Hoffman, "Ferritic Steels as Alternate Structural Materials for High-Temperature Applications," pp. 3-6 in Ferritic Steels for High-Temperature Applications, proceedings of ASM International Conference cn Production, Fabrication, Properties, and Application of Ferritic Steels for High-Temperature Applications held in Warren, $\mathrm{Pa}$, on Oct. 6-8, 1981, ed. A. K. Khare, American Socicty for Metals, Metals Park, Ohio, 1983.

S. A. David and L. Boatner, Future Directions for Research on Composite Materials at Oak Ridge National Laboralory. ORNL/TM-9010, limited distribution, January 1984. 
S. A. David and C. T. Liu, Modification of Weld Fusion Zone Grain Structure in ThoriumDoped Iridium Alloys," pp. 249-58 in Grain Refinement in Castings and Welds, proceorlings of symposium sponsored by Solidification Committee of The Metallurgical Society of AIME beld in St. Louis on Oct. 25-26, 1982, ed. G. J. Abbaschian and S. A. David, The Metallurgical Society of AIME, Warrendale, Pa., 1983.

S. A. David and J. M. Vitek, "Solidification Behavior, Structure, and Modification of Austenitic Stainless Steel Weld Metal," pp. 199-204 in Welding Technology 82. proceedings of 30th National Conference held on Oct. 9-15, 1982. Australian Welding Institute. Hobart, Tasmani?, 1982.

J. H. DeVan, -Materials Compatibility Considerations for a Molten Salt Fusion Breeder," pp. 210-11 in 1984 Annual Meeting of the American Nuclear Society. New Orleans, Louisiana. June 3-7, 1984, ed. L. Palagi, American Nuclear Society Transactions, vol. 46, 1984.

J. H. DeVan, J. R. DiStefano, and E. E. Hoffman, "Compatibility of Refractory Alloys with Space Reactor System Coolants and Working Fluids," pp. 34-85 in Refractory Alloy Technology for Space Nuclear Power Applications, proceedings of symposium held in Oak Ridge, Tenn., on Aug. 10-11, 1983, CONF-8308130, ed. R. H. Cooper, Jr., and E. E. Hoffman, U. S. Department of Energy, January 1984.

J. A. DeVan and P. F. Tortorelli, -Materials Compatibility Considerations for a Fusion-Fission Hybrid Reactor Desigñ," Nucl. Technol./Fusion 4, 421-26 (Sepiember 1983).

C. V. Dodd, "Improved Eddy-Curreni l'csting for Longitudinal and Circumferential Flaws in Steam Generator Tubing," pp. 47-60 in Tenth Water Reactor Safety Research Information Meeting. Volume 4. Materials Engineeriä Research, proceedings of the U.S. Nuclear Regulatory Commission meeting held in Gaithersburg, Md., on Oct. 12-15, 1982, NUREG/CP-0041, Office of Nuclear Regulatory Research, Washington, D.C., January 1983.

C. V. Dodd, "Improved Multifrequency Eddy-Current Testing of Steam Generator Tubing," pp. 81-97 in Proceedings of the U.S. Nuclear Regulatory Commission Eleventh Water Reactor Safety Research Information Meeting held at National Bureau of Standards, Gaithersburg, Md., on Oct. 24-28, 1983, NUREG/CP-0048, vol. 4, Office of Nuclear Regulatory Research, 1983.

C. V. Dodd and W. E. Deeds, "Design Considerations for Multiple-Frequency Eddy-Current Tests," pp. 121-23 in Quantitative NDE in the Nuclear Industry, proceedings of the Fifth International Conference on Nondestructive Evaluation in the Nuclear Industry held in San Diego, Calif., on May 10-13, 1982, ed. R. B. Clough, American Society for Metals, Metals Park, Ohio, 1983.

C. V. Dodd, W. E. Deeds, and R. W. McClung, Eddy.Current inspection for Steam Generator Tubing Program Quarterly Progress Report for Period Ending June 30, 1982. NUREG/CR-2824, vol. 2, ORNL/TM-8418/V2, January 1983.

C. V. Dodd, W. E. Deeds, and R. W. McClung, Eddy-Current Inspection for Steam Generator Tubing Program Quarterly Progress Report for Period Ending September 30. 1982. NUREG/CR-2824, vol. 3, ORNL/TM-8418/V3, February 1983.

C. V. Doód, W. E. Deeds, and R. W. McClung, Eddy-Current Inspection for Steam Generator Tubing Program Annual Progress Report for Period Ending December 31. 1982. NUREG/CR-3151, ORNL/TM-8741, July 1983.

C. V. Dodd, W. E. Deeds, J. H. Smith, and R. W. McClung, Eddy-Current Inspection for Steam Generaiur Tubing Program Quarterly Progress Report for Period Ending March 31, 1983, NUREG/CR-3200, vol. 1, ORNL/TM-8796/VI, Augus' 198 ?.

C. V. Dodd, W. E. Deeds, J. H. Smith, and R. W. McClung, Eddy-Current Inspection for Steam Generator Tubing Program Quarterly Progress Report for Period Ending June 30, 1983. NUREG/CR-320C, vol. 2, ORNL/TM-8796/V2, September 1983. 
C. V. Dodd, W. E. Decds, J. H. Smith, and R. W. McClung, Eddy'-Current Inspection for Steam Generator Tubing Program Quarterly Progress Report For Period Ending September 30, 1983. NUREG/CR-3200, vol. 3, ORNL/TM-8?96/V3, March 1984.

D. S. Easton, E. H. Henninger, O. B. Cavin, and C. C. Koch, "Some Properties of Electron Beam Evaporated Amorphous Mo-N Films," J. Mater. Sci. 18, 2126-34 (1983).

D. P. Edmonds and B. Chew, Effect of Chemical Compasition on Weld Microstructure in Some Commercial $9 \mathrm{Cr}-\mathrm{I}$ Mo Steel Boiler Tubes, TPRD/M/1258/N82, Central Electricity Generating Board, Marchwood Engineering Laboratories, Marchwood, England, July 1982.

K. Farrell and E. H. i $x$, "Characterization of Precipitates in an Fe-10 Cr-6 Mo-0.5 Nb Ferritic Steel," Scr. Metall. 17, 791-96 (1983).

K. Farrell, P. J. Maziasz, E. H. Loe, and L. K. Mansur, -Modification of Radiation Damage Microstructure by Helium," Radiat. Eff. 78, 277-95 (1983).

K. Farrell and N. H. Packan, "Comparison of Neutron and Heavy-Ion Damage in a SinglePhase Austenite," pp. 953-62 in Effects of Radiation on Materials, proceedings of the 11th International Symposium held in Scottsdale, Ariz, on June 28-30, 1982, ASTM STP 782, ed. H. R. Brager and J. S. Perrin, American Society for Testing and Materials, Philadelphia, 1983.

J. I. Federer, Corrosion of Fluidized-Bed Boiler Materials in Synthetic Flue Gas, ORNL/TM-8819, November 1983.

J. I. Federer, Selecting and Testing Oxygen-Measuring Systems for Fluidized-Bed Combustors, ORNL/TM-8520, January 1983.

J. I. Federer, "The Effect of Reactive Gases on Oxygen Sensor Responses," J. Electrochem. Soc. 131(4), 755-60 (April 1984).

M. K. Ferber and P. F. Becher, "Subcritical Crack Propagation in $\mathrm{Al}_{2} \mathrm{O}_{3}$ and $\mathrm{BeO}$ Exposed to Reactive and 'Ineri' Environments," abstract, Am. Ceram. Sac. Bull. 61,3), 415 (March 1982).

M. K. Ferber and P. F. Becher, "Temperature Dependence of Static Fatigue in Polycrystalline BeO," abstract, Am. Ceram. Soc. Bull. 62(3), 384 (March 1983).

M. K. Ferber, P. F. Becher, and C. B. Finch, "Effect of Microstructure on the Properties of $\mathrm{TiB}_{2}$ Ceramics," J. Am. Ceram. Soc. S4y (1), C2-4 (1983).

M. K. Ferber, H. D. Kimrey, and P. F. Becher, Analysis of the Temperature and Stress Distributions in Ceramic Window Materials Subjected to Micrownve Heating. OR NL/TM-8718, July 1983.

M. K. Ferber and V. J. Tennery, "Analysis of the Corrosion Products Formed from Reactions Between Silicon Carbide and Fluid Coal Slag," abstract, Am. Ceram. Soc. Bull. 62(3), 392 (March 1983).

M. K. Ferber and V. J. Tennery, "Behavior of Tubular Ceramic Heat Exchanger Materials in Acidic Coal Ash from Coal-Oil-Mixture Combustion," Am. Ceram. Soc. Bull. 62(2), 236-43 (February 1983).

P. J. Ficalora, -Corrosion in Atmospheric Fluidized Bed Combustors-The Reactions of $\mathrm{CaSO}_{4}$ with $\mathrm{Cr}, \mathrm{Ni}, \mathrm{Co}, \mathrm{Fe}$, and Several Alloys," Metall. Trans. A 14A, 2423-34 (November 1983).

P. J. Ficalora, Hot Corrosion Reactions of Calcium Sulfate with Cr, Ni, Co, Fe, and Several Alloys. ORNL/TM-8735, June 1983.

P. J. Ficalora, "Sulfidation-Oxidation of Nickel and Cobalt-Reactions Beiween the Metals and Their Sulfates," Oxid. Met. 18(1/2), 19-26 (1982).

P. J. Ficalora and T. G. Godfrey, Technique to Study Corrosion in Fluctuating Creosus Atmospheres, ORNL/TM-8734, July 1983. 
C. B. Finch, P. Angelini, P. F. Becher, and J. Brynestad, -Effect of Oxygen and Carton on the Densification and Grain Size of Hot-Pressed Submicrometer TiB 2 Powders," abstract, Am. Ceram. Soc. Bull. 62(9), 966 (September 1983).

C. B. Finch and P. F. Becher, "Growth of Monoclinic Macroctystalline $\mathrm{ZrO}_{2}$ by Hydrolysis of $\mathrm{ZrF}_{4}$-LiF-NaF Melts at $650-800^{\circ} \mathrm{C}, " J$. Cryst. Growth 60, 321-24 (1982).

C. B. Finch, P. F. Becher, and M. K. Ferber, "The Relation Between Thermal Expansion, Fracture Toughness, and Microstructure in $\mathrm{TiB}_{2}-\mathrm{Ni}_{\mathrm{i}}$ Ceramies," abstract, Am. Ceram So: Bull. 61(3), 408 (March 1982).

C. B. Finch, V. J. Tennery, and R. M. Curlee, "Erosion Behavior of CVD TiB Coatings on $\mathrm{TiB}_{2}$-Based Ceramic Substrates in High-Velocity Coal-Oil Slurries," pp. 415-21 in Specialty Steels and Hard Materials, ed. N. R. Comins and J. B. Clark, Pergamon Press, New York, 1983.

H. A. Fine, S. H. Jury, D. L. McElroy, and D. W. Yarbrough, -The Thermal Conductivity of Semitransparent Maierial," pp. 359-68 in Thermal Conductivity 17, proceedings of 17th Interndtional Conference held in Gaithersburg, Md., on June 15-19, 1981, ed. J. G. Hust, Pleaum Press, New York, 1933.

H. A. Fine, S. H. Jury, D. W. Yarbrough, and D. L. McElroy, "The Optically Thin Esundary Approximation to Conductive and Radiative Heat Transfer," J. Thermal Insul. 6, 216-31 (1983).

J. R. Foulds, J. Moteff, V. K. Sikka, and J. W. McEnerncy, "Deformation Behavior of a 16-8-2 GTA Weld as Influenced by Its Solidification Substructure," Metall. Trans. A 14A, 1357-66 (July 1983).

G. R. Gessel and C. L. White, "Use of AES and RGA to Study Neutron Irradiation Enhanced Segregation to Internal Surfaces," pp. 239-52 in Advanced Techniques for Characterizing Microstructures, ed. F. W. Wiffen and J. A. Spitznagel, The Metallurgical Society of AlME, Warrendale, Pa., 1982.

N. M. Ghoniem, S. Sharafat, and L. K. Mansur, "The Kinetics of the Interaction Between Helium and Displacement Damage in Irradiated Materials," pp. 865-68 in Point Defects and Defect Interactions in Metals, ed. Jin-ichi Takamura, Masao Doyama, and Michio Kiritani, University of Tokyo Press, Tokyo, 1982.

N. M. Ghoniem, S. Sharafat, J. Williams, and L. K. Mansur, "Theory of Helium Transport and Clustering in Materials Under Irradiation," J. Nucl. Mater. 117, 96-105 (1983).

A. Gonis, W. H. Butler, and G. M. Stocks, "First-Principles Calculations of Cluster Densities

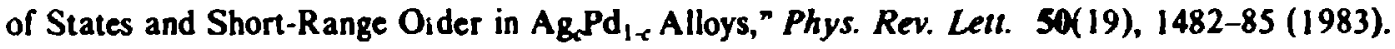

A. Gonis, G. M. Stocks, and W. H. Butler, "Local Environment Fluctuations and Densities of States in Substitutionally Disordered Alloys," abstract, Bull. Am. Phys. Soc. 28(3), 530-31 (March 1983).

A. Gonis, G. M. Stocks, W. H. Butler, and H. Winter, "Local-Environment Fluctuations and Densities of States in Substitutionally Disordered Alloys," Phys. Rev. B 29(2), $555-67$ (January 1984).

R. S. Graves, R. K. Williams, and J. P. Moore, "The Thermal Conductivity, Electrical Resistivity, and Seebeck Coefficient of SRM-735," pp. 343-49 in Thermal Conductivity 16, proceedings of the 16th International Conference held in Chicago, III., on Nov. 7-9, 1979, ed. D. C. Larsen, Plenum Press, New York, 1983.

R. J. Gray and C. W. Houck, Metallurgical Examinations of a Fragmented Blank Firing Adapter and Associated Components, OR NL/TM-8995, March 1984.

R. J. Gray, C. W. Houck, and D. O. Hobson, "Meta!lurgical Investigation of a Gray Cast-Iron 16-in.-Diam Water Line Failure at Oak Ridge National Laboratory," Microstruct. Sci. 11, 351-70 (1983). 
J. C. Griess, S. A. David, R. J. Gray, and C. W. Houck, Electrochemical Etching of Titanium Alloy Castings, ORNL/TM-8830, October 1983.

J. C. Griess and J. H. DeVan, Behavior of Inconel 600 in Sulfur-Contaminated Boric Acid Solusions, ORNL/TM-8544, March 1983.

M. L. Grossbeck and E. E Bloom, -In-Reactor Uniaxial Fracture Strain of 20\%-Cold-Worixed Type 316 Stainless Steel," pp. 53-56 in Dimensional Stability and Mechanical Behovior of Irradiated Metals and Alloys, proceedings of conference held in Brighton, England, on Apr. 11-13, 1983, British Nuclear Society, Lordon, 1984.

B. L. Gyorffy, J. Kollar, A. J. Pindor, J. Staunton, G. M. Stocks, and H. Winter, "Spin Polarized Band Theory at Finite Temperatures," in Abstracts, Workshop on 3d Metallic Magnetism, Institut von Laue-Langevin, Grenoble, France, Mar. 25-26, 1983.

B. L. Gyorfy and G. M. Stocks, -Concentration Waves and Fermi Surfaces in Random Metallic Alloys," Phys. Rev. Lett. 50(5), 374-77 (Jan. 31, 1983).

S. A. Hackney, E. A. Kenik, R. W. Carperter, and K. R. Lawless, "In-Situ Oxidation Studies of Vanadium-20\% Titanium Alloy," pp. 273-78 in Proceedings of the Seventh International Conference on High Voltage Electron Microscopy. August 16-19, 1983, held in Berkeley, Calif., LBL-16031, ed. R. M. Fisher, R. Gronsky, and K. H. Westmacott, Lawrence Berkeley Laboratory, Berkeley, Calif., 1983.

G. C. Hadjipanayis, R. C. Hazelton, K. R. Lawless, and L. L. Horton, "Magnetic Domains in Rare-Earth Cobalt Magnets," IEEE Trans. Magn 18(6), 1460-62 (November 1982).

G. C. Hadjipanayis and L. L. Horton, "Lorentz Electron Microscopy of Rare-Earth Permanent Magnets," pp. 254-55 in Proceedings of the 41st Annual Meeting of the Electron Microscopy Society of America. Phoenix, Arizona. August 8-12, I983, d. G. W. Bailej, San Francisco Press, San Francisco, 1983.

L. A. Harris, "Application of Optical and Electron Microscopy to Coal Conversion Systems," pp. 373-81 in Process Mineralogy II: Applications in Metallurgy. Ceramics, and Geology. proceedings uf symnosium sponsored by the Process Mineralogy Committee of The Metallurgical Society of AIME held in Dallas on Feb. 14-18, 1982, ed. R. [. Hagni, The Metallurgical Society of AIME, New York, 1982.

H.-G. Haubold and J. S. Lin, "He Bubbles in Ni: A Small-Angle X-Ray Scattering Study," J. Nucl. Mater. 111 \& 112, 709-14 (1982).

T. L. Hebble, D. A. Canonico, D. P. Edmonds, G. M. Goodwin, and R. K. Nanstad, Analysis of $\delta$-Ferrite Data from Production Stainless Steel Pipe Welds, NUREG/CR.-3482, ORNL-6024, January 1984.

R. L. Heestand, "Description of Electroslag Processes (Remelting. Welding, and Casting)," pp. 9-14 in Symposium on Electroslag Component Casting, proceedings of meeting held in Morgantown, W.Va., on June 1-2, 1983, DOE/METC/84-4, ed. R. R. Judkins and J. M. Hobday, U.S. Department of Energy, March 1984.

R. W. Hendricks, "The Use of Small-Angle X-Ray and Neutron Scattering for Characterizing Voids in Neutron-Irradiated Metals and Alloys," pp. 381-95 in Advanced Techniques for Characterizing Microstructures. ed. F. W. Wiffen and J. A. Spitznagel, The Metallurgical Society of AIME, Warrendale, Pa., 1982

B. Heshmatpour, G. L. Copeland, and R. L. Heestand, "Decontamination of Transuranic Contaminated Metals by Melt Relining," Nucl. Chem. Waste Manage. 4, 129-34 (1983).

A. Hishinuma and L. K. Mansur, "Critical Radius for Bias-Driven Swelling-A Further Analysis and Its Application to Bimodal Cavity Size Distrihutions," J. Nucl. Mater. 118, 91-99 (1983). 
D. O. Hobeon and R. K. Nanstad, Effects of Off-Specification Procedures on the Mechanical Properites of Half-Bead Weld Repairs," NUREG/CR-3265, ORNL/TM-8661, July 1983.

J. A. Horton and C. C. Koch, Microstructural Characterization of Rapidly Solidified and Welded Ni, Al," abstract, J. Met. 35(8), 53 (August 1983).

J. A. Horton, C. C. Koch, and C. T. Liu, -Segretation and Domain Structure in Rapidly Solidified Ni $\mathrm{Al}_{3}$," pp. 248-49 in Proceedings of 41 st Annual Meeting of the Elcctron Microscopy Society of America, Phoenix, Arizona, August 8-12, 1983, ed. G. W. Bailey, San Francisco Press, San Francisco, 1983.

L. L. Horton and K. Farrell, "Comparison of Damage Microstructures in Neutron-Irradiated Vanadium and Iron," Fp. 232-33 in Proceedings of 4Ist Annual Meeting of the Electron Microscopy Society of America, Phoenix, Arizona, August 8-12, 1983, ed. G. W. Bailey, San Francisco Press, San F: incisco, 1983.

Y. L. Hotsur ati V. X. Sikka, Mechanical Property Characterization of an Electroslag Cast Valve Body of CF8M CCmposition, ORNL/TM-8854, November 1983.

W. P. Huxtable, R. C. Gwaltney, R. A. Just, F. F. Helms, L. F. Parsly, H. A. Mitchell, A. N. Smith, and R. W. Swindeman, Summary of Selected H-Coal Reactor Thermal Fatigue Studies. ORNL/ENG/TM-29, October 1983.

G. L. Jackson, R. E. Clausing, A. F. Lietzke, S. Ejima, L. C. Emerson, and L. Heatherly, "Initial Wall Conditioning in Doublett III," J. Vac. Sci. Technol. A 1(4), 1851-67 (October-December 1983).

G. L. Jackson, R. E. Clausing, A. F. Lietzke, S. Ejima, L. C. Emerson, and L. Heatherly, Initial Wall Conditinning in Doublett III, GA-A 16885, General Atomies, San Diego, Calif., September 1982.

D. D. Johnson, F. J. Pinski, and G. M. Stocks, "Self-Consistent KKR-CPA: A Fast Method Utilizing the Complex Energy Plane," abstract, Bull. Am. Phys. Soc. 29(3), 270 (March 1984).

R. R. Judkins, "Description of the Surface Gasification Materials Program Electroslag Component Casting Project Plan. pp. 207-17 in Symposium on Electroslag Component Casting. proceedings of meeting held in Morgantown, W.Va, on June 1-2. 1983, DOE/METC/84-4, ed. R. R. Juokins and J. M. Hobday, U.S. Department of Energy, March 1984.

R. R. Judkins and J. M. Hobday, eds., Symposium on Electroslag Component Casting. proceedings of meeting held in Morgantown, W.Va., or June 1-2, 1983, DOE/METC/84-4, U.S. Department of Energ:. March 1984.

R. R. Judkins and J. R. Keiser, "Chlorine Transport and Corrosion Mechanisms in Coal Liquids," pp. 179-95 in Conference, Corrosion-Erosion-Wear of Materials in Emerging Fossil Energy Systems. Berkeley. California, January 27-29, 1982, ed. A. V. Levy, National Association of Corrosion Engineers, Houston, 1982.

R. R. Judkins, J. R. Keiser, A. K. Irvine, and V. B. Baylor, "Corrosion in Coal Liquefaction Plant Fractionation Columns," pp. 209-17 in Materials Overview for 1982, proceedings of the 27th National SAMPE Symposium and Exhibition held in San Diego, Calif, on May 4-6, 1982, vol. 27, Society for the Advancement of Material and Procsss Engineering, Azusa, Calif., 1982.

P. R. Kasten, P. L. Rittenhouse, D. E. Bartine, and J. P. Sanders, High-Temperature GasCooled Reactor Technology Development Program Annual Progress Report for Period Eiding December 3I, 1982, ORNL-5960, June 1983.

P. R. Kasten, P. I.. Rittenhouse, D. ¿. Bartine, and J. P. Sanders, High-Temperalure GasCooled Rear'or Technology Development Program Annual Progress Report for Period Ending December 31, 1983, ORNL-6053, June 1984.

J. R. Keiser and V. B. Baylor, "Malizials Performance in Coal Liquefaction Pilot Plan s," abstract, p. 51 in 1980 ASM Materials and Processes Congress, Clevelund, Ohio. October 28-30. 1980. American Society for Metals, Metals Park, Ohio, 1980. 
J. R. Keiser, V. B. Baylor, W. P. Barnett, and D. R. Canfield, -Failure Analysis Assistance to Solvent Refined Coal Pilot Plants," abstract, p. 69 in 1980 ASM Materials and Processes Congress, Cleveland, Ohio, Cxiober 28-30, 1980, American Society for Metals, Metals Park, Ohio, 1980.

J. R. Keiser, V. B. Baylor, M. Howell, and J. F. Newsome, Corrasion Conpon Studies at Coal Liquefaction Pilot Plants, ORNL, TM-8508, September 1983.

J. R. Keiser, V. B. Baylor, J. F. Newsome, and M. Howell, -Study of Fractionation Area Corrosion at Solvent Refined Coal Pilot Plants," abstract, p. 64, in 1980 TMS-AlME Fall Meeting Program Piltsburg. Penusylvania, October 5-9, 1980, The Metallurgical Society of AIME, New York, 1980.

J. R. Keiser and R. R. Judkins, -Role of Chlorine in Corrosion of Liquefaction Plant Fractionators. pp. 1-6 in Materials and Components in Fassil Energy Applications, DOE/FE-0053/44, U.S. Departinent of Energy, June 1, 1983.

J. R. Keiser, A. R. Olsen, and V. B. Baylor, "Corrosion Sample Studies in Coal Liquefaction Pilot Plants," paper 83 in Corrosion 83, International Corrosion Forum, sponsored by tre National Association of Corrosion Engineers, beld in Anaheim. Calif., on Apr. 18-22, 1983, National Association of Corrosion Engineers, Houston, 1983.

J. R. Keiser, A. R. Olsen, R. R. Judkins, and V. B. Baylor, "Material Selections for Direct Coal Liquefaction Systems," pp. 182-83 in Extended Abstracts, vol. 82-2, Electrochemical Society 162d Meeting held in Detroit on Oct. 17-2!, 1982.

E. A. Kenik, "Dynamic Recording System for HVEM In Situ Studies," pp. 107-10 in Proceedings of the Seventh International Conference on High Voltage Electron Microscopy. August 16-19, 1983, held in Berkeley, Calif., LBL-16031, ed. R. M. Fisher, R. Gronsky, and K. H. Westmacott, Lawrence Berkeley Laboratory, Berkeley, Calif., 1983.

E. A. Kenik, "SHaRE Program," Rev. Sci. Instrum 55(4), 626-27 (April 1984).

E. A. Kenik, R. Crooks, and E. A. Starke, "In Situ Deformation and Fracture Studies on Precipitation-Hardened Aluminum Alloys," pp. 199-204 in Proceedings of the Seventh International Conference on High Voltage Electron Microscopy. August 6-19. 1983, held in Berkeley, Calif., LBL-1603I, ed. R. M. Fisher, R. Gronsky, and K. H. Westmacott, Lawrence Berkeley Laboratory, Berkely, Calif., 1983.

E. A. Kenik and E. H. Lee, "Radiation Damage and Phase Ins'ability in Irradiated Stainless Steel," pp. 234-35 in Proceedings of the 4/st Annual Meeting of the Electron Microscopy Society of America, Phoenix, Arizona, August 8-12, 1983, ed. G. W. Bailey, San Francisco Press, San! Francisco, 1983.

R. L. Klueh, "Chromium-Molybdenum Steels for Fusion Reactor First Walls--A Review," Nucl. Eng. Des. 72, 32944 (1982).

R. L. Kluch, "Dissimilar-Metal Weld Failures in Boiler Tubing," Power Eng. 82, 52-56 (February 1984).

R. L. Klueh, "Heat-to-Heat Variations in Creep-Rupture Properties of Annealed $21 / 4 \mathrm{Cr}$ 1 Mo Steel," Pressure Vessel Technol. 105, 320-28 (November 1983).

R. L. Klueh, "Metals in the Nuclear-Fusion Enviornment," Mater. Eng. 99(2), 39-42 (February 1984).

R. L. Klueh and E. E. Bloom, Alloy Development for Fast Indurea Radioactivity Decay for Fusion Reactor Applications, ORNL/TM-8994, March 1984.

R. L. Kluch and E. E. Blonm, "Radiation Facilities for Fusion Reartor First Wall and Blanke: Structural Materials Development," Nucl. Eng. Des. 73, 101-25 (1982).

R. L. Klueh, J. F. King, and J. L. Griffith, "A Simple Test for Dissimilar-Metal Welds," Weld. J. (Miami) 62(6), IS4 S9-s (1983). 
R. L. Klueh and R. W. Swindeman, Mechanical Properties of a Modified 2 l/4 Cr-1 Mo Sieel for Pressure Vessel Applications. ORNL-5995, December 1983.

R. L. Klueh and J. M. Vitek, "The Resistance of $9 \mathrm{Cr}-1 \mathrm{MoVNb}$ and $12 \mathrm{Cr}-1 \mathrm{MoVW}$ Steels to Helium Embrittlement," J. Nucl. Mater. 117, 295-302 (1983).

C. C. Koch, O. B. Cayin, C. G. McKamey, and J. O. Scarbrough, -Preparation of 'Amorphous' $\mathrm{Ni}_{60} \mathrm{Nb}_{40}$ by Mechanical Alloying," Appl. Phys. Lett. 43(11), 1017-19 (December 1983).

C. C. Koch, D. M. Kroeger, J. S. Lin, J. O. Scarbrough, W. L. Johnson, and A. C. Anderson, "Effect of Annealing on the Structure of an Amorphous $\left(M_{02 c}: u_{0,4}\right)_{82} B_{18}$ Alloy," Phys. Rev. $B$ 27(3), 1586-95 (February 1983).

C. C. Koch, J. O: Scarbrough, D. M. Kroiger, and D. S. Easton, -Superconductivity in Rapidly Quenched Mo-P-B Alloys," J. Mater. Sci. 18, 759-65 (1983).

O. C. Kopp and L. A. Harris, "Initizl Volatilization Temperatures and Average Volatilization Rates of Coal-Their Relationship to Coal Rank and Other Characteristics," Int. J. Coal Geol. 3, 333-48 (1984).

P. Krautwasser, G. M. Begun, and P. Angelini, -Raman Spectral Characterization of Silicon Carbide Nuclear Fuel Coatings," J. Am. Ceram. Soc. 66(6), 424-34 (1983).

D. M. Kroeger, C. C. Koch, C. G. McKamey, and J. O. Scarbrough, "The Effect of Chemical Short Range Ordering on Crystallization of $\mathrm{Zr}-\mathrm{Ni}$ Glasses," J. Non-Cryst. Solids 61 \& 62, 937-42 (1984).

D. M. Kroeger, C. C. Koch, J. O. Scarbrough, and C. G. McKamey, "Effec's of Short-Range Order on Electronic Properties of $\mathrm{Zr}-\mathrm{Ni}$ Glasses as Seen from Low-Temperature Specific Heal," Phys. Rev. B 29(3), 1199-1208 (February 1984).

R. J. Lauf, High-Voltage-Gradient Zinc Oxide Varistors: Fabrication and Properties, ORNL/TM-8484, March 1983.

R. J. Lauf, "Irradiat:,n Behavier of Pyrolytic Silicon Carbide," pp. 72-73 in Proceedings of 4/st Annual Meeting of the Electron Microscopy Society of America, Phoenix, Arizona, August 8-12. 1983, ed. G. W. Bailey, San Francisco Press, San Franciscs, 1983.

R. J. Lauf and W. D. Bond, -Fabrication of High-Field Zinc Oxide Varistors by Sol-Gel Processing," Am. Ceram. Soc Bull. 63(2), 278-81 (February 1984).

R. J. Lauf and L. A. Harris, "Behavior of Mineral Maiter During "oal Combustion," pp. 329-38 in Proceedings of the Symposium on High Temperature Materials Chemistry-II held in San Francisco on May 8-13, 1983, proc. vol. 83-7, ed. Z. A. Munir and D. Cubicciotti, The Electrochemical Society, Pennington, N.J., 1983.

R. J. Lauf, T. B. Lindemer, and R. L. Pearson, "Out-of-Reactor Studies of Fission Product-Silicon Carbide Interactions in HTGR Fuel Particles," J. Nucl. Mater. 120, 6-30 (1984).

R. J. Lauf and A. E. Pasto, "Graphite from the Lead Hill Mine, Ticunderoga, New York," Mineral. Rec. 14(1), 25-30 (January-February 1983).

K. Lawiess, S. Hackney, and E. Kenik, "HVEM In Situ Oxidation Behavior of Vanadium and V-20 Ti," abstra tt, J. Met. 33, 56 (1981).

E. H. Lee, N. H. Packan, and L. K. Mansur, "Effects of Pulsed Dual-Ion Irradiation on Phase Transformations and Microstructure in Ti-Modified Austenitic Alloy," $J$. Nucl. Mater. 117, 123-33 (1983).

D. L. Lennen and A. R. Olsen, Assessment of Critical Materials Requirements for a Direct Coal Liquefaction I zcility, ORNL/TM-8797, November 1983.

M. B. Lewiz and K. Farrell, -Arsenic and Platinum Deposition During Cathodic Hydrogenation," Scr. Metall. 1i(3). 36569 (1983). 
C. T. Liu and C. C. Koch, "Development of Ductile Polycrystalline Ni,Al for HighTemperature Applications, ${ }^{n}$ pp. P42-1-19 in Technical Aspects of Critical Materials Use by the Steel Industry. vol. IIB, proceedings of a public workshop on Trends in Criticai Materials Requirements for Steels of the Future: Conservation and Substitution Technology for Chromium held in Nashville, Tenn., on Oct. 4-7, 1982, NBSIR 83-2679-2, National Bureau of Standards, June 1983.

C. T. Liu and E. M. Schulson, "The Fracture of Ordered (Fe, $\mathrm{CO})_{3} \mathrm{~V}$," Metall. Trans. A 15A, 701-6 (April 1984).

C. T. Liu, C. L. White, C. C. Koch, and E. H. Lee, "Preparation of Ductile Nickel Aluminides for High Temperature Use," pp. 32-41 in Proceedings of the Symposium on High Temperature Materials Chemistry -II held in San Francisco on May 8-13, 1983, proc. vol. 83-7, ed. Z. A. Munir and D. Cubiaiotti, The Electrochemical Society, Pennington, N.J., 1983.

T. S. Lundy, "Building Thermal Research Utilization," pp. 2010-14 in Energy for the Marketplace,- procedings of the 18th Intersociety Energy Conversion Engineering Conference held in Orlando, Fla., on Aug. 21-26, 1983, Institute of Electrical and Electronics Engineers, New York, 1983.

A. P. Maclin and G. M. Stocks, "Band Structure Calculations of Aluminides," abstract, Bull. Am. Phys. Soc. 2913, 393 (March 1984).

L. K. Mansur and W. A. Coghlan, "Mechanisms of Helium Interaction with Radiation Effects in Metals and Allo's: A Review," J. Nucl. Mater. 119. 1-25 (1983).

L. K. Mansur and W. A. Coghlan, "Relationships of Irradiation Creep to Swelling Implicit in the Theories of Thise Processes," pp. 65-69 in Dimensional Stability and Mechanical Behovior of Irradiated Metals ana .Al'oys, proceedings of conference held in Brighton, England, on Apr. 11-14, 1983, British Nuclear Energy Society, London, 1984.

L. K. Mansur, W. A. Coghlan, K. Farrell, L. L. Horton, E. H. Lee, M. B. Lewis, and N. H. Packan, "Fusion-Relevarit Basic Radiation Effects-Theory and Experiment," paper 16 in Japan-U.S. Workshop on Radiation Damage in Fusion Structural Materials, proceedings of meeting held in Tsukuba, Japan (limited distribution), on Dec. 5.-7, 1983, comp. S. Tamura and R. Nakagawa, National Research Institute for Metals. Tsukuba, Japan, 1983.

P. J. Maziasz, "Identification of Preferential Polishing Effects Using Broad-Probe AEM," pp. 196-97 in Proceedings of 4lst Annual Meeting of the Electron Microscopy Society of America, Phoenix. Arizona, August 8-12, 1983, ed. G. W. Bailey, San Francisco Press, Sail Francisco, 1983.

P. J. Maziasz and G. R. Odette, "Wide Area Beam Averaged AEM of Precipitute Particles Extracted on Replicas from Type 316 Stainless Steel,- pp. 198-99 in Proceedings of the 41st Annual Meeting of the Electron Microscopy Society of America, Phoenix, Arizona, August 8-12. 1983, ed. G. W. Bailey, San Francisco Press, San Francisco, 1983.

R. W. McClung, review of Ultrasonic Testing-Non-Conventional Testing Techniques, to. J. S. Szilard, Wiley, New York, 1982, J. Test. Eval. 11(2), 162 (March 1983).

R. W. McClung, K. V. Cook, C. V. Dodd, B. E. Foster, and W. A. Simpson, Jr., "Recent Advances in NDT of Steam Generators for LMFBR," transactions of Conference on Nondestructive Testing in the Nuclear Power Indusiry held in Columbus, Ohio, on Sept. 2i 25, 1974, ed. R. Farmakes, Trans. Am. Nucl. Soc. 19(suppl. 2), 6-7 (1970,).

R. W. McClung, K. V. Cook, C. V. Dodd, and J. H. Smith, “Nondestructive Testing of Metallic Sheath for Internally Conled Supercondictor," Nucl. Technol./Fusion 4, 1378-83 (Siptember 1983).

R. W. McClung, K. V. Cook, C. V. Dodd, and J. H. Smith, "Nondestructive Testing of Metallic Sheath for Superconducting Cable," pp. 53132 in Fifth Tcpical Meeting on the Technole,y of 
Fusion Energy, Knoxville, Tennessee, April 26-28, 1983, Program and Summaries, CONF-830406, Oak Ridge National Laboratory, Oak Ridge, Tenn., 1983.

H. E McCoy: Studies of Waste-Canister Compatibility, ORNL/TM-8491. January 1983.

H. E. McCoy and J. F. King, Creep and Tensile Properties of Alloy 80CH-Hastelloy X Weldments, ORNL/TM-8728, August 1983.

D. L. McElroy, "Thermal Insulation," in Proceedings of the First Annual Conservation Conference, New Orleans, November 16-19, 1980, CONF 80!120-1, U. S. Department of Energy, 1980, 33 pp.

D. L. McElroy, R. K. Williams, F. J. Weaver, and R. S. Graves, "The Physical Properties of $\mathrm{V}(\mathrm{Fe}, \mathrm{Co}, \mathrm{Ni})_{3}$ Alloys from 300 to $1000 \mathrm{~K}$," pp. 337-41 in Thermal Conductivity 16, procedings of the 16th International Conference held in Chicago, IIl., on Nov. 7-9, 1979, ed. D. C. Larsen, Pienum Press, New York, 1983.

D. L. McElroy, D. W. Yarbrough, and R. S. Graves, “An In Situ Study of Antic Loose-Fill Thermal Insulation in Residential Applications," pp. 343-57 in Thermal Performance of the Exterior Envelopes of Buildings. II. vol. 4, proceedings of the ASHRAE/DOE Conference held in Las Vegas, Nev., on Dec. 6-9, 1982, ASHRAE SP 38, ed. E. L. Bales, Americen Society of Heating, Refrigeration ard Air-Conditiening Engineers, New York, 1983.

J. J. McGowan, “Use of an On-Line Data Base in Pressure Vessel Design," pp. 69-73 in An On-Line Materials Property Base, MPC-20, ed. J. A. Graham, American Society of Mechanical Engineers, New York, 1983.

C. J. McHargue, "Chromium Substitution/Conservation in Alloys for Use in Energy Systems," J. Met. 35(7), 30-36 (July 1983).

C. J. McHargue, M. B. Lewis, B. R. Appleton, H. Naramoto, C. W. White, and I. M. Williams. "Alteration of Surface Properties by Ion Implantation," pp. 451-65 in Science of Hard Materials, proceedings of International Conference held in Moran, Wyo., on Aug. 23-28, 1981, ed. R. K. Viswanadham, D. J. Rowcliffe, and J. Gurland, Plenum Press, ivew York, 1983.

C. J. McHargue and Sigfred Peterson, Metals and Ceramics Division Materials Science Program Annual Progress Report for Period Ending December 31, 1981, ORNL/TM-8627, May 1982.

C. J. McHargue, P. S. Sklad, P. Angetini, and M. B. Lewis, "Microstructure and Properties of $\mathrm{TiB}_{2}$ Implanted with $1 \mathrm{MeV}$ Nickel," Nucl. Irstrum. Methods Phys. Res. B1, 246-52 (1984).

C. J. McHargue and C. S. Yust, "Lattice Modification in Ion-Implanted Ceramics," J. Am. Ceram. Soc. 67(2), 117-23 (February 1984).

R. A. McKee, "A Generalization of the Nernst-Einstein Equation ior Self-Diffusion in High Defect Concentration Solids," Solid S!ate Ionics 5, 133-36 (1981).

R. A. McKee, "Analysis of the Stoichiometry and Temperature Dependence of Cation Diffusion in Wustite, Fe ${ }_{18} \mathrm{O}^{\prime \prime}$ Phys. Rev. B 28(6), 3007-13 (Sept. 15, 1983).

R. A. McKee, "Chemical and Tracer Diffusion "n Nonstoichiometric Binary Oxides," Radiat. Eff. 75, 145-50 (1983).

R. A. McKee and R. E. Druschel, "Evolution of Scale Micrpstructure and the Pressure Dependence of the Sulfidation Rate of Iron," J. Electrochem. Soc. 130(4), 898-904 (1983)

R. A. McKee and R. E. Druschel, "The Microstructures and Growth Rates of FeS on Pure and Not-So-Pure Iron," J. Electroc'.2m. Soc. 131(4), 853-57 (April 1984).

X. Miyahara, N. H. Packar, and N. Igata, "The Effect of Pulse Irradiation on Void Swelline of a 'Pure' 316 Stainless Steel," pp. 941-52 in Effects of Radiation on Materials, proceedings of the Ifth International Symposium held in Scottsdale, Ariz., on June 28-30, 1982, ASTM STP 782, ed. H. R. Brager and J. S. Perrin, American Society for Testing and Materials, Philadelphia, 1982. 
R. W. Moir, . . J. H. Devan, P. Tortorelli . . ., "Fusion Breeder Reactor Design Studies," Nucl. Technol./Fusion 4, 589-98 (September 1983).

J. P. Moore and C. B. Finch, "Thermal Conductivity of $\mathrm{Mn}_{2} \mathrm{SiO}_{4}$ in the [100] Direction from 80 to 400 K," J. ' $m$. Ceram. Soc. 65(11), C-184 (1982).

J. P. Moore and R. S. Graves, "The Thermal Transport Properties of a POCO AXM-5Q1 Giaphite irom 80 to $970 \mathrm{~K}$," pp. 153-62 in Thermal Conductivity 17, proceedings of 17th International Conference held in Gaithersburg, Md., on June 15 -19, 1981, ed. J. G. Hust, P'snum Press, New York, 1983.

J. P. Moore, D. L. McElroy, and S. H. Jury, "A Technique for Measuring the Apparent Thermal Coniuctivity of Flat Insulations," pp. 727-35 in Thermal Conductivity 17, proceedings of the 17th Internatic nal Thermal Conductivity Conference held in Gaithersburg, Md., on June 15-18, 1981, ed. J. G. Hust, Pienum Press, New York, 1983.

A. J. Mourhead, "Welding and Brazing of Film Probe Sensor Assemblier" Weld. J. (Miami) 62(10), 17-27 (October 1983).

A. J. Moorhead, P. F. Becher, R. J. Lauf, and C. S. Morgan, "Fabrication, Testing and Brazing of Dispersed Metal-Toughened Alumina," pp. 291-99 in Proceedings of the Twentieth Automotive Technology Development Contractors' Coordination Meeting, Dearborm, Michigan, October 25-28, 1982, P-120, Society of Automotive Engineers, Inc., Warrendale, Pa., 1983.

A. J. Moorhead and C. R. Kennedy, "Brazing of Carbon and F:aphite," pp. 1061-63 in Metols Handbook. Welding, Brazing, and Soldering, 9th ed., vol. 6, ed. K. Mills, J. R. Davis, and B. R. Sanders American Society for Metals, Metals Park, Ohio, 1983.

A. J. Moorheaf, T. N. Tiegs, and R. J. Lauf, "Dispersed Metal-Toughened Ceramics and Ceramic Brazino," pp. 223-29 in Proceedings of the Twenty-First Automotive Technology Development Cuntractors' Coordination Meeting, Dearborn, Michigan, November 14-17, 1983, P-138, Society of Automotive Fngineers, Warrendale, Pa., March 1984.

J. Muteff, C. E. Pugh, and R. W. Swindeman, “Correlations Between Metallurgical Characterization Studies, Exploratory Mechanical Tests, and Continuum Mechanics Approaches to Constitutive Equations," pp. 235-38 in Nonlinear Constitutive Relations for High Temperature Applications, pruceedings of symposium held at the University of Akron, Akron, Ohio, on May 19-20, 1982, NASA Conf. Publ. 2271, National Aeronautics and Space Administration, 1983.

R. Müller, R. N. Shelton, C. C. Koch, and D. M. Kroeger, "Pressure Dependence of the Superconducting Transition Terinperature of $T_{5} T_{9}$ Metallic Glasses $\left(T_{5}=N b, T a ; T_{9}=R h\right.$, Ir)," Solid State Commun. 45(4), 327-30 (1983).

R. K. Nanstad, "The Heavy-Section Steel Technology Program," pp. 36-40 in Welding Research Council Progress Reporis. vol. 37. No. 10, Welding Research Couricil, New York, December 1982.

H. Naramoto, C. J. McHargue, C. W. White, J. M. Williams, O. W. Holland, M. M. Abraham, and B. R. Appleton "Near Surface Modification of $\alpha-\mathrm{Al}_{2} \mathrm{O}$, by Ion Implanta.io: Followed by Thermal Annealing," Nucl. Instrum. Methods 209/210, 1159.56 (199: ).

H. Naramoto, C. W. White, J. M. Williams, C. J. McHargue, O. W. Holland, M. M. Aioraham, and B. R. Appleton, "Ion Implantation and Thermal Anrealing of $\alpha-\mathrm{Al}_{2} \mathrm{O}_{3}$ Single Crystals," J. Appl. Phys. 54(2), 683-98 (Febri ary 1983).

D. M Nicholson, A. Chowdhary, and L. Schwartz, "Structure Dependence of Electionic Stales in Amorf hous Metals," abstract, Bull Am. Phys. Soc. 28(3), 483-84 (March 1983).

D. M. Nicholson and J. S. Faulkner, "Non-Muffin-Tin Effects in Transition Metal3," abstract, Rull. Am. Phys. Soc. 29(3), 392 (March 1984).

D. M. Nichn!son, L. Huisman, L. Schwartz, A. Bransil, and R. Prasad, "Electronic States in Early-Late 'ransition Metal (ilasses: Application to $\mathrm{Cu}_{0.60} \mathrm{Zr}_{0.40}$ " . Solid State Commun. 46(12), 89194 (1983). 
A. R. Olsen, J. R. Keiser, R. R. Judkins, and V. B. Baylor, -Materials Selections for Direct Coal Liquefaction Systems," pp. 305-27 in Proceedings of the Symposium on Corrosion in Favsil Fuel Systems, vol. 83-5, ed. I. G. Wright, Electrochemical Society, Pennington, N.J., 1983.

N. H. Packan and K. Farrell "Radiation-Induced Swelling in an Austenitic Alloy: Oóservations and Interpretation of the Effects of Helium," Nucl. Technol./Fusion 3, 392-404 (May 1983).

R. A. Padgett and C. L. White, "Retardation of Grain Boundary Diffusiun in Nickel Doped with Antimony and Tin," Scr. Metall. 18, 459-62 (1984).

G. S. Painter and F. W. Averill, "Augmented Gaussian-Orbita! Basis for Atomic-Cluster Calculations Within the Density-Functional Formalism: Application to $\mathrm{Cu}_{2},{ }^{\prime}$ Phys. Rev. $B$ 28(10), 5536-48 (Nov. 15, 1983).

G. S. Painter and F. W. Averill, "Transition Metal Dimer Studies Wittin the Local Spin Density Approximation (LSDA) [ lsing an Augmented Gaussian Orbital Approach," abstract, Bull. Am. Phys. Soc. 28(3), 557 (March 1983).

R. W. Pasco and P. I. Ficalora, "A Work Function-Chemisorption Study of Hydrogen on Iron: Kinetics and Strain Effects," Acta Metall. 31(4), 541-58 (1983).

P. Patriarca, "The Selection of Tube-to-Tutresheet Joints for Sodium-Cooled Fast Reactors," pp. 115-21 in Shell and Tube Heat Exchangers, proceedings of Second Symposium held in Houston on Sept. 14-16, 1982, ed. W. R. Apblett, Jr., American Society for Metals, Metals Park, Ohio, 1982.

R. E. Pawel, "Acicuracy of the Linear Gradient Approximation for Diffusion-Controlled Growth of Iron Sulfide Scales," Oxid. Met. 19(1/2), 19-25 (1983).

R. E. Pawel and J. J. Campbell, "The Effect of Structural Changes in the Oxide on the Oxidation Kinetics of Zirconium, ${ }^{n}$ pp. 162-67 in High Temperature Corrosion, NACE-6, National Association of Corrosion Engineers, Houston, 1983.

T. D. Pay, S. S. Patel, W. C. Ulrich, H. D. Cochran, J. M. Holmes, K. H. Lin. A. R. Olsen, W. R. Williams, and :. L. Youngblood, Foreign Coul Liquefaction: Survey and Assessment. ORNL/TM-8288, May 1984.

S. Peteisun, "Torio," pp. 347-54 in Enciclopedia della Chimica. vol. X, USES Edizioni Scientifiche Firenze, Florence, Italy, 1983.

A. J. Pindor, J. Stauntun, G. M. Stocks, and H. Winter, "Disordered Local Moment State of Magnetic Transition Metals: A Self-Consistent KKR CPA Calculation," J. Phys. F 13, 979-89 (1983).

F. J. Pinski, W. H. Butler, and P. B. Allen, "Ideal Thermal Conductivity of Pd and Nb," pp. 155-63 in Thermal Conductivity 16, proceedings of the 16th International Conference held in Chicago, Ill., on Nov. 7-9, 1979, ed. D. C. Larsen, Plenum Press, New York, 1983.

F. J. Pinski and G. M. Stocks, "Eleztronic Structure of $\mathrm{Fe}_{\mathbf{c}} \mathrm{Ni}_{1 . c}$ Alloys," abstract, Bull. Am. Phys. Soc. 28(3), 531 (March 1983).

M. L. Poutsma, L A. Harris, E. C. Hise, R. M. Wham, and J. E. Wortman, Initial Exploration of Application of Open-Gradient Magnetic Separation of Coal to Beneficiation of Liquefaction Feeds, ORNL/TM-8529, February 1983.

P. L. Rittenhouse and H. E. McCoy, "Long-Term Testing of $21 / 4 \mathrm{Cr}-1$ Mo Steel in HTGR Helium," pp. 37581 in Proceedings of the Third Japan-L. $\therefore$ Seminar 0. HTGR Safety Technology held in Upton, N.Y., on June 2-3, 1982, NUREG/CP-0045 BNL-NUREG-51674, vol. 11, R-8, U.S. Nuclear Regulatory Commission, Washington, D.C., 1982.

P. L. Rittenhouse and D. I. Roberts, HTGR Structurat Materials Efforts in the U.S., GA-A 16775, General Atomic Company, San Diego, Calif., July 1982 
T. M. Rosseel, J. P. Young, J. M. Dale, A. DasGijpta, L. D. Hulett, H. F. Krause, C. T. Liu, S. Raman, and C. R. Vane, "Application of Heavy-Ion-Induced X-Ray Satellite Emission to AIloys," J. Phys. F 14, L37-41 (1984).

A. F. Rowcliffe and T. K. Roche, "Mictostructural Control During D9 Cladding Fabrication," pp. 53-63 in National Cladding/Duct Materials Development Program Annua! Information Meeting. Richland, Washingtom, October 20-22, 1981, TC 160-30, Hanford Engineering Development Laboratory, Kichland, Wash., September 1981.

T. F. Scanlan, C. K. Bayne, and D. R. Johnson, "Investigation of Attic Insulation Effectiveness by Using Actual Energy Consumption Data," pp. 502-15 in Thermal Insulation, Materials and Systems for Energy Conservation in the '80s, proceedings of conference held in Clearwater Beach, Fla., on Dec. 8-11, 1981, ed. F. A. Govan, D. M. Greason, and J. D. McAllister, ASTM STP 789, American Society for Testing and Materials, Philadelphia, 1981.

A. C. Schaffauser, V. J. Tennery, and E. L. Long, Ceramic Technology for Advanced Heat Engines Fer.gram Plan, ORNI /TM-8896, June 1984.

J. H. Schneibel and P. M. Hazzledine, "The Role of Coble Creep and Interface Control in Superplastic Sn-Pb Alloys," J. Mater. Sci. 18, 562-70 (1983).

J. H. Schr bel and G. F. Petersen, "The Influence of Trace Additions of Zirconium on Diffusional Creep in Ni-20\%6 Cr," Scr. Metall. 17, 353-58 (1983).

J. L. Scott, comp. and ed., Fifth Annual Progress Report on Special Purpose ilaterials for Magnetically Confined Fusion Reactors, DOE/ER-0!13/2, October 1983.

J. L. Scott, comp. and ed., Sirsh Annual Progress Report on Special Purpose Materials for Magnetically Confined Fusion Reactors, DOE/ER-0113/3, May 1984.

J. L. Scott, "Interactions Between Designers and Materials Development People," pp. 20.2-3 in Prociedings of the Second Meeting on Electrical Insulators for Fusion Magnets held in Germantown, Md., on Sept. 8-9, 1982, CONF-8209153, U.S. Department of Energy, July 1983.

V. K. Sikka, "Development of Modified 9 Cr-i Mo Steel," pp. P27-1-27 in Technical Aspects of Critical Materials Use by the Steel Industry, vol. IIB, proceedings of a public workshop on Trends in Critical Materials Requirements for Steels of the Fiture: Conservation and Substitution Technology for Chromium held in Nashville, Tenn., on Oct. 4-7, 1982, NBSIR 83-2679-2, National Burtau of Standards, June 1983.

V. K. Sikka, "Mechanical Properties of Electroslag Casting:" pp. 97-142 in Symposium on Electroslag Component Casting, proceedings of meeting held in Morgantown, W.Va., on June 1-2, 1983, DOE/METC/84-4, ed. R. R. Judkins and J. M. Hobday, U. S. Department of Energy, March 1984.

V. K. Sikka, "Modified 9 Cr-1 Mo Steel-An Improved Alloy for Steam Generator Application," pp. 65-84 in Ferritic Steels for High-Temperature Applications, proceedings of ASM International Conferenence on Production, Fabricstion, Properties, and Application of Ferritic Steels for High-Temperature Applications held in Warren, Pa., on Oct. 6-8, 1982, ed. A. K. Khare, American Society for Metals, Metals Park, Ohio, 1983.

V. K. Sikka, G. M. Goodwin, J. F. King, and K. V. Cook, Fabrication of Modified $9 \mathrm{Cr}-\mathrm{I} \mathrm{Mo}$ Steel Test Article for Exposure in Sodium Components Test Loop at Energy Technolngy Engineering Center, ORNL-6034, April 1984.

W. A. Simpson, Jr., L. Adler, and T. K. Bolland, "Boundaries Between Isntropic and Anisotropic Solids and Their Effect on Qualtitative Nondestructive Evaluation," pp. 217-31 in Nondestructive Evaluation: Microstructural Characterization and Realiability Strategies, proceedings of symposium held in Pittsburgh, Pa., on Oct. 5-9, 1980, ed. O. Buck and S. M. Wolf, The Metallurgical Sxiety of AlME and the Energy and Resources Activity of the American Society for Metals, New York, 1981. 
W. A. Simpson, Jr., and R. W. McClung, "Nondestructive Techniques for Fatigue Damage Detertion," pp. 240-49 in Proceeaings of the DOE Physical and Chemical Energy Storage Annual Contractors' Review Meeting he'd in Arlington, Va on Aug. 23-26, 1982, CONF-820827, U.S. Department of Energy, Washington, D.C., 1982.

W. A. Simpson, Jr, and R. W. McClung. "Ultrasonic Characterization of Advanced Compusite Flyw icels," abstiact, p. 302 in Abstracts, Review of Progress in Quantitative NDE, University of California, Santa Cruz, August 7-12, 1983, IS-4838, CONF-830811, Ames Laboratory, Ames, Iowa, 1983.

P. S. Sklad, "Analytical Electron Micrnerop; of Grain Buundaries in TiB $\mathbf{2}_{\mathbf{2}}-\mathrm{Ni}$ Ceramics," pp. 695-96 in Electron Microscopy 1982, Vol. I. Symposia and Physical Scienres, papers presented at the Tenth International Congress on Electron Microscopy beld in Hamburg, West úermany, on Aug. 17-24, 1982, ed. Congress Organizing Committee, Deutsche Gesellschaft für Elektronenmikroskopie c.V., Frankfurt, West Germany, 1982.

P. S. Sklad, P. Angelini, M. B. Lewis, J. T. Houston, and C. J. McHargue, "Analytical Electron Microscopy of $\mathrm{TiB}_{2}$ Implanted with $1 \mathrm{MeV}$ Nickel," pp. 66-67 in Proceedings of the 4Ist Annual Meeting of the Electron Microscopy Society of America, Phoenix, Arizona, August 8-12. 1983, ed. G. W. Bailey, San Francisco Press, San Francisco, 1983.

P. S. Sklad and C. S. Yust, "Characterization of $\mathrm{TiB}_{2}-\mathrm{Ni}$ Ceramics by Transmission and Analytical Eleztron Microscopy," pp. 911-30 in Science of Hard Materials, p-.x.dings of International Conference held in Moran, Wyo., on Aug. 23-28, 1981, ed. R. K. “ wanadham, D. J. Rowcliffe, and J. Gurland, Plenum Press, New York, 1983.

A. A. Solomon, C. S. Yust, and N. H. Packan, "Primary Creep of $\mathrm{UO}_{2}$ and the Effect of Amorphous Grain Boundary Phases," J. Nucl Mater. 110, 333-42 (1982).

C. J. Sparks, Jr., "X-Ray Fluorescence Analysis," pp. 429-47 in Applied Atomic Collision Physics, ed. S. Datz, Acr demic Press, New York, I' 83.

L. D. Stephenson, J. Bentley, R. B. Benson, Jr., and P. A. Parrish, "Analytical Electron Microscopy of Aluminum Ion Implanted with Molybdenum," pp. 262-63 in Proceedings of $4 /$ st Annual Meeting of the Electron Microscopy Society of Americn, Phoenix, Arizona, August 8-12, 1983, ed. G. W. Bailey, San Francisco Press, San Francisco, 1983.

D. P. Stinton, W. J. Lackey, and P. Angelini, "Immobilization of Radioactive Cesium in Pyrolytic Carbon-Coated Zeolite," J. Am. Ceram. Soc. 66(6), 389-92 (1983).

D. F. Stinton, E. W. McDaniel, and H. O. Weeren, Characterization of Hydrofracture Grouts for Radi inuclide Migration, ORNL/TM-8798, July 1983.

F. P. Stinton, E. W. McDaniel, and H. O. Weeren, "Partioning of Cesium in Phases Prodused by Grouted Waste Injection," pp. 521-26 in Scientific Basis for Nuclear Waste Management VII, proceedings of meeting held in Boston on Nov. 13-18, 1983, ec. G. L. McVay, Materials Research Society Symposium Proceedings, vol. 2ó, 1984.

G. M. Stocks and B. L. Gyorffy, "Fermi Surface Driven Concentration Waves in $\mathbf{C L}_{\mathrm{C}_{1}} \mathbf{P d}_{1-r}$ and $\mathrm{AB}_{\mathrm{B}} \mathrm{Pd}_{1, c}$ Random Alloys, " abstract, Bull. Am. Phys. Soc. 28(3), 529 (March 1983).

R. W. Swindeman, "Response of Ferritic Steels to Nonsteady Loading at Elevated Temperatures," pp. 31-42 in Research on Chrome-Moly Steels, proceedings of 1984 Pressure Vessels and Piping Conference and Eauibition held in San Antonio, Tex., on June 17-21, 1984, MPC-21, ed. R. A. Swift, American Society oi Mechanical Engineers, New York, 1984.

R. W. Swindeman, M. K. Booker, and W. J. McAfee, Desixn Methodology and Materials Dala Base for Solvent Refined Coal Disso.ver Vessels, ORNL/TM-8577, August 1983. 
R. W. Swindeman, K. Farrell, and J. B. Conway, -Time-Dependent Fatigue of Type 304 Stainless Steel Containing Microvoids in the Starting Microstructure," pp. 121-37 in Thermal and Environmental Effect: in Fatigue: Research-Design Interface, proceodings of Fourth National Congress on Pressure Vessel and Piping Technology held in Portland, OTe., on June 19-24, 1983, PVP vol. 71, ed. C. E. Jaske, S. J. Hudak, Jr., and M. E. Mayfield, American Society of Mechanical Engineers, New York, 1983.

R. W. Swindeman and C. W. Houck, Metallographic Examinations of Type 304 Stainless Steel (Heat 9T2796) Tested in High-Temperature Liniaxial and Multiaxial Experiments, ORNL-6013, March 1984.

R. W. Swindeman and J. Moteff, "Correlation of Rupture Life, Creep Rate, and Microstructure for Type 304 Stainless Steel," pp. 1-11 in Nonlinear Constitutive Relations for High Temperature Applications, proceadings of symposium held in Akron, Ohio, on May 19-20, 1982, NASA Conf Publ. 2271, National Aeronautics and Space Administration, 1983.

R. W. Swindeman, V. K. Sikka, and R. L. Klueh, "Residual and Trace Element Effects on the High-Temperature Creep Strength of Austenitic Stainless Steels, Metall. Trans. A 14A, 581-93 (April 1983).

R. W. Swindeman and B. C. Williams, "Fatigue of Bainitic $21 / 4 \mathrm{Cr}-1$ Mo Steel Weldments at $482^{\circ} \cong$, paper 84-PVP-57, presented at ASME Pressure Vessel and Piping Division Conference held in San Antonio. Tex., on June 20, 1984.

Z. Szotek, B. L. Gyorffy, G. M. Stocks, and W. M. Temmerman, "On the Positron Annihilation Process in $\mathrm{Ni}_{c} \mathrm{Cu}_{1-c}$ Alloys," pp. 251-53 in Positron Annihilation, proceedings of Sixth International Conference held in Forth Worth, Tex., on Apr. 3-7, 1982, ed. P. G. Coleman, S. C. Sharma, and L. M. Diana, North Holland Publishing Company, Elsevier, New York, 1982.

V. J. Tennery, "United States Ceramic Heat Exchanger Technology Status ind Opportunities," pp. 507-19 in Heat Exchangers: Theory and Practice, proceedings of Seminar of International Centre for Heat and Mass Transfer: Advancement ir. Heat Exchangers held in Dubrovnik, Yugoslavia, on Sept. 7-12, 1981, ed. J. Taborek, G. C. Hewitt, and N. Afgan, Hemisphere Publishing Corp., New York, 1983.

V. J. Tennery, C. B. Finch, C. S. Yust, and G. W. Clark, "Structure-Property Correlations for $\mathrm{TiB}_{2}$-Based Ceramics Densified Using Active Liquid Metals," pp. 891-909 in Science of Hard Materials, proceedings of International Conference held in Moran, Wyo., on Aug. 23-28, 1981, ed. R. K. Viswanadham, D. J. Rowcliffe, and J. Gurland, Plenum Press, New York, 1983.

V. J. Tennery, C. L. White, R. A. Padgett, and C. B. Finch, "Auger Electron Spectroscopy Analyses of Fracturs Surfaces in $\mathrm{TiB}_{2}$ Ceramics," pp. 312-24 in Character of Grain Boundaries, proceedings of Irie-national Symposium on Grain Boundaries and Interfaces in Ceramics held in Cincinnati on May 4.5, 1982, vol. 6, ed. M. F. Yan and A. H. Hauer, Advances in Ceramics, American Ceramic Society, Columbus, Ohio, 1982.

P. F. Tortorelli and J. H. DeVan, "Compatibility of Stainless Steel with Pb-17 at. Pct Li," J. Mater. Energy Syst. 4(2), 78-83 (September 1982).

P. F. Tortorelli and J. H. DeVan, "Corrosion of Fe-Ni-Cr Alloys in Thermally Convective $\mathrm{NaNO}_{3}-\mathrm{KNO}_{3}$," pp. 122-23 in Extended Abstracts, vol. 82-2, Electrocheinical Sociciy Fall Meeting held in Detroit on Oct. 17.21, 1982.

P. F. Tortorelli and J. H. DeVan, "Corrosive Effects of a Lithium Environment," Fp. 53-54 in Extended Atstracts, vol. 82 1, Electrochemical Society Spring Meeting held in Montreal on May $914,1982$.

J. M. Vitek, A. DasGupta, and S. A. David, "Microstructural Podification of Austenitic Stainless Steels by Rapid Solidification," Metall. Trans. A 14A, 183341 (September 1983).

J. M. Vitek and R. L. Klueh, "Precipitation Reacions During the Heat Treatment of Ferritic Steels," Metall. Trans. A 14A, 104755 (1983). 
F. G. Waelbroeck, J. Winter, P. Wienhold, K. Kornen, T. Banno, L. Grobusch, E. Rota, K. G. Tschersich, and R. E. Clausing, "First Wall Conditioning of TEXTOR." pp. 693-705 in Proceedings of the Ninth International Vacuum Congress and Fifth International Conference on Solid Surfaces, Madrid. Spain, September 26-30, 1983, ed. J. L. de Segovia, Instituto de Fisica de Materiales, Madrid, 1983.

G. C. Wei, "Beta SiC Powders Produced by Carbothermic Reduction of Silica in a HighTemperature Rotary Furnace," J. Am. Ceram. Soc. 66(7), C-111-13 (July 1983).

P. Weightman, P. T. Andrews, G. M. Stocks, and H. Winter, -A Siudy of the Band Structures

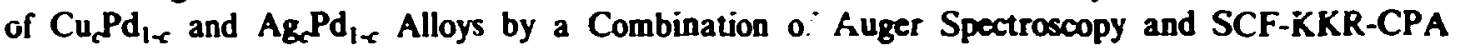
Calculations, " p. 24 in Informal Newsletter Associated with Collaborative Computational Project No. 9 on El_etre.jic Structure of Solidi, No. 5, ed. P. Strange and W. Temmerman, January 1983, published by Daresbury Laburatory, Daresbury, Warrington WA4 4AD, England, 1983.

P. Weightman, P. T. Andrews, G. M. Stocks, and H. Winter, "Band-Structure Effects on the

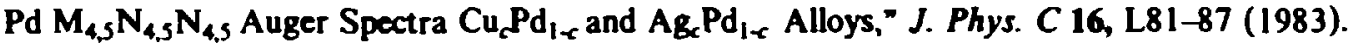

J. R. Weir, Jr., J. E. Cunningham, and Irene Brogden, Metals and Ceramics Division Propress Report for Period Ending December 31, 1982, ORNL-5943, April 1983.

C. L. White, L. Hieatherly, and R. A. Padgett, "Thorium Segregation to Grain Boundaries in Ir $+0.3 \%$ W Alloys Containing 5-1000 ppm Thorium," Acta Metall. 31, 111-19 (1983).

C. L. White and R. A. Padgett, "Effects of Antimony Additions on the Fracture of Nickel at $600^{\circ} \mathrm{C}, "$ Acta Metall. 31 (7), 1005-12 (1983).

C. L. White, J. H. Schneibel, and R. A. Fadgett, "High Temperature Embrittlemen* of Ni and Ni-Cr Alloys by Trace Elements," Metall. Trans. A 14A, 595-610 (Arril 1983).

C. L. White, J. H. Schneibel, and M. H. Yoo, "Sulfur and Antimony Segregation to Ereep Cavity Suifaces in Ni and an FCC Fe-Ni-Cr Alloy," pp. 347-58 in Proceedings of Second International Conference on Creep and Fracture of Engineering Materials and Structures held in Swansea, England, on Apr. 1-6, 1984, Pineridge Press, Swansea, Engiand, 1984.

F. W. Wiffen, comp., Alloy Development for Irradiation Performance Semiannual Progress Report for Period Ending September 30, 1983. DOE/ER-0045/11.

F. W Wiffen, "Insulators for the TF Coils of Fed-R," pp. 23.1-.4 in Proceedings of $t^{2}$ ? Second Meeting on Electrical Insulators for Fusion Magnets, Germantown, Maryland, September 8-9. 1983, CONF-8209153, U.S. Department of Energy, July 1983.

F. W. Wiffen and J. A. Spitznagel, eds., Advanced Techniques for Characterizing Microstructures, The Metallurgical Secinty of AlME, Warrendale, Pa., 1982.

J. M. Williams, C. J. McHargue, and B. R. Appleton, "Structural Alterations in SiC as a Result of $\mathrm{Cr}^{+}$and $\mathrm{N}^{+}$Implantation," Nucl. Instrum. Methods 209/210, 317-23 (1983).

R. K. Williams, W. H. Butler, R. S. Graves, and J. P. Moore, "Experimental and Theoretical Evaluation of the Phonon Thermal Conductivity of Niovium at Intermediate Temperatures," Phys. Rev. B. 28(11), 6316-24 (1983).

R. K. Williams, R. S. Graves, F. J. Weaver, and D. L. McElroy, "The Physical Properties of $9 \mathrm{Cr}-1 \mathrm{Mo}$ Steel from 300 to $1000 \mathrm{~K}$," pp. 219-28 in Thermal Conductivity 17, proceedings of 17th International Conference held in Gaithersburg, Md, on June 15-19, 1981, ed. J. G. Hust, Plenum Press, New York, 1983.

R. K. Williank R. K. Nanstad, R. S. Graves, and R. G. Berggren, "Irradiation Effects on Therma! Conductivity of a Light-Water Reactor Pressure Vessel Steci," J. Nucl. Matcr. 115, 211 IS (1983). 
R. K. Williams, F. W. Wiffen, J. Bentley, and J. O. Stiegler, "Irradiatic I Induced Precipitation in Tungsten Based, W-Re Alloys," Metall. Trans. A 14A, 655-66 (April 1983). (1984:

R. O. Williams, "The Calculation of Coherent Phase Equilibria," CALPHAD \&(i), 1-14

R. O. Williams. "The Relation Between Heats of Mixing of the Liquid and Soid in Metallic Systems," CALPHAD 7(1), 21-26:1983).

R. O. Williams, "The Representation of Thermodynamics and Phase Equilibria of Complex Alloys," CALPHAD 7(3), 175-83 (1983).

R. O. Williams, "Virbrational and Configurational Contributions to the Thermodynamies of Metallic Solutions," CALPHAD \&(2), $135-48$ (1984).

R. O. Williams and A. E. Pasto, "High-Temperature Chemistry of Glass Furnace Atmospheres," J. Am. Ceram. Soc. 65(12), 602-6 (1982).

H. Winter, P. J. Durham, and G. M. Stocks, "Theory of Valence-Band XPS Spectra of Random Alloys: Application to $\mathrm{Ag}_{\mathbf{x}} \mathbf{P d}_{1-\mathrm{s}}$ J. Phys. F 14, 1047-60 (1984).

H. Winter and G. M. Stocks, "Calculation of Self-Consistent Potentials for Substitutionally Disordered Systems with Application to the Ag $_{x}-$ Pd $_{1-x}$ Alloy Series," Phys. Rev. B. 2?(2), 882-904 (1983).

H. Winter and G. M. Stocks, "Charge Self-Consistency in Random Alloys," abstract, Am. Ceram. Soc. Bull. 28(3), 530 (March 1983).

J. Winter, F. Waelbroeck, P. Wienhold, H. G. Esser, L. Könen, T. Banno, E. Rota, and R. E. Clausing, "Surface Conditioning of the TEXTOR Liner and Limiters by Plasmachemical Carbon Deposition," pp. 483-86 in Proceedings of the 1/th European Conference on Controlled Fusion and Plasma Physics, Aachen, Federal Republic of Germany, September 5-9, 1983, vol. 7D, part Ii, Plasma Physics and Controlled Fusion Series, ed. A. Gibson, Institute of Physics, Bristol, England, Pergamon Press, Oxford, England, 1983.

1. L. Yakel, “Atom Distributions in Sigma Phases. I. Fe and $\mathrm{Cr}$ Atom Distributions in a Binar: Sigma Phase Equilibrated at 1063, 1013, and 923 K," Actu Crystallogr. B39, 20-28 (1983).

H. L. Yakel, "Aium Distributions in Sigma Phases. Il. Estimations of Average Site-Occupation Parameters in a Sigma Phase Containing Fe, Cr, Ni, Mo, and Mn," Acta Crystallogr. B39, 28-33 (1983).

D. W. Yarbrough, Assessment of Reflective Insulations' Residential and Commerial Applications, ORNL/TM-8891, October 1983.

D. W. Yarbrough, R. K. Williams, and R. S. Graves, "Transport Properties of Concentrated Ag. ${ }^{n d}$ and $\mathrm{Cu}-\mathrm{Ni}$ Alloys from 300-1000 K," pp. 319-24 in Thermal Conductivity 16, proceedings of 16th International Conference held in Chicago, Ill., on Nov. 7-9, 1979, ed. D. C. Larsen, Plerium Press, New York, 1383.

D. W. Yarbrough, J. H. Wright, D. L. McElroy, and T. F. Scarlan, "Settling of Loose-Fill insulations Due to Vibration," pp. $7 r-14$ in Thermal Insulation, Materials, and Systems for Energy Conservation in the '80s, ASTM -. P 789, ed. F. A. Govan, D. M. Greason, and J. D. McAllister, American Society for Testing anc iaterials, Philadelphia, 1983.

M. H. YoO and H. Trinkaus, "Crack and Cavity Nucleation at Interfaces During Creep," pp. 54761 in Thermal Conductivity 17, proccedings of 17th International Conference held in Gaithersburg, Md., on June 15-19, 1981, ed. J. G. Hust, Plenum Press, New York, April 1983.

C. S. Yust, "Low Speed Sliding Damage in $\mathrm{TiB}_{2}$-Ni Composites," pp. 167-73 in Wear of Marerials 1983, ed. K. C. Ludema, American Society of Mechanical Engineers, New York, 1983.

C. S. Yust and E. L. Long, Jr., "Optical and Electron Microscopy of WC-Co Alloys," Am. Ceram. Soc. Bull. 62(9), 10১9-44 (Septer.aber 1983). 
Appeadix $\mathrm{H}$

PRESENTATIONS AT TECHNICAL MEETINGS

\author{
Compiled by Faye Roseberry
}

Eighth European Thermal Physical Properties Meeting, Baden Baden, West Germany, October 2-7, 1982:

D. L. McElroy, G. Neuer, and R. Tye, "Thermophysical Properties of Industrial Insulators"

American Society for Testing and Materials Committee C16 and N.R.C.C. Seminar on Guarded Hot Plz:e, Quebec, Canada, October 7-8, 1982:

D. L. McElroy," R. S. Graves, D. W. Yarbrough, and J. P. Moore. "A Flat Insulation Tester That Uses an Unguarded Nichrome Screen Wire Heater"

Materials Research Society 1982 Meeting, Boston, Massachusetts, November I -4, 1982:

A. G. Dhere, R. J. Deringelis, ${ }^{*}$ J. Bentley, and P. J. Reucroft, "Structural Characteristics of Cobait Particles in a 9.5\% Co-ZSM-5 Catalyst"

Symposium on First Principles Calculations of Atomic Arrangements, Lattice Vibrations, and Magn stism in Metsls, Institute of Physics, University of London, England, December 20-22, 1982:

B. L. Gyorffy, J. Kollar, A. J. Pindor, J. Staunton," G. M. Stocks, and H. Winter, "SninPolarized Band Theory at Finite Temperatures"

P. Weightman, * P. T. Andrews, G. M. Stocks, and H. Winter, "A Study of the Band Structures of $\mathrm{Cu}_{c} \mathrm{Pd}_{\mathrm{l}-\mathrm{c}}$ ar.d $\mathrm{Ag}_{\mathrm{g}} \mathrm{Pd}_{\mathrm{l}-\mathrm{c}}$. Alloys by a Combination of Auger Spectroscopy and SCFKKK-CPA Calculations"

Seminar, Arizona State University, Tempe, January 14, 1983:

L. K. Mansur, "Mechanisms of Radiation Effects in Structural Materials"

Seventh Annual Conference on Ceramics and Advanced Materials, American Ceramic Society, Cocoa Beach., Florida, January 16-20, 1983:

E. L. Long, Jr.," and C. S. Yust, "Evaluation of Pressure Letdown Valve Trim Materials Used in Coal Liquefaction Plants"

A. J. Moorhead," P. F. Becher, and R. J. Lauf, "Fracture Mechanics Tests of Dispersed Metal-Toughened Aluminas"

Nuclear Regulatory Commission-Industry Steam Generator Tube Degradation Seminar, Palo Alto, California, February 9, 1983:

C. V. Dodd, "Multifr juency Eddy-Current Development for In-Service Inspection of Steam Generator Tubing"

Seminar, Mechanicai Engineering Department, College of Engineering, University of Kentucky, Lexington, February 10, 1983:

R. W. McClung, "An Overview of Nondestructive Testing"

-Speaker 
12th Annual Symposium on Vacuum Science and Technology, Clearwater Beach, Florida, February 14-16,1983:

R. E. Clausing, "Modification of Surfaces in Tokamak Fusion Devices by Exposure to Hydrogen Plasmas"

Seminar, Department of Metallurgical, Chemical, and Polymer Engineering, University of Tennessex, Knoxville, February 22, 1983:

C. J. McHargue, "Ion Implantation Treatment of Ceramic Surfaces"

Seminar, Department of Metallurgical, Chemical, and Polymer Engineering, University of Tennessee, Knoxville, March I, 1983:

H. L. Yakel, "Estimating Site-Occupation Parameters in Sigma Phases and Tau Carbides"

Ilath Annual Meeting of the American Institute of Mining, Metallurgical, and Petroleum Engineers, Atlanta, Georgia, March 6-10, 1983:

J. Bentley* and E. A. Kenik, "Application of Analytical and High-Voltage Electron Microscopy to Defect and Phase Identification in Materials"

I-W/ei Chen and M. H. Yoo," "Nucleation of Intergranular Cavities During Creep"

A. DisGunta* and C. T. Liu, "A Study of the Order-Disorder Transformation in $\left(\mathrm{Ni}_{70} \mathrm{Fe}_{30}\right)_{3}\left(\mathrm{~V}_{98-x} \mathrm{Ti}_{2} \mathrm{Al} \mathrm{l}_{x}\right)$ by Differential Scanning Calorimetry and X-Ray Diffraction"

C. T. Liu, "Alloying Effects on Ordered Intermetallic Alloys"

J. H. Schneibel* and P. M. Hazzlcoine, "The Role of Coble Creep and Interface Control in Superplastic $\mathrm{Sn}-\mathrm{Pb}$ Alloys"

J. H. Schneibel, G. F. Petersen, and C. L. White, "The Improvement of Creep Ductility of $\mathrm{Ni}-20 \% \mathrm{Cr}_{\mathrm{r}}$ by Trace idditions of $\mathrm{Zr}^{n}$

C. J. Sparks, Jr., "Synchrotron Radiation Applied to Materials Science"

L D. Stephenson," J. Bentley, R. B. Benson, Jr., and J. Hirvonen, "Analytical Electron Microscopy of Aluminum Implanted with Molybdenum"

J. M. Vitek" and S. A. David, "Aging Behavier of 308 Stainless Steel Weld Filler Metal"

M. H. Yo," J. C. Ogle, 1-Wei Cher, and J. H. Schneibel, "Deformation-Induced Grain Boundary Cavitation-A Small-Angle Neutron Scai:ering Study"

Meeting of the Advisory Technical Awareness Council, American Society for Metals, Cleveland, Ohio, March 16, 1983:

J. E. Cunningham, "Recent Developments in Graphite”

American Physical Society Meeting, Los Angeles, California, March 21-25, 1983:

W. H. Butler* and G. M. Stncks, "Hall Coefficient of $\mathbf{A g}_{\mathbf{B}} \mathbf{P d}_{\mathrm{I}-\mathrm{x}}$ Alloys"

A. Gonis, ${ }^{*}$ G. M. Stocks, and W. H. Butler, "Local Environment Fluctuations and Densities of States in Substitutionally Disordered Alloys"

D. M. Krocger, C. C. Kach, and J. O. Scarbrough, "Correlations Among Crystallization Beha* Physical Properties, and the Equilibrium Phase Diagram in Glassy Zr-Ni"

D. A. Nicholson, A. Chowdary, and L. Schwartz, "Structure Dependence of Electionic States in Amorphous Metals"

G. S. Painter* and F. W. Averill, "Transition Metal Dimer Studies Within the Local Spin Density Approximation (LSDA) Using an Augmented Gaussian Orbital Approach"

F. J. Pinski" and G. M. Stocks, "Electronic Structure of $\mathrm{Fe}_{\boldsymbol{c}} \mathrm{Ni}_{\mathrm{l} \cdot \mathrm{c}}$ Alloys"

G. M. Stucks* and B. L. Gyorffy, "Fermi Surface Driven Concentration Waves in $\mathrm{Cu}_{c} \mathrm{Pd}_{1, c}$ and $\mathrm{Ag}_{r} \mathbf{P d}_{1, r}$ Random Alloys"

G. M. Stocks" and H. Winter, "Charge Self-Consistency in Random Alloys" 
Technical Seminar on Dynamic Young's Modulus Measurements, sponjored by ASTM Committce E-28 on Mechanical Testing, Louisville. Kentucky, March 24, 1983:

C. R. Kennedy, "Elastic Constants of Graphite"

Meeting on Materials Problems in the Energy Business, sponsored by the American Society for Metals, Rocky Mountain Chapter, and the Colorado School of Mines, Golden, Colorado, March 24-25, 1983:

D. N. Brasti* and S. A. David, "(Fe,Ni) $)_{3}$ Ordered Alloys for Fusion Reactor First Wall"

J. R. Weir, Jr., "Materials and Our Energy Future"

Third Workshop on Metallic Magnetism, Institut von Laue Langevin, Grenoble, France, March 25-26, 1983:

B. L. Gyorfy," J. Kollar, A. J. Pindor, J. Staunton, G. M. Stocks, and H. Winter, "Spin Polarized Band Theory at Finite Temperatures"

Tochnical Meeting of Golden Gate Chapter, American Society for Metals, Merkeley, California, April 4, 1983:

J. M. Vitek, "Solidification and Microstricture of Rapidly Solidified Austenitic Stainless Steels"

Fast Reactor Exchange Meeting, Brighton, England, April 10-15,1983:

M. L. Grossbeck and E. E. Bloom (presented by A. F. Rowcliffe), "In-Reactor Uniaxial Fracture Strain of 20\%-Cold-Worked Type 316 Stainless Steel"

Steam Generator Users Group Meeting, Electr:- Power Research Institute, Palo Alto, California, April 11, 1983:

C. V. Dodd, "Multifrequency Eddy-Current Development for In-Service Inspection of Steam Generator Tubing"

Seminar, University of Virginia, Charlottesville, April 11, 1983:

E. E. Bloom, "Radiation Damage to Fusion Reactor Materials"

International Conference on Dimensional Stability and Mechanical Behavior of Irradiated Metals and Alloys, Brighton, England, April $1 \mathrm{i}-\mathrm{i} 3,1983$ :

K. Farrell (presented by L. K. Mansur), "Response of Aluminum and Its Alloys to Exposure in the High Flux Isotop. Reacior"

M. L. Grossbeck and E. E. Bioom (presented by A. F. Rowcliffe), "In-Reactor Uniaxial Fracture Strain"

L. K. Mansur" and W. A. Coghlan, "Relationships of Irradiation Creep to Swelling Implicit in the Theories of These Processes"

A. F. Rowcliffe" and E. H. Lee, "The Stability of the MC Phase in a Stainless Steel Irradiated in Various Environments"

International Conference on Wear of Materials, sponsored by the American Society of Meshanical Engineers, Reston, Virginia, April 11-14, 1983:

C. S. Yust, "Low Speed Sliding Damage in TiB 2 -Ni Composites"

Meeting of Study Group on Critical and Strategic Materials, Idaho National Engineering Laboratory, Idaho Falls, Idaho, April 12-13, 1983:

C. J. McHargue, "Basic Energy Sciences-Materials Sciences Program Elements Dealing with Strategic-Critical Materials at Oak Ridge National Laboratory"

C. J. McHargue, "Chromium, Substitution in Alloys"

C. J. McHargue, "Opportunities for Surface Modification - Ceramics" 
Symposium on Advances in Materials Analysis, American Society ior Metals, Oat Ridge Chapter, Oak Ridge, Tennessee, April 15, 1983:

J. Bentley, "Electron Diffraction Techniques in an Analytical Flectron Micrix sope"

C. J. Sparics, Jr., "Synchrotrou X-Radiation Applied to Materials Characterization"

Seminar, Massachusetts Institute of Technology, Cambridge, April 15, 1983:

M. H. Yoo, "Precipitation and Cavitation Studies Using Small-Angle Neutron Scattering"

Seminar, International Business Machines, Yorktown Heights, New York, A pril 18, 1983:

M. H. Yoo, "Precipitation and Cavitation Stuwies Using Small-Angle Neutron Scattering"

Seminar, Berkeley Nuclear Laboratories, Berkeley, England, April 19, 1983:

L. K. Mansur, "Progress in the Theoretical Understanding of Helium Interaction with Microstructural Evolution"

Seminar, Atomic Energy Research Establishment, Harwell, England, April 20, 1983:

L. K. Mansur, "Progress in the Theoretical Understanding of Helium Interaction with Microstructural Evolution"

85th Annual Meeting of the American Ceramic Society, Chicago, Illinois, April 24-27, 1983:

P. F. Becher," M. K. Ferber, and B. G. Koenke, "Slow Crack Growth Behavior in Anisotropic Polycrystalline Ceramics"

J. Bentley, P. Angelini, and P. F. Becher, "Analytical E! $*$ ron Microscopy of $\mathrm{Al}_{2} \mathrm{O}_{3}$ Toughened with $\mathrm{Y}$-Doped $\mathrm{ZrO}_{2}{ }^{\text {" }}$

C H. Carter, Jr.," R. F. Davis, and J. Bentley, "Kinstics and Mechanisms of Creep in CVD Silicon Carbide"

G. W. Clark" and P. F. Becher, "Eutectic-Like Morphology and Fracture Toughness of $\mathrm{ZrO}_{2}\left(\mathrm{Y}_{2} \mathrm{O}_{3}\right)-\mathrm{ZrB}_{2}=$

A. DasGupta" and Y. T. Chou, "Flux Pinning by Surfaces and Interfaces in Type-II Superconductors"

M. K. Ferber* and P. F. Becher, "Temperature Dependence of Static Fatigue in Pciycr;'stal:" re BeO"

M. K. Furber and V. J. Tennery," "Analysis of the Corrosion Products Formed from Reactions Between Silicon Carbide and a Fluid Coal Slag"

L. A. Harris, C. R. Kennedy, and F. P. Jeffers, "A Study of Silicon Carbide Powder Agglomerates"

F. J. Homan* and M. J. Kania, "Particle Design and Fabrication Influences on HTGR Fuel Performance"

C. J. McHargue and C. S. Yust, "Lattice Modifications in Ion-Implanted Ceramics"

D. P. Stinton," E. W. McDaniel, and H. O. Weeren, "Detailad Characterization of Hydrofracture Grouts Revealed No Migration of Radionuclides"

G. C. Wei, "Synthesis and Characterization of SiC Powder"

64th Annual American Welding Society Meeting, Philadelphia, Pennsylvania, April 24-29, 1983:

S. A. David, C. T. Liu, D. N. Braski, and G. M. Goodwin, "Weiding and Associaled Phase Transition in Ductile Long-Range-Ordered Alloys"

R. L. Klueh" and J. F. King, "A Simple Test for Dissimilar-Metal Welds"

V. K. Sikka, J. F. King, and V. Biss, "Weldability and Microstructure of Modified $9 \mathrm{Cr}-1$ Mo Steel"

J. M. Vitek" and S. A. David, "The Aging Behavior of Types 308 and 308CRE Stainless Steel Weld Metal" 
Fifth Topical Meeting on the Technology of Fusion Energy, Knoxville, Tennessee, April 26-28, 1983:

J. H. DeVan* and P. F. Tortorelli, "Materials Compatibility for a Fusion-Fission Hybrid Reactor Design"

R. W. McClung," K. V. Cook, C. V. Dodd, and J. H. Smith, "Nondestructive Teating of Metallic Sheath for Superconoucting Cable"

Meeting of the National Board of the American Society of Mechanical Engineers, Vancouver, British Columbia, Canada, May 2, 1983:

P. Patriarca, "Advances in the U.S. Liquid Metal Fast Breeder Reactor Program"

Seminar, University of Caiffornia, Santa Barbara, May 2, 1983:

J. Bentley, "Modern Electron Diffraction Techniques"

Meeting of the American Society for Metals, Birmingham Chapter, Birmingham, Alabama, May 3, 1983:

R. J. Gray "Novel Metallographic Techniques for Analyses of Microstructures"

Electrochemical Society High-Temperature Materials Chemistry Conference, San Francisco, California, May 8-13, 1983:

R. J. Lauf* and J. B. Bates, "Ceramic-Metal Solid Electrolytes"

R. J. Lauf" ard L. A. Harris, "Behavior of Mineral Matter During Coal Combustion"

C. T. Liu, C. C. Koch, and C. L. White, "Prcparation of Ductile Nickel Aluminides for High-Temperature Uses"

Meeting of American Society for Nondestructive Testing, Oak Ridge Section, Oak Ridge, Tennessec, May 10, 1983:

R. W. McClung, "P.ecent Nondestructive Testing Activities at Oak Ridge National Laboratory"

Informal workshop sponsored by the American Society for Testing and Materials Committee E9.08 on Recommended Practice E600, Louisville, Kentucky, May 10, 1983:

R. W. Swindeman, "Effect of Specimen Geometry on Low-Cycle Fatigle Behavior of Steels" American Society for Testing and Materials Spring Meeting, Louisville, Kentucky, May 11, 1983:

K. C. Liu" and M. L. Grossbeck, "Fatigue Testing of Irradiated Specimens at Elevated Temperature and in High Vacuum"

Seminar, University of Tennessee Veterinary Teaching Hospital, College of Veterinary Medicine, University of Tennessee, Knoxville, May 16, 1983:

R. J. Gray, "A Metallurgical Survey of the Causes of Failed Implants from the Human Body"

Fusion Technology Course, Department of Nuclear Ergineering, University of Tenressee, Knoxville, May 16-18, 1983:

J. L. Scott, "Materials Problems”

Leco Corporition Symposium on Metallography in Fai ure Analysis, Fort Lasiderdale, Florida, May 19 20, 1983:

R. S. Crouse, "Electron Beam Microanalysis and Failure Studies"

R. J. Gray, "Metallographic Studies of Failed Implants from the Human Body"

Meeting of German Society for Metals, Erlangen, Germany, May 24-27, 1983 :

G. L. Copeland" and J. L. Stielgrove, "Post Irradiation Evaluation of Irradiated High-U. Loaded $\mathrm{U}_{3} \mathrm{O}_{8}$-Al Fuel Plates" 
Second International Conference on Radiation Effects in Insulators, Albuquerque, New Mexico, May 30-June 3, 1983:

B. R. Appleton, N. Naramoio, C. W. White, O. W. Holiand, C. J. McHargue, G. Farlow, J. Marayan, and J. M. Williams, "Ion Implantation, Ion Beam Mixing, and Annealing Studies of Metals in $\mathrm{Al}_{2} \mathrm{O}_{3}, \mathrm{SiC}$, and $\mathrm{Si}_{3} \mathrm{~N}_{4}$

C. J. McHargue," P. S. Sklad, P. Angelini, and M. B. Lewis, "Microstructure and Properties of TiB 2 Implanted with 1 MeV Niciel"

P. S. Sklad, P. Angelini, M. B. Lewis, J. T. Houston, and C. J. McHargue," “Analytical Electron Microscope Observations of the Microstruciure of $\mathrm{TiB}_{2}$ Implanted with $1 \mathrm{MeV}$ iviciel"

Department of Entrgy Symposium on Electroslag Component Casting, Morgantown, West Virginia, June 1-2, 1983:

R. L. Heestand, "Description of Electroslag Processes (Remelting, Welding, and Casting)"

R. R. Judkins, "The Electroslag Component Casting Project Plan"

V. K. Sikka, "Mechanical Properties of Electroslag Castings"

Conference on Crack Tip Structure and Processes, National Bureau of Standards, Washington, J.C., June 6-8, 1983:

M. H. Yoo, H. Trinkaus, and I-W. Chen, "Cavity Nucleation During High-Temperature Deformation"

First Annual Meeting of Building Thermal Envelope Coordinating Council, Washington, D.C., June 7, 1983:

T. S. Lundy, -Status of the National Program for 'Building Thermal Envelope Systems and Insulating Materials (BTESIM)"

57th Colloid and Surface Science Symposium, University of Toronto, Toronto, Ontario, Canada, JL .re 12-15, 1983:

P. J. Reticroft," R. J. DeAngelis, A. G. Dhere, and J. Bentley, "Meta!-Supporı Interactions in Dispersed Metal Catalysts"

American Nuclear Society Spring Meeting, Detroit, Michigan, June 12-17, 1983:

R. G. Berggren" and F. W. Stallman, "Statistical Analysis of Pressure Vessel Steel Embrittlement Data"

W. P. Eatheriy* and C. B. Engle, "Recent Developments in Graphite for HTGR Applications

M. J. Kania* and F. J. Homan, "Irradiation Performance of LEU Fuel Particle Designs"

International Symposium on Structure-Property Relatinnships for $\mathrm{MgO}$ and $\mathrm{Al}_{2} \mathrm{O}_{3}$, Massachusetts Institute of Technology, Cambridge, June 13-16, 1983;

P. Angelini, P. S. Sklad, J. Bentiey, and C. J. Mchargue, "Analytical Electron Micruscopy of Ion-Implanted $\mathrm{Al}_{2} \mathrm{O}_{3}{ }^{n}$

J. Bentley, P. Angeiini," and P. F. Becher, "Characterization of Aluniza Toughened with Yutria-Doped Zirconia by Analytical Electron Microscopy"

Heavy-Secion Steel Technology Program Vessel Integrity Review Group Meeting, Oak Ridge, Teri:essec, : ine 14, 1983:

W. R. Corwin, "HSST Materials Investigations"

Seminar, Joint Research Center, Petten, Netherlands, June 16, 1983:

M. L. Grossheck" and E. E. Blonm, "In-Reactor Uniaxial Fracture Strain of 20\%-ColdWorked Tyre 316 Stainless Steel" 
Topical Conference on Ferritic Alloys for Use in Nuclear Energy Technologies, Snowbird, Utah, June 19 23, 1983:

L. L. Horton" and J. Bentley, "Swelling Behavior of a Simple Ferritic Alloy"

R. L. Klueh" and J. M. Vitek, "Tensile Propeties of Three Commercial Ferritic Steels After Low-Temperature Irradiation"

P. Patriarca, "Use of Ferritic Steels in Brecoler Reactors Worldwide"

V. K. Sikka, "Developmint of a Modified $9 \mathrm{Cr}$-l Mo Steel for Elevated-Temperature Service"

V. K. Sikka," M. G. Cowgill, and B. W. Roberts, "Creep Properties of Modified 9 Cr-l Mo Steel"

P. F. Tortorelli* and J. H. DeVan, "Corrosion of an Fe-12 Cr-1 MoVW Steel in Thermaliy Convective Lithium"

J. M. Vitek* and R. L. Klueh, "Microstructure of HFIR-Irradiated 12 Cr-1 MoVW Ferritic Steeln $^{\text {n }}$

F. W. Wiffen" and R. T. Santoro, "Control of Activation Levels to Simplify Waste Management of Fusion Reactor Ferritic Steel Components"

American Society of Mechanical Engineers Fourth National Congress on Pressure Vessels and Piping, Portland, Oregon, June 19-24, 1983:

R. W. Swindeman," K. Farrell, and J. B. Conway, "Time-Dependent Fatigue Behavior of Type 304 Stainless Steel Containing Microvoids in the Sterting Microstructure"

Seminar, Centre d'Études Nucléaires, Mol, Belgium, June 20, 1983:

M. L Grossbeck" and E. E. Bloom, "In-Reactor Uniaxial Fracture Strain oi 20\%-ColdWorked Type 316 Stainless Steel"

Gordon Resea:ch Conference on Physical Metallurgy, Plymouth, New Hampshire, June 20-24, 1983:

C. T. Liu, “Mechanical Properties of Ordered Intermetallic Alloys”

Workshop on Evaluation of Simulation Techr que for Radiation Damage in 'ne Bulk of Fusion First-Wall Materials, Swiss Federal Institute for Reactor Research, Interlaken, Switzerland, June 27-30, 1983:

M. L. Grossbecik, "Investigation of Fusion Reactor Candidate First-Wall Materials Usi $1 \mathrm{~g}$ Mixed-Spectrum Fissio ! Reactors"

Fusion Reactor Faculty Wr:kshop, sponsored by Oak Ridge Associated Universities and U.S. Department of Energy, Oak Ridge, Tennessee, June 27-July I, 1983:

J. L. Scott, "Materials"

Naval Tribology Workshop, Annapolis, Maryland, June 28-30, 1983:

J. A. Carpenter, Jr. (preserted by M. B. Peterson), "Overview of the Tribology Project of the Department of Energy (DOE) Energy Conversion and Utilization Technologies (ECUT) Program"

NATO Advanced Study Institute on Surface Engincering, Les Arcs, France, July 3-16, 1983:

C. J. McHargue," B. R. Appleton, and C. W. White, "Structure Property Relationships in Ion-Implanted Ciramics"

Semisuar, Joint Research Center, Ispra, Italy, July 4, 1983:

M. L. Grossbeck" and E. E. Bloom, "In-Reactor Uniaxial Fracture Strain of 20\%-ColdWorked Type 316 Stainless Steel* 
American Carbon Society Carbon Confirence, San Diego, California, July 16, 1983:

C. R. Kennedy, "The Effect of Steam Oxidation on the Fracture Mechanies of Graphite"

C. R. Kennedy. W. P. Eatherly, ano D. Minderman, "A Comparison of the Characteristics of Graphites Irradiated at 600 and $900^{\circ} \mathrm{C}^{\prime \prime}$

Symposium on Energy Removal and Particle Control in Toroidal Fusion Devices, Princeton Plasma Physics Laboratory, Princeton, New Jrrsey, July 26-29, 1983:

R. E. Clausing, F. Waelbroech, J. Winter, P. Weinhold, L. Könen, and N. Noda, EEffects of

Wall Conditioning on Plasma Parameters, Impurities and Hydrogen Recycling in TEXTOR*

16th Annual International Metallographic Society Technical Meeting, Calgary, Alberta, Canada, July 27-28, 1983:

R. J. Gray" and R. S. Crouse, "Metallographic Examination of a Broken 1/4-in.-ID Type 304L Stainless Steel Pipe in the Weld Area from a Chemical Dissolvar Vessel"

R. J. Gray, * R. K. Holbert, and T. H. Thrasher, "Micrustructural Analysis of Series 300 Stainless Steel Welds and Tensile Specimens"

J. R. Keiser" and A. R. Olsen, "Corrosion Studies in Coal Liquefaction Plants"

P. F. Tortorelli" and J. H. DeVan, "Effects of a Flowing Lithium Environment on the Surface Morphology and Composition of Austenitic Stainless Stecl"

New Rings Workshop, Stanford Synchrotron Radiation Laboratory, Stanford, California, July 27-29, 1983:

G. E. Ice, "Near Threshold Electron Spectroscopy"

41st Annual Electron Microscopy Society of America Meeting, Phoenix, Arizona, August 6-12, 1983:

P. Angelini,* J. Bentley, C. B. Finch, and P. S. Sklad, "Microstructure of TiB 2 Liquid Phase Sintered with $\mathrm{Ni}_{3} \mathrm{Al}^{\prime \prime}$

P. Angelini, G. L. Lehman," and J. Brynestad, "Microstructure of Highly Reactive Submicrometer $\mathrm{TiB}_{2}$ Powders"

J. Bentley,* L. D. Stephenson, R. 2. Benson, Jr., and P. A. Parrish, "In Situ Annealing of Aluisinum Ion Implated with Molybdenum"

D. N. Braski, P. D. Godell, J. V. Cathcart, and R. H. Kane, "The Oxidation of Inconel Alloy MA754 at Low Oxidation Potential"

G. C. Hadjipanayis and L. L. Horton," "Lorentz Electron Microscopy of Rare-Earth Permanent Magnets"

J. A. Horton, C. C. Koch, and C. T. Liu, "Segregation and Domain Structure in Rapidly Solidified $\mathrm{Ni}_{3} \mathrm{Al}^{\mathrm{*}}$

L. L. Horton" and K. Farrell, "Comparison of Damage Microstructures in Neutron-Irradiated Vanadium and Iroi"

E. A. Kenik" and E. H. Lee, "Radiation Damage and Phase Instability in Irradiateo Stainless Steel"

R. J. Lauf, "Irradiation Behovior of Pyrolytic Silicon Crrbide"

P. J. Maziasz, "Identification of Preferential Polishing Effects Using Broad Probe AEM"

P. J. Maziasz" and G. R. Odette, "Wide Area-Peain' Averaged AEM of Precipitate Particles Extracted on Repiicas from Type 316 Stainless Steel"

P. S. Sklad," P. Angelini, M. B. Lewis, J. T. Houstun, and C. J. McHargue, "Analytical Electron Microscopy of $\mathrm{TiB}_{2}$ Implanted with $1 \mathrm{MeV}$ Nickel"

L. D. Stephenson, J. Bently, R. B. Benson, Jr., and P. A. Parrish, "Analytical Electron Microscopy of Aluminum Ion Implantet with Molybdenum" 
Review of Progress in Quancitative NDE, University of of California, Santa Cruz, August 7-12, 1983:

W. A. Simpson, Jr., and R. W. McClung, -Ultrasonic Characterization of Advanced Composite Flywhecls"

Symposium on Refractory Alloy Technology for Space Nuclear Power Applications, Technical Informaiion Center, Oak Ridge, Tennessee, August 10-11, 1983:

F. W. Wiffen, -Effects of Irradiation on Properties of Refractory Alloys with Emphasis on Space Power Reactor Applications"

Fifth International Conference on Liquid and Amorphous Metals, University of California, Los Angeles, August 15-23, 1983:

D. M. Kroeger, C. C. Koch, G. C. McKamey, and J. O.Scarbrougn, "The Effect of Chemical Short Range Ordering on Crystailization of $\mathrm{Zr}$-Ni Glasses"

D. M. Kroeger, C. C. Koch, J. O. Scarbrough, and G. C. McKamey, "Stability and Electronic Properties of Zr-Ni Glasses"

Seventh International Conference on High Voltage Electron Microscopy, Berkeley, California, August 16-19, 1983:

E. A. Kenik, "Dynamic Recording System for HVEM In Situ Studies"

E. A. Kenik, R. Crooks, and E. A. Starke, "In Situ Deformation and Fracture Studies on Precipitation-Hardened Aluminum Alloys"

18th Intersociety Energy Conversion Engineering Conference, Orlando, Florida, August 21-26, 1983:

T. S. Lundy, "Building Envelope Research Utilization"

Meeting of L. H. Roddis, Jr., Chairman, Energy Research Advisory Board to the U. S. Department of Energy, with the ORNL Fusion Energy Division, Y-12 Plant, Oak Ridge, Tennessee, August 23, 1983:

J. L. Scott, "Bulk Materials"

Seminar, lowa State University-Ames Laboratory, Ames, August 30, 1983:

A. DasGupta, "Metallic Glasses and Rapidly Quenched Crystalline Alloys - Some Studies"

American Society for Nondestructive Testing Section Meeting, Nashville, Tennessee, September 12, 1983:

J. H. Smith, "Basic Introduction to Nondestructive Testing"

Physical and Chemical Energy Strrage Contractors' Annual Review Meeting, Arlington, Virginia, September 12-14, 1983:

L. A. Harris (presented by Mitchell Olszewski), "Structural Properties of Composite TES Media"

U.S. Department of Energy Third National Conference on Synchrotron Radiation Instrumentation, Brookhaven National Laboratory, Upton, N.Y., September 12-14, 1983:

G. E. Ice" and C. J. Sparks, Jr., "Focusing Optics for a Synchrotron X-Radiation Microproben

Third Topical Meeting on Fusion Reactor Materials, Albuquerque, Now Mexico, September 19-22, i983:

D. N Braski, "Micrnstructure and Bend Ductility of an ( $\mathrm{Fe}, \mathrm{Ni}$ ), $\mathrm{V}$ Alloy Irradiated in HFIR"

D. N. Braski* and P. J. Maziasz, "Tensile Properties of Unirradiated PCA from Room Temperature to $70^{\circ} \mathrm{C}^{\prime \prime}$ 
R. E Clausing* and L. Heatherly, "Surface Composition Changes of Inconel 625 During RG and ECR Glow Discharge Cleaning of TEXTOR at $300^{\circ} \mathrm{C}^{\circ}$

W. A. Coghlan" and L. K. Mansur, "Critical Radius for Cavities Containing a Van der Waals Gas"

W. R. Corwin,* R. L. Klueh, and J. M. Vitek, "Effect of Specimen Size and Nickel Content on the Impact Properties of 12 Cr-I MoVW Ferritic Sicel"

M. L. Grossbeck* and K. C. Lid, "Fatigue Behavior at $650^{\circ} \mathrm{C}$ of $20 \%-C o l d-W o r k e d ~ T y p e ~ 316$ Stainless Steel Irradiated at $550^{\circ} \mathrm{C}$ in the HFIR"

M. L. Grossbeck" and K. C. Liu, "Fatigue Performance of HFIR-Irradiated Nimonic PE-16 at $430^{\circ} \mathrm{C}^{-}$

A. Hishinuma, N. H. Packan," E H. Lee, and L. K. l iansur, "Effects of Pulsed and/or Dual Ion Irradiation on Microstructural Evolution in Ti and Si Modified Austenitic Alloys"

L. L. Horton" and K. Farsell, "A TEM Study of Neutron-Irradiated Vanadium"

L. L. Horton" and K. Farrell, "The Temperature Dependence of the Damage Microstructures in Neutron-Irradiated Vanadium"

R. L. Klueh" and M. L. Grossbeck, "A Comparison of the Irradiated Tensile Properties of a High-Manganese Austenitir. Steel and Type 316 Stainless Steel"

E. H. Lee," L. K. Aifansur, and A. F. Rowcliffe, "The Effect of Phosphorus on the Swelling and Precipitation Behavivr of Austenitic Stainless Steels During Irradiation"

K. C. Liu and C. M. Loring, Jr. (presented by R. L. Klueh), "Low-Cycle Fatigue Behavior of Oxygen-Free High-Conduct ivity Copper at $300^{\circ} \mathrm{C}$ in High Vacuum"

R. F. Mattas, F. A. Garner, Mi. L. Grossbeck, P. J. Mariarz, G. R. Odette, and R. Stoller, "The Impact if Swelling on Fusion Reactor First Wall Jifetime"

P. J. Maziasz, "Anticipating Fusion Swelling Resist'nce for Austenitic Stainless Steels Based on Fission Reactor Data"

P. J. Maziasz, "Com sarison of Dislocation and Precipitation Evolution for Type 316 Stainless Steel Irradiated in EBR-II and HFIR"

P. J. Maziasz, "Comparison of Swelling and Cavity Microstructural Development for Typc 316 Stainless Steel Irraated in EBR-II and HFIR"

P. J. Maziasz, "Swelling and Swelling Resistance Possibilities of Austenitic Stainless Steel it Fusion Reactors"

P. J. Maziasz" and D. N. Braski, "Alloy Development Summary for Path A Prime Candidate Alloy: Grain Bounaary Microstructural Development and Stability Under HFIR Irradiation"

P. J. Maziasz" and D. N. Braskj, "Alloy Development Summary for Path A Prime Candidate Alloy: Swelling and Microstructural Development Under HFIR Irradiation"

P. J. Maziasz," and D. N. Braski, "Improved Swelling Resistance for PCA Austentic Stainless Steel Under HFIR Irradiation Through Microstructural Control"

K. Miyahara, iN. H. Packan, and N. Igata, "The Effect of Pulsed Irradiation on Void Swelling of a Pure Austenitic Al:oy"

N. H. Packan, "Temperature Aspects of Pulsed Ion Bumbardment in an Austenitic Alloy"

A. F. Rowcliffe" and M. L. Grossbeck, "Radiation Effects in Austenitic Steeis"

A. F. Rowcliffe* and M. L. Grossbeck, "The Resposise of Austenitic Steels to Radiation Damage"

E. P. Simonen," N. M. Ghoniem, and N. H. Packan, "Pulsed Flux Effects on Radiation Damage" 
P. S. Sklad* and H. Schroeder, "The Effect of Implanted Helium on the Micrsstrusture and

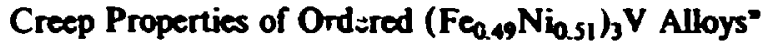

P. F. Tortorelli* and J. H. DeVan, -Mass Transfer Behavior of a Modified Austenitic Stainless Stoel in Lithium"

P. F. Tortorelli* and J. II. Devan, "Surface Analysis of Ferrous Alloys Exposed to Static $\mathrm{Pb}-17$ at. \% $\mathrm{Li}^{\prime}$

J. M. Vitek" and R. L. Klueh, "Microstructure of $9 \mathrm{Cr}-1$ MoVNb Steel Irradiated to $40 \mathrm{dpa}$ at Elevated Tempeiatures in HFIR"

F. W. Wiffen, -FEDC Design of Experimental Fusion Reactors"

F. W. Wiffen,* T. C. Reuther, and R. E Gold, "Summary Report on the DOE-OFE Workshop 'Copper and Copper Alloys for Fusion Reactor Applications"'

Meeting of Amerizan Society for Nondestructive Testing, Chattanooga Section, Chattanooga, Tenressee, September 20, 1983:

J. H. Smith, "Ultrasonic Inspection of Dissimilar-Metal Weld Joints"

American Society for Testing and Materials Sympssium on the Use of Nonstandard Subsized Specimens fer Irradiation Testing. Albuquerque, New Mexico, Septersber 23, 1983:

W. R. Corwin and A. M. Hougland, -Effect of Specimen Size and Material Condition on the Charpy Impact Properties of 9 Cr-1 Mo Steel"

R. L. Klueh" and D. N. Braski, "Disk-Bend Ductility Tests for Irradiated Materials"

K. C. Liu a nd M. L. Grossbeck, "Use of Subsized Fatigue Specimens for Reactor Irradiation Testing"

Advanced Reactor Sessiuns of the ASME-AIEE Joint Power Generator Conference, Indianapolis, Indiana, September 25-29, 1983:

J. A. Horak, "Long-Term Mechanical Propeties of Materials for LMFBR Components"

Ninth International Vacuum Congress and Fifth International Conference on Solid Surfaces, Madrid, Spain, Septemler 26-October 1, 1983:

F. G. Waelbroeck, J. Winier, P. Wienhold, L. Könen, T. Banno, L. Groubusch, E. Rota, K. G. Tschersich, and R. E. Clausing, "First Wall Conditioning of TEXTOR"

American Society for Metals 198 j Metals Congress-The Metallurgica! Society of AIME Fall Meeting, Philadelphia, Pennsylvania, October 1-6, 1983:

J. E. Cunningham, "Fusion Reactor Materials"

J. A. Horton" and C. C. Koch, "Micrnstructural Characterization of Rapidly Solidified and Welded $\mathrm{Ni}_{3} \mathrm{Al}^{\prime \prime}$

Y. L. Hotsur and V. K. Sikka, "Mechanical Properties and Microstructure of an Electroslag"

R. L. Klue., and R. W. Swindeman, "Creep Behavior of a Modified 2 1/4 Cr-1 Mo Steel for Pressure Vessel Applications"

J. H. Schneibel, G. F. Petersen, and M. H. Yo, "Grain Boundary Sliding and Segregation"

J. H. Schneibei" and H. Trinkaus, "Cavitation in the Diff ssional Creep Regime"

R. W Swindeman" and C. W. Houck, "Comparison of Metallographic Techniques for the Examination of Creep-Damaged Type 304 Stainless Steel"

P. F. Tonorelli, J. H. DeVan, and J. R. Keiser, -Oxidation of Fe-Ni-Cr Alloys by Nitrate and Nitrate-Nitrite Salts"

C. L. White" and R. A. Padgett, Jr., "Application of Unusual Metallographic Techniques to the Study of Grain Boundary Cavitation in Nickel + 1\% Sb"

M. H. Yoc, C. L. White, and H. Trinkaus, "Intertacial Segregation and Fracture" 
18th International Confererice on Thermal Conductivity, Rapid City, South Dakota, October 2-6, 1983:

G. L. Copeland, D. L. McElroy, and H. A. Fine, "Insulatioss with Low Thermal Conductivity"

R. S. Graves, D. W. Yarbrough, and D. L. McElroy, "Apparent Thermal Conductivity Measurements by an Unguarded Technique"

J. P. Moore, F. J. Weaver, R. S. Graves, and D. L. McElny," "The Thermal Conductivity and Expansion Enhancemezt Associated with Formation of the Superionic State in $\mathrm{SrCl}_{2}{ }^{*}$

J. P. Moore, F. J. Weaver, and D. L. McEroy," The Thermal Conductivities of $\mathrm{SrCl}_{2}$ and $\mathrm{SrF}_{2}$ from 85 to $400 \mathrm{~K}^{*}$

R. K. Williams," F. J. Weaver, and R. S. Graves, "Transport Properties of Polyctystalline $\mathrm{Ni}_{3} \mathrm{Al}^{*}$

Department of Energy Committee on Synchrotron Radiation Facilities Meeting, Altuquerque, New Mexico, October 8-10, 1983:

C. J. Sparks, Jr.," and G. E Ice, -Requirements on Advanced Storage Rings for an X-Ray Fluorscence Microprobe"

International Atomic Energy Agency International Working Group on Fast Reactors Specialists' Meeting on Mectanical Properties of Structural Materials Including Environmer!al Effects, Chester, England, October 10-14, 1983:

J. A. Horak, V. K. Sikkia, and D. T. Raske, "Review of Mechanical Properties and Microstructures of Types 304 and 316 Stainless Steel After Long-Term Aging"

Seminar, University of Pennsylvania. Phi.udelphia, Uctober 11, 1983:

C. T. Liu, "Recent Development of Ductile Ordered Intermetallis Alloys for High Temperature Use"

Seminar, Tokyo Institute of Technology, Tokyo, Japan, Cetober 13-14, 1983:

W. J. Lackey, "Chemical Vapor Deposition of Ceramic Coatings"

International Symposium on Ceramic Components for Engine, Hakone, Japan, October 17-21, 1983:

W. J. Lackey, D. P. Stinton, G. A. Cerney, L. I. rehrenbacher, and A. C. Schafthauser, "Ceramic Coatings for Heat Engine Materials-Status and Future Needs"

C. S. Yust, "Wear Coefficients and Wear of Sliding Ceramics"

C. S. Yust* and F. J. Carignan, "Damage Processes in Sliding Partially Stabilized Zirconia Pairs"

Department of Energy Materials Directors' Meeting, Los Alamos, New Mexico, October 19-20, 1983:

J. E. Cuaningham, "Solidification and Phase Stability in Austenitic Stainless Steels"

IIth Water Reactor Safety Research Informaticn Meeting, National Bureau of Standards, Gaithersburg, Marylanó, October 24-28, 1983:

C. V. Dodd, "Improved Multifrequency Eddy-Current Testing of Steam Generator Tubing"

Meeting of the Oak Ridge Chapter of the American Vacuum Society, Oak Ridge, Tennessee, October 27, 1983:

G. E. Iec, "New Surface Research Opportunities with Synchrotron Radiation" 
American Ceramic Society Fall Mating, Columbus, Ohio, October 30-November 2, 1983:

P. F. Becher and J. C. Wei." "Toughening Behavior in SiC Whisker Reinforced Alumnia"

C. B. Finch, P. Angelini, P. F. Becher, and J. Brynestad, -Effect of Oxygen and Carbon on the Densification and Grain Size of Hot-Pressed Submicrometer TiB 2 Powders"

G. C. Wei, P. F. Becher, and R. L. Beatty, "Silicon Carbide Whisker Reinforced Aluminum Oxide Composite"

American Institute of Chemical Engineers Diamond Jubilee Meeting, Washington, D.C., October 31-November 4, 1983:

J. R. Keiser, A. R. Olsen, and R. R. Judkins, "Corrosion of Alloys in Direct Coal Liquefaction Systems"

Meeting of American Society for Metals Hudson Valley Ctapter, Nyack, New Jersey, November i, 1983:

G. M. Slaughter, "Brazing and Soldering Technology-Past, Present, and Future"

Fourth International Brazing and Soldering Conference, British Association for Brazing and Soldering, London, England, November 1-3, 1983:

A. J. Moorhead and P. F. Becher," "Wetting and Bonding Behavior in Some Metal-Alumina Systems"

Symposium on Automated Test Methods for Fracture and Fatigue Crack Growth, Pittsburgh, Pennsylvania, November 7-8, 1983:

J. J. McGowan* and J. L. Keating, "A Microprocessor-Based System for Determining NearThreshold Fatigue Crack Growth Rates"

Department of Energy Contractors' Meeting on Heterogeneous Catalysis, National Bureau of Standards, Gaithersburg, Maryland, November 7-9, 1983:

P. J. Reucroft," R. J. DeAngelis, and J. Bentley, "Structural Characterization of Dispersed Metal Catalysts"

21st Automotive Technology Development Contract Coordinators' Meeting, Dearborn, Michigan, November 14-17, 1983:

P. F. Becher" and G. C. Wei, "Transformation Toughened and Whisker Reinforced Ceramics"

A. J. Moorhead," T. N. Tiegs, and R. J. Lauf, "Dispersed Meial-Toughened Ceramics and Ceramic Brazing"

Annual Materials Research Society Meeting, Boston Massachusetts, November 14-18, 1983 :

P. Angelini," P. F. Becher, J. Bentley, C. B. Finch, and P. S. Sklad, "Processing and Microstructural Characterization of $\mathrm{TiB}_{2}$ Liquid Phase Sintered with $\mathrm{Ni}$ and $\mathrm{Ni}_{3} \mathrm{Al}^{\text {" }}$

J. Bentley, L. D. Stephenson, R. B. Benson, Jr., R. A. Parrish, and J. K. Hirvenen, "Second Phase Formation in Aluminum Annealed After Ion Implantation with Molybdenum"

G. W. Clark, "Eutectic Soldification of the Systems $\mathrm{Al}_{2} \mathrm{O}_{3}-\mathrm{TiB}_{2}, \mathrm{Al}_{2} \mathrm{O}_{3}-\mathrm{Z}, \mathrm{B}_{2}, \mathrm{Y}_{2} \mathrm{O}_{3}-\mathrm{TiB}_{2}$, and $\mathrm{ZrO}_{2}-\mathrm{ZrB}_{2}{ }^{\prime \prime}$

G. C. Farlow, C. W. White, C. J. McHargue, and B. R. Apppleton, "Behavior of Implanted Alpha- $\mathrm{Al}_{2} \mathrm{O}_{3}$ in an Oxidizing Annealing Environment"

J. I. Federer and R. J. Lauf," "Crystallization Behavior of Hygas Ash"

R. J. Lauf, "Characterization of the Mineralogy 'nd Michochemistry of Fly Ash"

M. B. Lewis" and C. J. McHargue, "High Energy Ion Beam Mixing in $\mathrm{Al}_{2} \mathrm{O}_{3}$ "

C. J. McHargue," C. W. White, B. R. Appieton, G. C. Farlow, and J. M. Williams, "Jon Beam Modificition of Ceramics" 
P. S. Sklad, " P. Angelini, M. B. Lewis, and C. J. Mchargue, "Microstructural Development of $\mathrm{TiB}_{2}$ Ion Implanted with $1 \mathrm{MeV}$ Nickel"

J. A. Spitznagel, B. O. Hall, N. J. Doyle, R. Jayrom, R. W. Wallace, J. R. Townsend, and M. Miller, "Ic $\perp$ Implantation and Ion Beam Processing of Materials"

D. P. Stinton," E. W. M:Daniel, and H. O. Weeren, "Partitioning of Cesium in Phases Produced by G. suted Waste Injection"

Symposium on An On-Line Materials Property Data Base, American Society of Mechanical Engineers, Boston, Massachusetts. November 15, 1983:

J. J. McGowan, "Use of An On-Line Data Base in Pressure Vessel Design"

Seminar, Henry Kromb School of Mines, Colulmbia University, New York, November 16, 1983:

J. S. Faulkner, "Alloy Theory and Applications"

Symposium on High-Temperature Materials for Coal Conversion and Utilization, Mol, Bilgium, sponsored by the Laboratory of the Studiecentrum voor Kernenergie/Centre D'étude de L'énergie Nucléaire, November 17, 1983:

R. A. Bradley, * R. R. Judkins, and J. P. Hammond, "Materials for Coal Conversion Systems"

Seminar, University of Connecticut, Storrs, November 30, 1983:

S. A. David, -Soldification Behavior, Microstructure, and Modification of Austenitic Stainless Steel Weld Metal"

Japan-U.S. Workshop on Fusion Reactor Materials, Tsukuba, Japan, December S-7, 1983:

L. K. Mansur,* W. A. Coghlan, K. Farrell, L. L. Horton, E. H. Lee, M. B. Lewis, and N. H. Packan, "Fusion-Relevant Basic Radiation Effects-Theory and Experiment"

A. F. Rowcliffe," M. L. Grossbeck, and P. J. Maziasz, "The Response of Austenitic Steels to Radiation Damage*

Seminar, Solid State Physics Department, Universidad Nacional Autónoma de México, Mexico City, December 6, 1983:

J. H. Schneibel, "Creep Cavitation in $\mathrm{Ni}-20 \% \mathrm{Cr}$ and Its Inhibition by Small Additions of Zirconium"

Tenth Institute of Electrical and Electronics Engineers Symposium on Fusion Reactor Technology, Philadelphia, Pennsylvania, December 6, 1983:

E. E. Bloom, T. C. Reuther, and J. L. Scott," "Candidate First-Wall Materials fnr Fusion Reactors"

Seminar, Columbia University, New York, December 7, 1983:

C. T. Liu, "Design of Ductile Ordered Alloys for High-Temperature Structural Uses"

Seminar, Hokkaido University, Sapporo, Japan, December 12, 1983:

L. K. Mansur, "Radiation Effects in Structural Materials"

Electric Power Research Institute Fusion Program Review, Palo Alto, California, December 14-15, 1983:

R. I. Klueh* and J. M. Vitek, "Elevated-Temperature Tensile Properties of Irradiated 2 1/4 Cr-1 Mo Steeln

Seminar, Allied Corporation, Morristown, New Iersey, December 15, 1983:

A. Bleier, "Ceramics Processing and Its Relation to Colloid Science" 
Seminar, Defense Metallurgical Research Laboratory, Hyderbad, India. December 31, 1983-January 1, 1984:

J. A. Carpenter, Jr., -Overview of the Materials and Tribology Projects of the United States Department of Energy (DOE) Energy Conversion and Uilization Technologies (ECUT) Program"

C. T. Liu (presentod by J. A. Carpenter, Jr.), "Recent Development of Ductile Ordered Intermetallic Alloys for High Temperature Use"

Siminar, Indian Institute o! Technology, Madras, India, January 5 and 7, 1984:

J. A. Carpente:, Jr., Overview of the Materials and Tribology Projects of the United States Department of Energy (DOE) Energy Conversion and Utilization Technologies (ECUT) Program"

C. T. Liu (presented by J. A. Carpenter, Jr.), "Recent Development of Ductile C:dered Intermetallic Alloys for High Temperature Use"

Meeting of American Society for Metals Cleveland Chapter, Cleveland, Ohio, January 9, 1984:

G. M. Slaughter, "Materials R \&D for Energy Applications"

Seminar, Indian Institute of Sciences, Bangalore, India, January 9, 1984:

C. T. Liu (presented by J. A. Carpenter, Jr.), "Recent Development of Ductile Ordered Intermetallic Alloys for High Temperature Use"

Seminar, Carnegie-Mellon University, Pịttsburgh, Pennsyivania, January 12, 1984:

S. A. David, "Soldification Behavic:, Microstructure, and Modification of Austenitic Stainless s.eel Weld Metal"

Seminar, Sandia National Laboratories, Albuquerque, New Mexico, January 12, 1984:

C. J. McHa:gue, "lon Implantation and Ceramics"

Eighth American Ceramic Society Arnual Conference on Composites and Advanced Ceramic Materials, Cocoa Beach, Florida, January 15-20, 1984:

A. J. Caputo* and W. J. Lackey, "Fabrication of Filver-Reinforced Ceramic Composites"

D. P. Stinton," W. J. Lackey, and R. J. Lauf. 'F jorication of Ceramic-Ceramic Composites by Chemical Vapor Deposition"

C. S. Yust, "Wear Coefficients of Sliding Ceramics".

Seminar, Banares Hindu University, Varanasi, India, January 16, 1984:

C. T. Liu (presented by J. A. Carpenter, Jr.), "Recent Development of Ductile Ordered Interme "jlic Alloys for High Temperature Use"

General Physics Seminar, Beil Laboratories, Murray Hili, New Jersey, January 17, 1984:

G. M. Stocks, -Fermi Suiface Driven Concentration Waves in Random Alloys"

Meeting of Technical Society of Knoxville, Knoxville, Tennessee, January 20, 1984:

D. R. Johnson, "Ceramic Technology for Advanced Automotive Engines"

Seminar, India Chapter of American Society for Metals, Bombay, India, January 24, 1984

J. A. Carpenter, Jr., -Overview of the Materials and Tribology Projects of the United States Department of Energy (DOE) Energy Conversion and Utilization Technologies (ECUT) Program"

C. T. Liu (presented by J. A. Carpenter, Jr.), "Recent Deveiopment of Ductile Ordered Intermetallic Alloys for High Temperatuse Usen 
Seminar, University of Tennessee, Knoxville, January 24, 1984:

A. Bleier, "Application of Coiloid Chemistry to Ceramics"

Naval Research Laburatory Meeting, Washington, D.C., February 9, 1984:

P. F. Becher, "Toughening Behavior in Ceramic Composites'

Meeting of Oak Ridge Chapter of American Society for Metak, Oak Ridge, Tennessee, February 9, 1984:

R. J. Gray, "There Are No Fortune Cookies in Chima"

Energy Sources Technology Conference and Exhibition, New Orleans, Louisiana, February 12-16, 1984:

A. R. Olsen," J. R. Keiser, and R. R. Judkins, "Materials for Coal Liquefaciion Systems"

Ilth Annual Welding and Testing Technology Exhibition and Conference, Knoxville, Tennessee, February 21-24, 1984:

R. S. Crouse, "Metallography of Highly Radioactive Materials"

R. J. Gray, "Metallography Can Be Colorful"

J. R. Keiser" and B. C. Leslie, "Metallography for Coal Liquefaction Pilot Plants"

Electric Power Research Institute Confe. on Solutions to Problems with Dissimilar-Metal Weldments in Fossil-Fired Power Plants, New Orleans, Louisiana, February 23-24, 1984:

G. M. Goodwin, "An Overview of the MPC Dissimilar-Metal Weld Program"

American Institute of Mining, Metallurgical, and Petroleum Engineers Annual Meeting, Los Angeles, California, February 26-March 2, 1984:

D. N. Braski" and C. T. Liu, "The Development of ( $\mathrm{Fe}, \mathrm{Ni})_{3} \mathrm{~V}$ Long-Range-Ordered Alloys for a Fusion Reactor First Wall

C. R. Brinkman* and V. K. Sikka, "Optimized Specifications for Types 304 and 316 Stainiess Steel in Long-Term High-Temperature Service Applications"

Y. T. Chou and A. DasGupta, "Flux Pinning by Grain Boundaries in Type II Superconductors"

IV. A. Coghlan, B. A. Chin, and L. K. Mansur, "Microstructural Dependence of the Ratio of Irradiation Creep to Swelling"

R. L. Klueh" and E. E. Bloom, "Alloy Development for Fast Induced Radioactivity Decay for Fusion Reactur Applicitions"

C. T. Liu* and C. L. White, "Effect of Alloy Stoichiometry on Ductility and Fracture Behavior of Boron-Doped Ni $\mathrm{Al}^{*}$

P. J. Maziasz, "Strate ${ }_{-}-{ }^{-}$and Results Underlying the Developinent of Advanced Austenitic Stainless Steels for Fusion"

J. H. Schneibel" and C. L. White. "The Effect of Small Alloyirg Additions on the Creep Deformation and Fracture of an Austenitic Stainless Steel"

V. K. Sikka, "Modified 9 Cr-1 Mo Steel-An Improved Alloy for Steam Generator Application"

P. F. Tortorelli" and J. H. DeVan, "Liquid Metal Compatibility Considerations in Alloy Development ${ }^{\top}$

H. Trinkaus" and M. H. Yoo, "Intergranular Cavity Nucleation Under Time-Dependent Stress Concentrations"

C. L. White" and M. H. Yo, "On the Temperature and Composition Dependence of Interfacial Energy"

R. O. Williams, "Calculation of Coherent Phase Equilibria" 
Materials Science Colloquium, University of Virginia, Chartottesville, February 27, 1984:

L. K. Mansur, "Mechanisms of Radiation Effects in Metals and Alloys"

Spring Meeting of Materials kesearch Society, Albuquerque, New Mexico, F-bruary 27-29, 1984:

R. E. Riman, D. M. Haaland. C. J. Northrup, Jr., H. K. Bowen, and A. Bleier," -FTIR Study of Alkoxide Precusors to $\mathrm{SrTiO}_{3}$ "

Meeting of Rocky Mountain Chapter of American Society for Metals, Colorado Schooi of Mines. Golden, Colorado, March 1, 1984:

R. W. Swindeman, "Developments in Microalloyed Ferritic Steels for High-Temperature Pressure Vessel Applications"

Department of Exergy Meeting on Submicron Ceramic Powders, Albuquerque, New Mexico, March 1-2, 1984:

A. Bleier, "Analytical Froblems of Submicron Nitride and Carbide Powders"

Seminar, Rensselaer Polytechnic Institute, Troy, New York, March 6, 1094:

S. A. David, "Welding and Weldability of Thorium-Doped Iridium Alloys Used for Space Power Systems"

Meeting, Waste Management/84, University of Arizona, Tucson, March 11-15, 1984:

J. C. Griess, "Considerations in Estimating Corrosion of Metallic Containers in Nuclea Waste Repositories"

Seminar, Department of Materials Science, Stanford University, Stanford, California, March 15, 1984:

J. Bentley, "A Critical Evaluation of Analytical Electron Microscopy ir. Materials Science”

Meeting of Major Materials Facilities Committee, National Research Co:ncil, Washington, D.C., March 17-20, 1984:

C. J. Sparks, Jr., "Materials Science with Synchrotron Radiation. The Case for a Superprobe"

C. J. Sparks, Jr., -X-Ray Microprobe Characterization of Materials: The Case for Undulators on Advanced Storage Rings"

Meeting of the American Physical Society, Detroit, Michigan, March 26-30, 1984:

W. H. Butler, "Theory of Electronic Transport in Random Alloys: Korringa-Kohn-P.ostokerCoherent-Potential Approximation*

A. P. Maclin," G. M. Stocks, and W. M. Temmerman, "Band Structure Calculations of Aluminides"

D. M. Nicholson" and J. S. Faulkner, "Non-Muifin-Tin Effects in Transition Metals"

Second Workshop on Examination of Radioactive Materials by Electron Beam Methods, Savannah River Laboratory, Aiken, South Carolisa, March 29-30, 1984:

D. N. Braski* and J. R. Gibson, -Modification of an SEM for Examination of Radioactive Materials"

Seminar, I . Jiversity of Missouri, Rolla, March 30, 1984:

N. H. Packan, "Pulsed Dual-Ion Irradiations of Stainless Steels,"

Secord International Conference on Creep and Fracture of Engineering Ma:-rials and Structures, Swansea, England, April 1-6, 1984:

C. 1. White," J. H. Schneibel, and M. H. Yoo, "Suliur and Antimony Segregation to Creep Cavity Surfaces in Ni and an FCC Fe-Ni-Cr Alloy" 
Int:inational Topical Conference on Kinetics of Aggregation and Gelation, University of Georgia, Athens, April 2-4, 1984:

M. K. Miller," S. S. Brenner, P. P. Camus, and W. A. Soffa, "The Atom Probe-A Direct Technique fo: Kinetic Mi asurements"

Fourth International Conference on High-Temperature and Energy-Related Materials, Los Alamos, New Mexicc, April 2-6, 1984:

D. W. Yarbrough," T. W. Tong, and D. L. McElroy, "Use of Fine Powders for High Thermal Resistance*

North Atlantic Treaty Organization Conference on Ceramic Coatings for Advanced Heat Engines, Aqua Fredda de Maratea, Italy, April 2-6, 1984:

A. C. Schafthauser, "Department of Energy Program on Ceramic Technology for Advanced Heat Engines"

Seminar, Department of Metallurgical, Chemical, and Polymer Engineering, University of Tennessee, Knoxville, April 3, 1984:

R. W. McClung, "An Overview of Nondestructive Testing"

Inorganic Chemistry Colloquium, University of Nottingham, Nottingham, England, April S, 1984:

P. F. Tortorelli, "Liquid Metal Corrosion Studies"

American Society for Metals Meeting of Lehigh Valley Chapter, Bethlehem, Pennsylvania, April 6, 1984:

G. M. Slaughter, “Brazing an': Soldering Technology-Past, Present, and Future”

Symposium, Rocky Mountain Chapter, American Society ior Metals, Colorado School of Mines, Golden, Colorado, April 6, 1984:

R. J. Gray, "A Look at Metallography of Yesterdzy, Today, and Tomorrow"

65th Annual American Welding Society Meeting, Dallas, Texas, April 8-13, 1984 :

R. K. Holbert, Jr., S. A. David, and G. M. Goodwin, "Hot Cracking Susceptibility Test for Thin Austenitic Stainless Steel Sheet"

J. M. Vitek" and S. A. David. "The Sigma Phase Transiormation in Type 308 Austenitic Stainless Steel Welds"

Oak Ridge National Laboratory Fusion Energy Division Annual Information Meeting, Oak Ridge, Tennessee, April 9-10, 1984:

J. L. Scoli," E. E. Bloom, D. N. Braski, M. L. Grossteck, R. L. Klueh, P. J. Maziasz, A. F. Rowcliffe, P. F. Tortorelli, J. M. Vitek, J. A. Conlin, Jr., I. T. Dudley, E. M. Lees, C. D. West, and R. A. Lillie, "Fusion Materials Program"

ORNL-TMS-AIME Conference on High-Temperature Alloys: Theory and Design, Bethesda, Maryland, April 9-11, 1984:

W. H. Butler, "First Princip!es Design of Transport Properties of High-Temperature Alloys"

W. H. Butler, "Resistivity of Alloys"

A. DasGupta" and C. T. Liu, "Phase Formation and Stability in the Pseudobinary Ni, V-Ni, $\mathrm{Al}$ Alloy System"

J. A. Horton, H. Inouye, C. r. Liu, and C. C. Koch, “Alloying Effects and Microstructure of Iron Aluminides"

C. T. Liu, "Design of Ordered Intermetallic Alloys for High-Temperature Structural Use"

A. P. Maclin," G. M. Stocks, and W. M. Temmerman, "Band-Structure Calculatiuns of Aluminides" 
D. M. Nicholson" and A. Chowdhary, "Électronic Structure of Liguid Metal Alloys"

G. M. Stocks, "Fermi Surface Driven Concentration Waves in Random Alloys"

Third International Conference on Liquid Metal Engineering and Technology in Energy Production, Oxford, England, April 9-13, 1984:

J. H. DeVan* and C. Bagnall, "A Perspective of the Corrosive Behavior of Lithium and Sodium"

P. F. Tortorelli* and J. 1. DeVan, "Mass Transfer Kineties in Lithium-Stainless Steel Syster 's"

Seminar, Massachusetts Institute of Technology, Cambridge, April 12, 1984:

P. J. Maziasz, "Influence of Precipitate Evolution on Droperty Changes in Austenitic Stainless Steels for Fusion"

Seminar. Naval Surface Weapons Center, White Oak, Silver Springs, Maryland, April 12, 1984:

C. T. Liu, "Development of New Structural Materials Based on Ordere" ıntermetaijic Alloys"

Seminar, Culham Laboratory, Culham, England, April 13, 1984:

P. F. Tortorelli, "Liquid Metal Corrosion Considerations in Fusion Blanket Design"

Seminar, North Carolina State University, Raleigh, April 18, 1984:

M. H. Yoo, "High-Temperature Deformation and Fracture"

Meeting, Philadelphia Chapter of the American Society for Metals, Philadelphia, Pennsylvania, April 19, 1984:

R. J. Gray, “Modern Metallography-New and Unusual Methods to Analyze Microstructures”

American Society for Metals Conference on Materials for Energy Systems, Washington, D.C., April 29-May 2, 1984:

E. E. Blvom" and D. L. Smith, "Fusion Reactor Blanket Structural Materials"

86th Annual American Ceramic Society Meeting, Pittsburgh, Pennsylvania, April 29-May 3, 1984:

P. Angelini,* P. F. Becher, and J. Bentley, "Processing and Characterization of Yutria-Doped Zirconia-Tcughened Alumina"

P. F. Becher, "Slow Crack Growth Behavior of Partially Stabilized Zirconia"

P. F. Berher" and M. K. Ferter, "Environmental Effects on Crack Growth in BeO"

P. F. Becher* and G. C. Wei, "Fracture Toughness and Crack Growth in SiC Whisker Reinforced Oxide Ceramics"

J. Bentley," M. M. Nasraliah, and H. U. Anderson, "Electron Microscopy of Donor-Doped $\mathrm{SrTiO}_{3}{ }^{n}$

R. L. Berger," D. P. Stinton, and E. W. McDaniel, "Selective Adsorption of Radionuclides by Major Phases of Hydrofracture Grouts"

G. C. Farlow; C. W. White, B. R. Appleton, P. Angelıni, and C. J. McHargue, " imperature Effects on Ion-Induced Damage in $\mathrm{Al}_{2} \mathrm{O}_{3}$ "

J. I. Feaerer, "Corrosion Resistance of SiC Ceramics in Industrial Combustion Environments" M. K. Ferber," V. J. Tennery, and S. B. Waters, "Fracture Strength Characterization of Tubular Ceramic Materials Using a Sample C-Ring Geometry"

C. B. Finch." P. F. Becher, and R. K. Williams, "Mechanical and Electricai Anisotropy in Crystalline $\mathrm{Ni}_{3} \mathrm{~B}$, a Binder Phase in $\mathrm{TiB}_{2}-\mathrm{Ni}$ Ceramics"

L. A. Harris" and O. C. Kopp. "Microstructural Studies of an Advanced Thermal Enargy Storage Composite Ceramic 
W. C. Hasz ard A. Bleier," "Limitations of Applying Classical Colloid Models to Consolidation of Ceramic Suspensions"

D. R. Johnson," A. C. Schzfthauser, and R. B. Schulz, "Status of Ceramic Technology for Advanced Heat Engines Program"

W. J Lackey, P. Angelini, A. J. Caputo, C. E. DeVore, J. C. McLaughlin, D. D. Stinton, and R. E. Hutchens. "Improved R.ate Controlled Technique for Drving and Calcining"

C. J. McHargue, B. R. Appleton, J. M. Williams, M. B. Lewis, and C. S. Yust (presented by G. C. Farlow), "Inert Gas Implantation Effects in $\mathrm{Al}_{2} \mathrm{O}_{3}$ "

R. E. Riman, A. Bleier," and H. E. Bomen, "Solution Environment Effects on the Synthesis of SrTiO, Powder"

P. S. Sklad, C. J. MoHargut, and J. M. Williams (preserted by C. S. Yust), “Microstructural Develupment in $\mathrm{SiC}$ Ion Implanted with Chromium"

D. P. Stinton,* W. J. Lackey, and R. J. Lauf, "Fabrication of Silicon Carbide Composites by Chemical Vapor Deposition"

V. J. Tennery,* M. K. Ferber, and J. C. Ogle, "Mechanical and Chemical Behavior of a Sintered Alpha $\mathrm{SiC}$ in a Basic Coal Slag Environment"

T. N. Tiegs, "Dispersed Metrid Tiughened Alumina"

G. C. Wei* and P. F. Becher, "Improvements in Mechanical Properties in SiC by the Addition of TiC Particles"

G. C. Wei* and P. F. Becher, "Processing and Properties of SiC-TiC Composites"

1984 Pacific Northwest Metals and Minerals Cunference, Portland, Oregon, April 30-May 2, 1984:

S. A. David, "Welding and Weldability of Ductile Iron Nickel Aluminides"

1984 Institute of Engineering Faculty, American Consulting Engineers Council, Ohio State University, Columbus, April 30-May 3, 1984:

T. S. Lundy, "The National Program Concept"

Casting Congress, American Foundrymen Society, St. Louis, Missouri, April 30-May 4, 1984:

V. K. Sikka* and A. Mitchell, "Steel Castings by the Electroslag Casting Technique"

American Society for Metals Conference on Materials for Future Energy Systems, Washington, D.C., May 1-3, 1984:

E. E. Hoffman * and R. H. Cooper, Jr., "Fuel Systems and Structural Alloys for Space Nuclear Reactor Systems"

J. R. Keiser," A. R. Olsen, and S. J. Ibarra, Jr., "Corrosion Resistant Materials for Coal Liquefaction Systems"

J. L. Straalsund," A. F. Rnwcliffe, and D. E. Mahagin, “Advanced Alloys for LMFBR Fuel Cladding and Ducts"

J. R. Weir, Jr., "Role of Materials: Priorities"

Fourth Annual Symposium of the Tennessee Valley Chapter of the American Vacuum Society, Knoxville, Tennessee, May' 1-3, 1984:

D. N. Braski,* P. D. Goodell, J. V. Cathcart, and R. H. Kane, "The Oxidation of Inconel Alloy MA754 at Low Oxidation Potential"

P. S. Sklad," P. Angelini, C. J. MiHargue, and J. M. iVilliams, "Analytical Electron Microscopy of Surface Modified SiC"

Ninth Conference on Chemical Vapor Deposition, Cincinnati, Ohio, May 6, 1984:

A. J. Caputo," W. J. Lackey, and I. G. Wright, "Chemical Vapor Deposition of Erosion Resistant $\mathrm{TiB}_{2}$ Coatings" 
American Society for Metals Meeting of Calgary Chapter, Calgary, Alberta, Canada, May 7, 1984:

G. M. Slaughter, "Materials R\&D for Energy Applications"

Meeting of American Society of Lubrication Engineers, Chicago, Illinois, May 7, 1984:

C. S. Yurt" and F. J. Carignan, "Observations on the Sliding Wear of Ceramics"

Seminar, Department of Metallurgical, Chemical, and Polymer Engineering, University of Tennessee, Knoxville, May 8, 1984:

R. L. Klueh, "Alloy Development for Fusion Reactors"

Seminar, Julich Nuclear Research Center, Jülich, Federal Republic of Germany, May 8, 1984:

N. H. Packan, "Pulsed Dual-Ion Irradiations of Stainless Steels"

American Society for Metals Meeting of Santa Clara Valley Chapter, San Francisco, California, May 9, 1984:

G. M. Slaughter, "Brazing and Soldering Technology-Past, Present, and Future"

Technical Symprsium of the American Society for Metals, Oak Ridge Chapter, Oak Ridge, Tennessec, May 11, 1984:

R. J. Gray, "Faiiure Analyses of Surgical Implants from the Human Body"

Sixth International Conference on Plasma Surface Interactions in Controlled Fusion Devices, Nagoya University, Nagoya, Japan, May 14-17, 1984:

R. E. Clausing and L. Heatherly (presented by J. B. Roberts), "Control of Surface Composition and Hydrogen Recycling by Plasma Conditioning"

Seminar, University of Tennessee, Knoxville, May 15, 1984:

J. M. Vitek, "Tempering Behavior of Ferritic Steel"

Institute of Electrical and Electronics Engineers Minicourse on Fusion, St. Louis, Missouri, May 17, 1984:

F. W. Wiffen, "Materials Requirements and Potential Solutions for Fusion Reactors"

Tristate Catalyst Symposium, Lexington, Kentucky, May 23, 1984:

A. G. Dhere, R. J. DeAngelis, P. J. Reucroft, and J. Bentley, "Size, Morphology, and Substructure of Metal Particles in Supported Metal Catalysts"

Materials Science Seminar, 984 Southeastern Section Meeting, Electron Microscopy Society, Birmingham, Alabama, May 24, 1984:

C. L. White, "Application of Surface Analysis in Materials Research"

Ar nual Meeting of the Ame. ican Nuclear Society, New Orleals, Louisiana, June 3-8, 1984:

R. H. Cooper, Jr.," and E. E. Hoffman, "Tantalum and Niobium Alloys for Space Nuclear Applications"

J. H. DeVan, "Materials Compatibility Considerations for a Molten Salt Fusion Breeder"

58th Culloid and Surface Science Symposium, American Chemical Society, Pittsburgh, Pennsylvania, Jur.e 10-13, 1984:

A. Bleier" and W. C. Hasz, "Implications of Charge Regulation to Concentrated Suspensions"

N. Strauss, T. A. Ring, H. K. Bowen, and A. Bleier," "Interaction Energies and Pressures in Concentrated Electrostatically Stabilized Suspensions"

Meeting of the Atlanta Section of the American Society for Nondestructive Testing, Atlanta, Georgia, June 11, 1984:

J. H. Smith, "Ultrasonic Inspection of Stainless Steel Welds" 
American Society of Mechanical Engineers Pressure Vessel and Piping Division Conference, San Antonio, Texas, June 17-22, 1984:

G. M. Goodwin* and R. K. Nanstad, "Effect of Temperature on the Stress-Relaxation Response of a Pressure Vessel Steel"

R. W. Swindeman, "Fatigue of Bainitic $21 / 4 \mathrm{Cr}-1$ Mo Steel Weldments at $482^{\circ} \mathrm{C}$ "

R. W. Swindeman, The Response of Bainitic Low Alloy Steels to Nonsteady Loading at Elevated Temperatures"

R. W. Swindeman, "The Response of Ferritic Steels to Nonsteady Loading at Elevated Temperatures"

12th International Symposium on Effects of Radiation on Materials, sponsored by the American Society for Testing and Materials, Williamsburg, Virginia, June 18-2n, 1984:

R. G. Berggren, J. J. McGowan, B. H. Menke," and R. K. Nanstad, "Effects of Neutron Irradiation on Fracture Toughness of A 533 Grade B Class 1 Plate and Four Submerged-Arc Welds"

R. G. Berggren, * R. K. Nanstad, F. W. Stallman, and J. R. Hawthorne, "An Analysis of Charpy V-Notch Impact Toughness of Irradiated A 533 Grade B Class 1 Plate and Four Submerged-Arc Welds"

D. N. Braski" and D. W. Ramey, "A Modified Tritium Trick Technique for Doping Vanadium Alloys with Helium"

W. A. Coghlan and L. K. Mansur," "The Effect of Microstructure on the Minimum Critical Cavity Radius for Bias-Driven Growth During Irradiation"

W. R. Corwin," R. G. Berggren, and R. K. Nanstad, "Charpy Toughness and Tensile Properties of a Neutron Irradiated Stainless Steel Submerged-Arc Weld Ciading"

K. Farrell and E. H. Lie, "Ion Bombardment Damage in a Modified Fe-9 Cr-1 Mo Steel"

M. L. Grossbeck" and K. C. Liu, "Fatigue Behavior at $650^{\circ} \mathrm{C}$ of $20 \%$-Cold-Worked Type 316 Stainless Steel Irradiated at $550^{\circ} \mathrm{C}$ in the IIFIR"

L. L. Horton* and L. K. Mansur, "Experimental Determination of the Critical Cavity Radius in $\mathrm{Fe}-10 \% \mathrm{Cr}$ for Ion Irradiation"

R. L. Klueh* and M. L. Grossbeck, "Tensile Properties and Swelling of 20\%-Cold-Worked Type 316 Stainless Steel Irradiated in HFIR"

E. H. Lee* and A. F. Rowclifie, "The Temperature Dependence of Phase Compositions in TiModified Austenitic Stainless Steels During Irradiation"

G. R. Odette, P. J. Maziasz, and R. E. Stoller, "An Assessment of the Mechanisms Controlling Swelling Resistance of Titanium Modified Stainless Steels"

Seminar, Exxon Research and Engineering Company, Annandale, New Jersey, June 26, 1984:

C. J. Sparks, Jr., "X-Ray Probes for tne Microcharacterization of Materials"

Third Annual Steam Generator Workshop, EPKI-NDE Center, Charlotte, North Carolina, June 26-27, 1984:

C. V. Dodd, "Improved Eddy-Current Inspection for Steam Generator Tubing"

Seminar, Ispra Nuclear Research Center, Varese, Italy, June 28, 1984:

N. H. Packan, "Pulsed Dual-Ion Irradiations of Stainless Steels" 


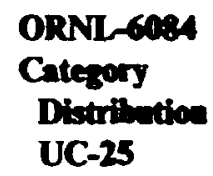

\section{INTERNAL DISTRIBUTION}

\section{1-2. Central Research Library}

3. Document Reference Section

4-5. Laboratory Records Department

6. Laboratory Records, ORNL RC

7. ORNL Patent Section

8. G. M. Aramson

9. P. F. Becher

10. J. Bentley

11. A. Bleier

12-14. E E Bloom

15. C. R. Brinkman

16. I. H. Brogden

17. V. R. Bullington

18. W. H. Butler

19. P. T. Carison

20. W. W, Carpenter

21. J. V. Cathcart

22. O. B. Cavin

23-27. J. E. Cunningham

28. A. DasGupta

29. S. A. David

30. J. H. DeVan

31. J. R. DiStefano

32. D. S. Eastos

33. W. P. Eatherly

34. W. Grimes

35. R. L. Heestand

36. J. A. Horton

37. L. L. Horton

38. G. E. Ice

39. R. R. Judkins

40. E. A. Kenik
41. W. J. Lacke;

42. C. T. Liu

43. T. S. Lundy

44. L. K. Mansur

45. M. M. Martin

46. R. W. McClung

47. D. L. McElroy

48. C. J. McHargue

49. C. G. McKamey

50. M. K. Miller

51. A. J. Moorhead

52. R. K. Nanstad

53. P. Patriarca

54. S. Peterson

55. P. L. Rittenhouse

56. A. F. Rowcliffe

57. A. C. Schaffhauser

58. J. L. Scott

59. P. S. Sklad

60-62. G. M. Slaughter

63. C. J. Sparks, Jr.

64-68. J. O. Stiegler

69-191. P. T. Thornton

192. F. W. Wiffen

193. R. O. Williams

194. A. Zucker

195. R. J. Charles (Consultant)

196. H. F. Cook (Consultant)

197. A. Lawley (Consultant)

198. T. B. Massalski (Consultant)

199. J. C. Y'illiams (Consultant)

200. K. M. Zwilsky (Consultant)

\section{EXTERNAL DISTRIBUTION}

201. J. M. Bailey, Research Consuitañ, Lesearch Department, Technical Center, Caterpillar Tractor Company, 100 NE Adams, Peoria, IL 61629

202. K. Baumert, Air Products and Chemicals, Inc., Box 538, Allentown, PA 18105

203. R. L. Beatty, ARCO Metals-Silag Operation, Greer, SC 29631

204. A. L. Bement, Jr., Vice President, Technical Resources, TRW, Inc., 23555 Euclid Avenue, Cleveland, OH 44117

205. C. G. Bergeron, Department of Ceramic Engineering, University of lllinois, Urbana, IL $6180 \mathrm{~h}$ 
206. L. S. Blair, Chemistry Division MS-J563, Los Alamos National Laboratory, Los Alamos, NM 87545

207. Milton Biander, Chemical Technology Division, Argonne National Laboratory, Argonne, IL 60439

208. H. T. Burns, Technical Library, MERT Division, Oak Ridge Associated Universities, P.O. Box 117, Oak Rijge, TN 37830

209. B. Butler, Mater:o!s Sranch, Solar Energy Research Institute, Gotden, CO 80401

210. D. i. Canonico, Combustion Engineering, Inc, 911 W. Main Street, Chattanooga, TN 37402

211. C. F. Cine, Lawrence Livermore National Laboratory, P.O. Box 808, Livermore, CA 94550

212. J. H. Crawford, Jr., Department of Physics, University of North Carolina, Chapel Hill, NC 27514

213. A. R. Cuiffreda, Exxun Research and Engineering Company, P.O. Box 101, Florhan Park, NiJ 07932

214. F. L. Culler, Jr., Electric Power Research Institute, P.O. Box 10412, Palo Alto, CA 94304

215. R. M. Curran, Manager, Turbine Materials Engineering, General Electric Company, Bidg. 41, Room 306, Schenectady, NY 12345

216. S. D. Dahlgren, Battelle-Pacific Northwest Laboratory, P.O. Box 999, Richland, WA 99352

217. R. A. Dean, Vice President, GA Technologies, Inc., P.O. Box 81608, San Diego, CA 92128

218. W. E. Dennis, Vice President, Manufacturing \& Research, AISI, 1000-16th Street NW, Washington, DC 20545

219. Dwight Diercks, Argonne National Laboratory, 9700 S. Cass Avenue, Argonne, IL 60439

220. J. R. Dietz, Naiional Steel Corp., 500 Three Springs Drive, Weirton, WV

221. H. C. Dilworth, Armco, Inc., Research \& Technology, Middletown, OH 45042

222. W. DuBroff, Director of Research, Inland Steel Company, 3001 E. Columbus Drive, East Chicago, IN 46312

223. L. L. Fehrenbacher, Technology Assessments \& Transfer, Inc., 9607 Muirfield Drive, Upper Marlboro, MD 20772

224. W. E. Felling, Oak Ridge Associated Universities, P.O. Box 117, Oak Ridge, TN 37830

225. L. J. Ferrell, Babcock \& Wilcox Research Center, P.O. Box 239, Lynchburg, VA 24505

226. C. W. Fox, Technical Director, Homogeneous Metals, Inc., P.O. Box 294-Main Streei, Clayville, NY 13322

227. F. Fradin, Argonne National Laboratory, 9700 Cass Avenue, Argonne, IL 60439

228. S. T. Freim, Babcock \& Wilcox Research Center, P.O. Box 239, Lynchburg, VA 24505

229. A. N. Goland, Brookhaven National Laboratory, Upton, NY 11973

230. M. Gold, Babcock \& Wilcox Company, $20 \mathrm{~S}$. Van Buren Avenue, Barberton, $\mathrm{OH}$ 44203

231. M. L. Good, Vice President, Director of Research, Signal UOP Research Center, 50 UOP Plaza, Des Plaines, IL 60016

232. H. C. Graham, Air Force Wright Aeronautical Laboratory, Materials Laboratury, Metals and Cerani:cs Division, AFWAL/MLLM, Wright-Patterson Air Force Base, $\mathrm{OH} 45433$

233. J. A. S. Green, Director, Research and Development, Martin Marietta Laboratories, 1450 South Rolling Road, Baltimore, MD 21227-3898

234. P. Gupton, Monsanto Company, P.O. Box 1311, Teras City, TX 77590

235. S. S. Hecker, Los Alamos National Laboratory, P.O. Box 1163, Los Alamos, NM 87545 
236. P. W. Heitman, Detroit Diesel Allison, Mail Stop W-5, Plant 8, P.O. Box 894, 2001 S. Tibbs, Indianapolis, IN 46206

237. G. S. Hoppin, III, Garrett Turbine Engine Company, 111 S. 34tr St, P.O. Box 5217, Phoenix, AZ 85010

238. R. I. Jaffec, Electric Power Research Institute, P.O. Box 10412, Palo Alto, LA 94304

239 C. Jaske, Battelic Columbus Laboratories, 505 King Avenue, Columbus, OH 43201

240. R. N. Katz, Ceramies Research Division, DRXMR-MC, Army Materials and Mechanics Research Center, Arsenal Streei, Watertown, MA 02172

241. C. H. Kim, Department of Materials Science \& Engineering, Kon .. Advanced Institute of Science \& Technology, P.O. Box 150, Cheongryang, Seoul KOREA

242. F. F. Lange, Science Center, Rockwell International, 1049 Camino Dos Rins, P.O. Box 1085, Thousand Oaks, CA 91360

243. K. R. Lawless, Department of Materials Science, Thornton Hall, University of Virginia, Charlottesville, VA 22901

244. W. W. Liang, Project Manager, Industrial Materials Research, Gas Research Institute, 8600 W. Bryn Mawr Avenue, Chicago, IL 6063:

245. L. W. Lherbier, Director, R\&D, Universal-Cyclops Specialty Steel Division, Bridgeville, PA 15017

246. Larry Long, Armco, Middletown, OH 45043

247. W. G. Long, Babcock \& Wilcox Research Center, P.O. Box 239, Lynciburz. VA 24505

248. C. L. McCabe, Vice President, Cabot Corporation, P.O. Box 1157, Oak Ridge, IN 37831

249. B. A. McDonald, Office of Naval Research, Code 471, Rocm $622,800 \mathrm{~N}$. Quincy Street, Arlington, VA 22217

250. A. F. McLean, Cetamic Materials Department, Ford Motor Company, P.O. Box 2053, Dearborn, MI 48121

251. John McTague, Executive Office of the President, Office of Science \& Technology Policy, Washington, DC 20506

252. Joseph Marone, OSTP, New Executive Office BIdg., Room 500;, Washington, DC 20506

253. Victor Maroni, Argonne National Laboratory, 9700 S. Cass Avenue, Argonne, IL 60439

254. W. R. Martin, Cabot Corporation, High Technology Materials Division, 1020 W. Park Avenue, Kokomo, IN 46901

255. G. E. Maurer, Director of R\&D, Allegheny International, Special Metals Corporation, Middle Settlement Road, New Hartfr,rd, NY 13413

256. M. J. Mayfield, Fossil Research Projects Branch, Tennessee Valley Authority, 1010 Chestnut Towers II, Chattanooga, TN 37401

257. J. W. Morfitt, EG\&G Idaho, Box 1625, Idaho Falls, ID 83415

258. J. I. Mueller, Ceramic Engineering Department, MS FB10, University of Washington, Seattle, WA 98195

259. H. Nickel, Institut fur Reaktorwerkstoffe, Kernforschungsanlage, Postfach 1913, D5170, Julich, Federal Republic of Germany

260. W. D. Nix, Department of Materials Science and Engineering, Staniord University, Stanford, CA 94305

261. L. D. Norman, J\&L Steel, 900 Agnew Road, Pittsburgh, PA 15227

262. B. F. Oliver, Department of Chemical and Metallurgical Engineering, University of Tennessee, Knoxville, TN 37916

263. J. R. Ogren, Staff Scientist, Defense and Space Systems Group, TRW, Inc., Bldg. RI, Room 2044, One Space Park, Redondo Beach, CA 90278

264. W. S. Owen, Department of Materials Science and Engineering, Massachusetts Institute of Technology, Cambridge, MA 02139 
265. N. E. Paton, Director, Materials Engineering and Technology, Rockwell International, Rocketdyne Division, 6633 Canoga Avenue, Canoga Park, CA 91304

266. J. W. Patten, Materials Engineering, Cummins Engine Company, Inc, Mail Code 50183, Box 3005, Columbus, IN 47201

267. D. A. Patterson, Staff Director, Tennessee Technology Foundation, One Energy Center, P.O. Box 23184, Knoxville, TN 37933

268. Harry Paxton, U.S. Steel, 600 Grant Street, Piatsburgh, PA 15230

269. J. Pentecost, Department of Ceramic Engineering, Georgia Institute of Technology, Atlanta, GA 30332

270. D. T. Peterson, 126 MD Ames Laboratory, Iowa State University, Ames, IA 50011

271. H. E. Probst, Non-Metallic Materials Branch, Materials Division, MS 49.3, NASALewis Researcis Center, 21000 Brookpark Road, Cleveland, OH 44135

272. W. E. Ray, Advanced Reactors Division, Westingt:ouse Electric Corporation, P.O. Box 158, Madison, PA 15663

273. D. W. Richerson, Supervisor, Advanced Materials, Garrett Turbine Engine Company, 111 S. 34 Street, P.O. Box 5217, Phoenix, A2 85010

274. D. I. Roberts, Manager, Reactor Structural Materials Branch, Fuels and Materiais Division, GA Technologies, Inc., P.O. Box 81608, San Diego, CA 92138

275. N. A. Robins, Vice President, Research, Inland Steel Company, 3001 E. Columbus Drive, East Chicago, IN 46312

276. R. W. Rohde, Sandia National Laboratory, Livermore, CA 94550

277. A. O. Schaefer, Executive Director, Metal Properties Council, Inc., United Engineering Center, 345 East 47th Street, New York, NY 10017

278 Alan Schriesheim, Argonne National Laboratory, 9700 S. Cass Avenue, Argonne, IL 60439

279. M. A. Schwartz, Bureau of Mises, 2401 Eye Street, N.W., Washington, DC 20241

280. R. L. Schwoebel, O.ig. 1800, Sandia National Laboratories, P.O. Box 5800, Albuquerque, NM 87185

281. W. W. Scott, Jr., Technical Director, American Society for Metals, Metals Park, OH 44073

282. A. W. Searcy, Lawrence Berkeley Laboratory, Berkeley, CA 94720

283. M. Semchyschen, Climax Molybdenum Company, P.O. Box 1568, Ann Arbcr, MI 84105

284. C. Z. Serpan, Jr., Materials Engineering Branch, Division of Engineering Technology, Office of Nuclear Regulatory Research, U.S. Nuclear Rigulatory Commission, Washington, DC 205: ,

285. J. P. Skalny, Associate Director, Research and Development, Martin Marietta Latoratories, 1450 South Rolling Road, Baltinore, MD 21227.3898

286. J. T. Smith, Director, Precision Materials Tech., GTE Laboratories, Inc., 40 Sylvan Road, Waltham, MA 02154

287. E. E. Stansbury, Department of Chemical and Metallurgical Engineering, University of Tennessee, Knoxville, TN 37916

288. D. F. Stein, Prissident, Michigan Technological University, Houghton, MI 49931

289. M. Suenaga, Brookhaven National Laboratory, Uptu:n, NY 11973

290. Earl Thompson, United Technologies Research Center, East Hartford, CT 06108

291. L. S. Tong, Wa:er Re or Safety Research, U.S. Nuclear Regulatory Commission, Washington, DC $2^{\circ}$ 'j

292. M. L. Torti, Senior 'cicris:-:. High Performance Ceramics, Norton Company, I New Bond Street, Worcester, MA 0:506

29'. R. Viswanathan, Electric Power Research Institute, P.O. Box 10412, Palo Alto, CA 94.304

294. F. L. Vook, Director, Solid State Scienc is, Sandia National Laboratories,

P.O. Box 5800, Albuquerque, NM 87185 
295. J. B. Wayner, Department of Materials Science, Arizona State University, Tempe, AZ 85281

296. H. W. Wrart, Department of Metallurgical Engineering Uriversity of Missouri-Rolla, Rolla, MO 64501

217. G. W. Weber, General Electric Company, 24400 Highland Roed, Richmond Heights, OH 44413

298. Richard Weeks, Argonne National Laboratory, 9700 S. Cass Avenue, Argonie, IL 60439

299. A. M. Weinberg, Institute for Energy Analysis, Oak Ridge Astociated Universities, Oak Ridge, TN 37830

300. J. E Werner, Bethlehem Steel Corp., Research Department, Bethlehem. iA 18016

301. C. Wert, Department of Metallurgical and Mining Engineering, University of Illinois, Urbana, IL 61801

302 C. W. Whitmore, General Electric Space Division, P.O. Box 8555, Philadetphia, PA 19101

31 3. B. F. Wilcox, Director, Materials Science Division, Advanced Research Projects Agency, (ARPA), 1400 Wilson Boulevard, Ariington, VA 22209

304. D. Wirth, Vice President, Technical Operations, Research and Development, Coors Porcelain Company, 17750 North 32 Street, Golden, CO 80401

305. H. Yoshikawa, Materials Engineering, Hanford Engineering Development Laboratory, P.O. Box 1971), Richland, WA. 99352

306-312 DOE, Conservation and Renewable Energy, Forrestal Building, 1000 Independince Avenue, Washington, DC 20545

A. J. Streb

Office of Energy Systems Research

J. J. Brogan

J. J. Eberhardt

Office of Vehicle and Engine Research and Development

Technology Development and Analysis Division

A. A. Chesnes

Heavy Duty Transport and Fuels Integration Branch

R. B. Schulz

Office of Buildings Energy Research and Development

J. P. Millhone

Office of Ind sstrial Programs

W. B. Williams

313 -318. DOE, Energy Research, Office of Basic Energy Sciences, Washington, DC 20545

J. C. Lanniello

D. K. Stevens

J. S. Kane

M. C. Wittels

F. V. Nolfi

S. Wolf

319. DOE, Idaho Operations Office, Energy Progrums Branch, 550 Second Street, Idaho

Falls, ID 8340 I

W. H. Thielbar

320. DOE, Materials and Radiation Effects Branch, Division of Development and

Technology, Office of Energy Research, E R-533, Washington, DC 20545

T. C. Reuther, Jr.

321 312. DOE, Morgantown Energy Resarch Center, P.O. Box 880, Collins Ferry Road, Morgantown, WV 26505

J. M. Hobday

A. Pitrolo 
323-332. DOE, Nuctear Energy, Offrce of Coordination and Special Projects, Washington, DC 20545
G. L. Bennett
T. W. Mclntosh
N. I. Gerstein
R. B. Marrow
J. S. Griffo
B. J. Roct
W. D. Kenney
F. A. Ross
J. J. Lombardo
W. F. Savage

333-334. DOE, Nuclear Reactor Programs, Office of Plans and Resource Management,

Washingtoa, DC 20545

N. Goldenberg

S. Rosen

335. DOE, Nuclear Reactor Programs, Office of Nuclear Power Systems-LWR,

Washington, DC 20545

J. W. Bennett

336-337. DOE, Nuclear Reactor Programs, Office of Nuclear Power Systems-HTR, Washington,

DC 20545

J. E. Fox

G. A. Newby

338. DOE, Nuclear Reactor Programs, Office of Nuclear Power Systems-Safety R \&D,

Washington, DC 20545

P. L. Havenstein

339-340. DOE, Nuclear Reactor Programs, Office of Reactor Research and Technology,

Washington, DC 20545

D. K. Magnus

C. M. Purdy

341-342. DOE, Nuclear Reactor Programs, Office of Safety, Quality Assurance ar, Standards,

Washington, DC 20545

N. P. Klug

E. Langston

343. DOE, Office of Fossil Energy, Washington, DC 20:45

S. J. Dapkunas

344 346. DOE, Deiense Waste Byproducts Programs, Mril Stop DP-12, Washington, DC 20545

J. E. Diec shoner

J. J. Jicha

G. K. Oentel

347-348. DOE, Terminal Waste Disposal and Remedial Action, Mail Stop NE 20, Washington,

DC 20545

F. E. Coffman

R. W. Ramsey, Jr.

349-35i. DOE, Oak Ridge Operations Office, P.O. Box E, Oak Ridge, TN 37831

Office of Assistant Manager for Energy Research and Development

E. E. Hoffman J. A. Lenhard S. J. Wolfe

352. DOE, Clinch River Breeder Reactor Project Office, P.O. Box U, Oak Ridge, TN 37831

E. A. Wright

353. DOE, Pittsburgh Energy Technology Center, P.O. Box 10940, Pittsburgh, PA 15236

J. J. Lacey

354 542. DOE, Technical Information Center, P.O. Box 62, Oak Ridge, TN 37831

For distribution as shown in DOE/TIC-4500 Distribution Categury, UC-25 (Materials) 


\section{PATENTS}

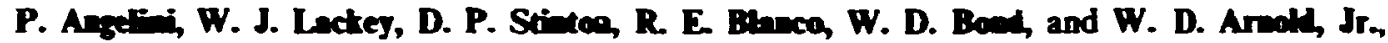
-Method for Primary Containment of Cesium Wastes," U.S. patent 4,376,792, Mar. 15, 1983.

K. V. Cook, R. A. C angram and H. T. Murria, -Ultrasonic Probe for Inspocting DoubleWall Tube," U.S. patent 4,391,143, July 5, 1983.

J. H. DeVan and J. E Sele, -Method for Inhibiting Alkaii Metal Corrosion of NickelContaining Alloys," U.S. patent 4,398,967, Aug. 16, 1983.

B. E. Foster and E V. Daris, "Pentrameter Positioner for Bore-Side Radiography of Tubes," U.S. patent 4,368,996, Jan. 18, 1983.

P. A. Hans and W. B. Stines, -Method for Improved Decomposition of Metal Nitrate Solutions," U.S. patent 4,409,157, Oct. 11, 1983.

R. L. Heestand and B. Heshatporr, "Method for Refining Contaminated Iridium," U.S. patent 4,406,693, Sept. 27, 1983.

R. J. Laef and C. S. Morgan, "Solid Electrolytes Strengthened by Metal Dispersions," U.S. patent 4,393,124, July 12, 1983.

C. T. Lin, H. Inowye, and A. C. Schnfinaser, "Long-Range-Ordered Alloys Modified by Group IV-B tietals," U.S. patent 4,410,371, Oct. 18, 1903.

C. S. Morgan, "Method for Fabricating Cermets of Alumina-Chromium Systems," U.S. patent 4,397,963, Aug. 9, 1983.

D. P. Stinton, -Mixed Uranium Dicarbide and Uranium Dioxide Microspheres and Process of Making Same," U.S. patent 4,367,184, Jan. 4, 1983. 